\title{
111
}

\section{TECHNISCHE UNIVERSITÄT MÜNCHEN}

Department Chemie

\section{Iminium Catalysis Inside a Self-Assembled Supramolecular Capsule}

\author{
Thomas Michael Bräuer
}

Vollständiger Abdruck der von der Fakultät für Chemie der Technischen

Universität München zur Erlangung des akademischen Grades eines

\section{Doktors der Naturwissenschaften}

genehmigten Dissertation.

Vorsitzender:

Prüfer der Dissertation:
Prof. Dr. Job Boekhoven

1. Prof. Dr. Konrad Tiefenbacher

2. Prof. Dr. Stephan A. Sieber

Die Dissertation wurde am 17.01.2018 bei der Technischen Universität München eingereicht und durch die Fakultät für Chemie 08.03.2018 angenommen. 
Der größte Teil der vorliegenden Arbeit wurde in der Zeit zwischen November 2013 und Juni 2016 unter Leitung von Jun.- Prof. Dr. Konrad Tiefenbacher an der Juniorprofessur für Organische Chemie der Technischen Universität München angefertigt. Die Arbeit wurde unter Leitung von Prof. Dr. Konrad Tiefenbacher an der Assistenzprofessur (mit Tenure Track) für Synthesis of Functional Modules der Universität Basel im März 2018 fertiggestellt.

Teile dieser Arbeit wurden veröffentlicht:

T. M. Bräuer, Q. Zhang, K. Tiefenbacher*, J. Am. Chem. Soc. 2017, 139, 17500-17507.

T. M. Bräuer, Q. Zhang, K. Tiefenbacher*, Angew. Chem. Int. Ed. 2016, 55, 7698-7701.

L. Catti, T. M. Bräuer, Q. Zhang, K. Tiefenbacher*, CHIMIA 2016, 70, 810-814. 


\section{Acknowledgements}

First and foremost, my deepest thanks and most sincere gratitude go to Prof. Dr. Konrad Tiefenbacher for performing my $\mathrm{PhD}$ studies under his supervision acknowledging his guidance und help in every kind of situation. Without his continuous support in my extremely interesting research project, the completion of my postgraduate studies would not have been possible. His knowledge of chemistry is staggering and prodigious and I feel extremely thankful to have learned from you. I really enjoyed being part of your group and if I had to choose again for a supervisor for my $\mathrm{PhD}$ studies, my choice would be the same one every time!

From all the people I met during my PhD studies, I would like to mention Dr. Qi Zhang as first. We spent most of our $\mathrm{PhD}$ studies in the same laboratory and - in Munich - even in the same fume hood; the latter helped me a lot to further gain practical working skills. Thanks for the fruitful discussions over chemistry, our common projects and the latest soccer results. Nonetheless, my profound thanks go to all my colleagues in the laboratories at the Technical University of Munich and the University of Basel for a very pleasant working atmosphere. When work colleagues become true friends, every day's life is wonderful. I am grateful to have met you. I especially want to mention Lorenzo Catti, Irene Thamm, Jesper Köster and Michael Heilmann with whom I spent times I will never forget. Fabian Bissegger is furthermore acknowledged for his excellent taste of music.

During my PhD studies, I had the opportunity to teach and supervise brilliant research students: Sebastian Koller, Catharina Theiß, Daniel Schwinger and Raphaela Graßl. Handing over knowledge to younger scientists is a very important tool of modern universities and I was pleased to do so as I also learned a lot of myself.

For proofreading, I want to thank Prof. Dr. Konrad Tiefenbacher, Dr. Qi Zhang and Jesper Köster.

For organizational efforts, thanks are expressed to Ms. Kerstin Voigt, Ms. Audrey Fischer and Ms. Isa Worni.

In addition, expressions of gratitude go to Prof. James L. Gleason who welcomed me in his laboratories at McGill University from May 2017 to June 2017. I deeply acknowledge his clear focus on the progress of chemical science. I also really enjoyed spending time with his group 
members. Thanks are especially expressed to Sam Plamondon who put his own research aside to make my stay more convenient.

Finally yet importantly, I want to thank my parents who supported me in any conceivable way through all the years of my studies and my PhD. Without you, none of this would have been possible! 


\section{English Abstract}

In the past decades, supramolecular structures have emerged as tools to mimic natural enzymes. Due to its spacious internal volume of approximately $1400 \AA^{3}$ and its capability to enclose guests in its cavity, the resorcin[4]arene hexamer IVa, self-assembled from subunit 34a and held together by hydrogen bonds, represents an interesting candidate for supramolecular catalysis. With the disclosure of its intrinsic mild Brønsted acidity ( $\mathrm{p} K_{\mathrm{a}}$ of 5.5-6) in 2013, a series of chemical transformations exploiting the catalytic activity of IVa were investigated.

Utilizing the ability of assembly IVa to stabilize positively charged species through cation- $\pi$ interactions, an iminium-catalyzed 1,4-reduction of $\beta$-substituted $\alpha, \beta$-unsaturated aldehydes was achieved by using hexamer IVa as the nanosized reaction container. Evidence for the participation of hexamer IVa in the reaction was established through a size-selective competition reaction and a series of control experiments. Most importantly, the capsule IVa was shown to modulate the stereoselectivity of the reaction occurring in its confinement. Contrary to the reaction in bulk solution, the presence of catalytic amounts of IVa led to the preferential formation of the $(S)$-enantiomer when using (L)-proline as the cocatalyst. The modulation effect was thoroughly investigated with a variety of organocatalysts, $\alpha, \beta-$ unsaturated aldehydes and reducing agents. The best result was observed with ortho-substituted derivative 68e, L-proline (69a) and Hantzsch ester 1a as hydride donor. This preference is rationalized by the stereoselective binding of the encapsulated iminium intermediate to the interior wall of capsule IVa. Kinetic studies and mechanistic investigations were performed to gain further insight into the reaction. The results obtained indicate that delivery of the hydride is the rate-limiting step of the catalytic cycle.

With this first example of an iminium-catalyzed reaction performed in a hydrogen-bonded, selfassembled supramolecular capsule, the feasibility of utilizing IVa as supramolecular nanoreactor was further underlined. The research demonstrates that the non-covalent combination of supramolecular containers with iminium catalysis is offering new opportunities to bias stereoselectivity in challenging reactions. 


\section{Deutsche Zusammenfassung}

In den vergangenen Jahrzehnten sind vermehrt supramolekulare Strukturen als EnzymMimetika untersucht worden. Aufgrund des großen internen Volumens von ca. $1400 \AA^{3}$ und der Fähigkeit, Gäste in dieser Kavität aufzunehmen, stellt Resorcin[4]aren-Hexamer IVa, das sich in einem Selbstassemblierungs-Prozess aus Teileinheit 34a bildet und durch Wasserstoffbrücken zusammengehalten wird, einen interessanten Kandidaten für supramolekulare Katalyse dar. Nach Beschreibung der intrinsischen, milden Brønsted-Azidität ( $\mathrm{p} K_{\mathrm{a}}$ von 5.5-6) des Hexamers in 2013 wurde eine Reihe organischer Reaktionen untersucht, die sich die katalytische Aktivität von IVa zu Nutze machen.

Die Fähigkeit des Hexamers IVa, positiv geladene Gäste über Kation- $\pi$-Wechselwirkungen zu stabilisieren, bildete die Grundlage für die Untersuchung einer Iminium-katalysierten 1,4Reduktion $\beta$-substituierter $\alpha, \beta$-ungesättigter Aldehyde in Gegenwart von IVa als Reaktionskammer. Nachweise für die Teilnahme von Hexamer IVa an der untersuchten Reaktion konnten mit substratselektiven Vergleichsexperimenten und einer Serie von Kontrollexperimenten belegt werden. Interessanterweise zeigt Kapsel IVa einen Einfluss auf die Stereoselektivität der in ihrem Hohlraum ablaufenden Reaktion. Anders als in Lösung wird bei Verwendung von (L)-Prolin als Co-Katalysator in Anwesenheit einer katalytischen Menge IVa bevorzugt das $(S)$-Enantiomer gebildet. Diese Veränderung des Enantiomerenüberschusses konnte für eine Reihe von Organokatalysatoren, $\alpha, \beta$-ungesättigten Aldehyden und Reduktionsmitteln festgestellt werden. Das beste Resultat konnte mit dem ortho-substituierten Aldehyd 68e, L-Prolin (69a) und Hantzsch-Ester 1a als Hydrid-Donor erzielt werden. Diese Bevorzugung kann durch eine stereoselektive Ausrichtung des reaktiven Iminium-Intermediats zur inneren Wand der Kapsel IVa erklärt werden. Kinetische und mechanistische Aspekte wurden untersucht, um weitere Einsichten in den Ablauf der Reaktion zu erlangen. Die dabei erhaltenen Ergebnisse weisen darauf hin, dass die Übertragung des Hydrids den geschwindigkeitsbestimmenden Schritt der Reaktion darstellt.

Mit der Beschreibung der ersten Iminium-katalysierten Reaktion in einer Wasserstoffbrückengebundenen, selbstassemblierten supramolekularen Kapsel konnte die Eignung von IVa als supramolekularer Katalysator nochmals hervorgehoben werden. Die Resultate zeigen, dass die nicht-kovalente Kombination supramolekularer Container mit Iminium-Katalyse neue Möglichkeiten eröffnet, die Stereoselektivität anspruchsvoller Reaktionen zu beeinflussen. 


\section{Table of Contents}

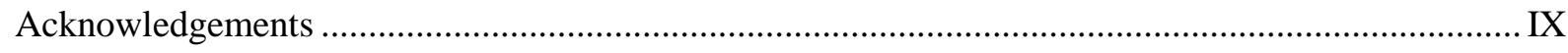

English Abstract ................................................................................................................ XIII

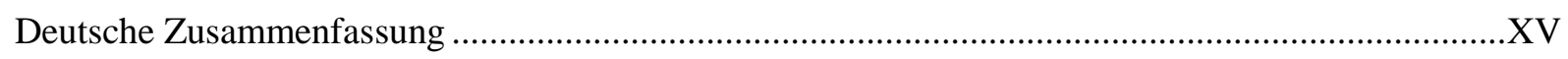

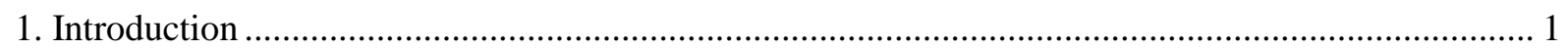

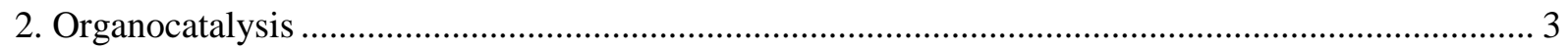

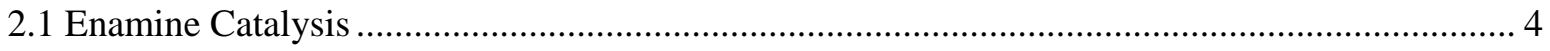

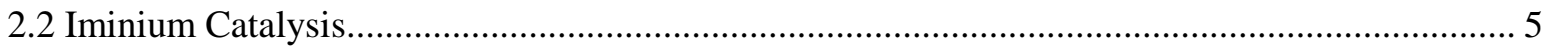

3. Supramolecular Hosts and Their Application in Catalysis......................................................... 8

3.1 Mechanically Interlocked Supramolecular Structures......................................................... 9

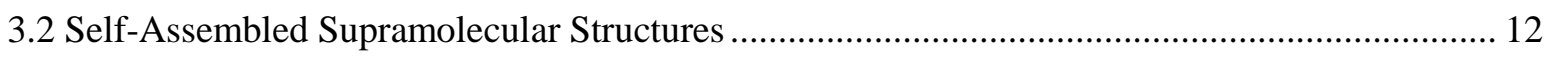

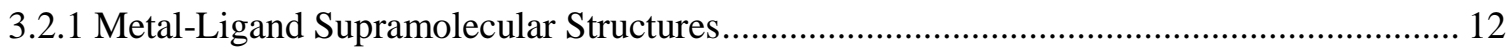

3.2.2 Hydrogen-Bonded Supramolecular Structures .................................................................. 15

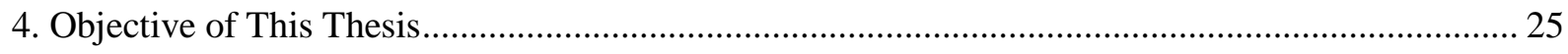

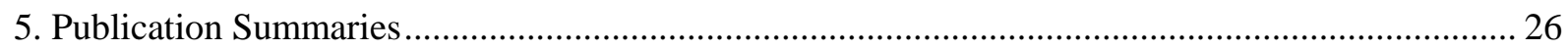

5.1 Iminium Catalysis Inside a Self-Assembled Supramolecular Capsule: Modulation of

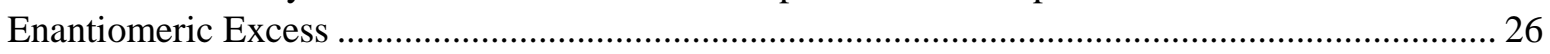

5.2 Iminium Catalysis Inside a Self-Assembled Supramolecular Capsule: Scope and Mechanistic

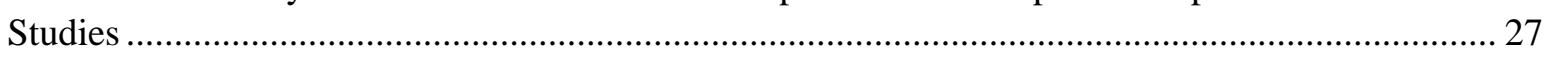

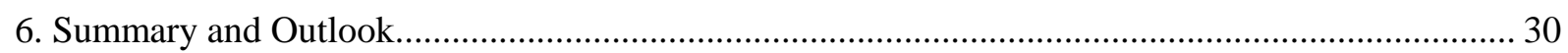

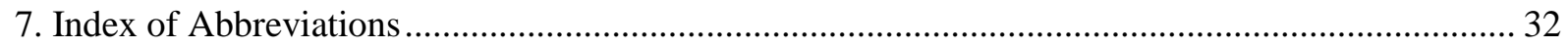

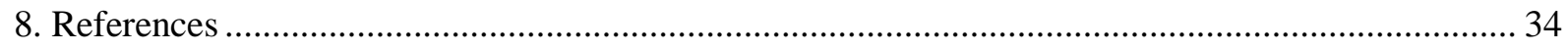

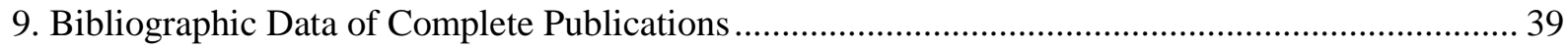

9.1 Iminium Catalysis Inside a Self-Assembled Supramolecular Capsule: Modulation of

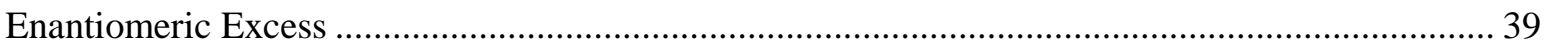

9.2 Iminium Catalysis Inside a Self-Assembled Supramolecular Capsule: Scope and Mechanistic

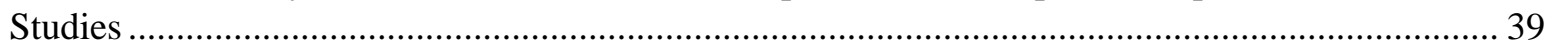

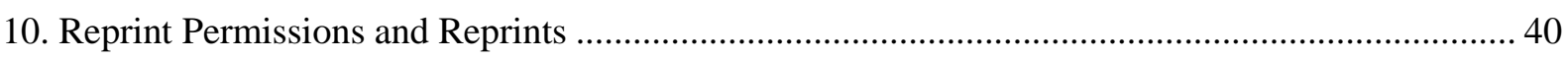

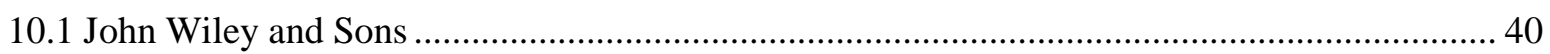

10.1.1 Reprint Permission of the Manuscript "Iminium Catalysis Inside a Self-Assembled Supramolecular Capsule: Modulation of Enantiomeric Excess" ................................................ 40

10.1.2 Manuscript "Iminium Catalysis Inside a Self-Assembled Supramolecular Capsule:

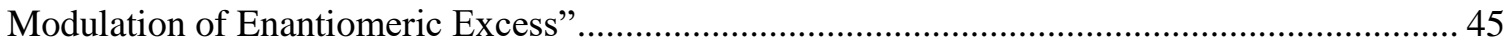

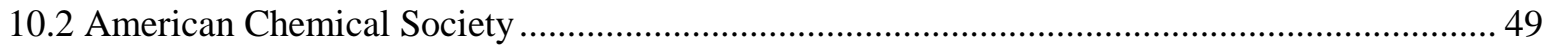

10.2.1 Reprint Permission of the Manuscript "Iminium Catalysis Inside a Self-Assembled

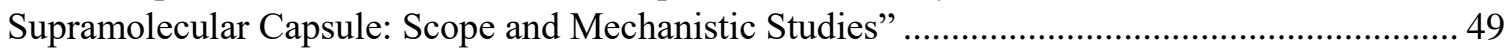

10.2.2 Manuscript "Iminium Catalysis Inside a Self-Assembled Supramolecular Capsule: Scope

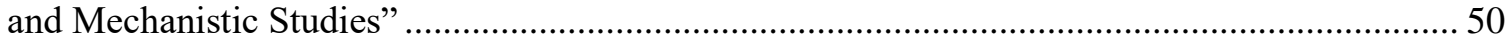




\section{Introduction}

With the fertilization of an egg cell, life begins. A myriad of catalytic processes are built up and enable the daily life of human beings. The cell metabolism is regulated by the complex interplay of numerous enzymes with different cofactors. One class of cofactors are coenzymes, redoxactive organic molecules that bind non-covalently to the respective enzymes. An important example of this class is the pair of NADH/NAD ${ }^{+}$(Scheme 1a). Originally, Harden described the NADH/NAD ${ }^{+}$pair as a cofactor in fermentation. Later von Euler-Chelplin identified the pair as a nucleoside sugar phosphate. It was left to Warburg in 1936 to isolate $\mathrm{NAD}^{+}$and discover its essential role for hydride transfer in biochemical reactions. ${ }^{[1]}$ A large number of biologically important enzymes depend on this coenzyme, e.g. the lactate dehydrogenase, which utilizes NADH to reduce pyruvate to lactate, two intermediates in the citrate cycle.

In 1881 Hantzsch reported a condensation reaction yielding "pyridine-like" compounds. ${ }^{[2]}$ The products, obtained in a reaction sequence including a Knoevenagel- and a Michael-type reaction, were later identified as 1,4-dihydropyridine dicarboxylates and have since become known as Hantzsch esters (Scheme 1b). Decades later, after realizing the structural resemblance of Hantzsch esters to the NADH/NAD ${ }^{+}$coenzyme, chemists started to use synthetic Hantzsch esters as substrates for hydride transfers in chemical reactions. Although Hantzsch did not recognize their synthetic potential, the use of these esters in organic chemistry serves as a great example of the possible insights to be gained from the interplay of initially unrelated topics. ${ }^{[3]}$
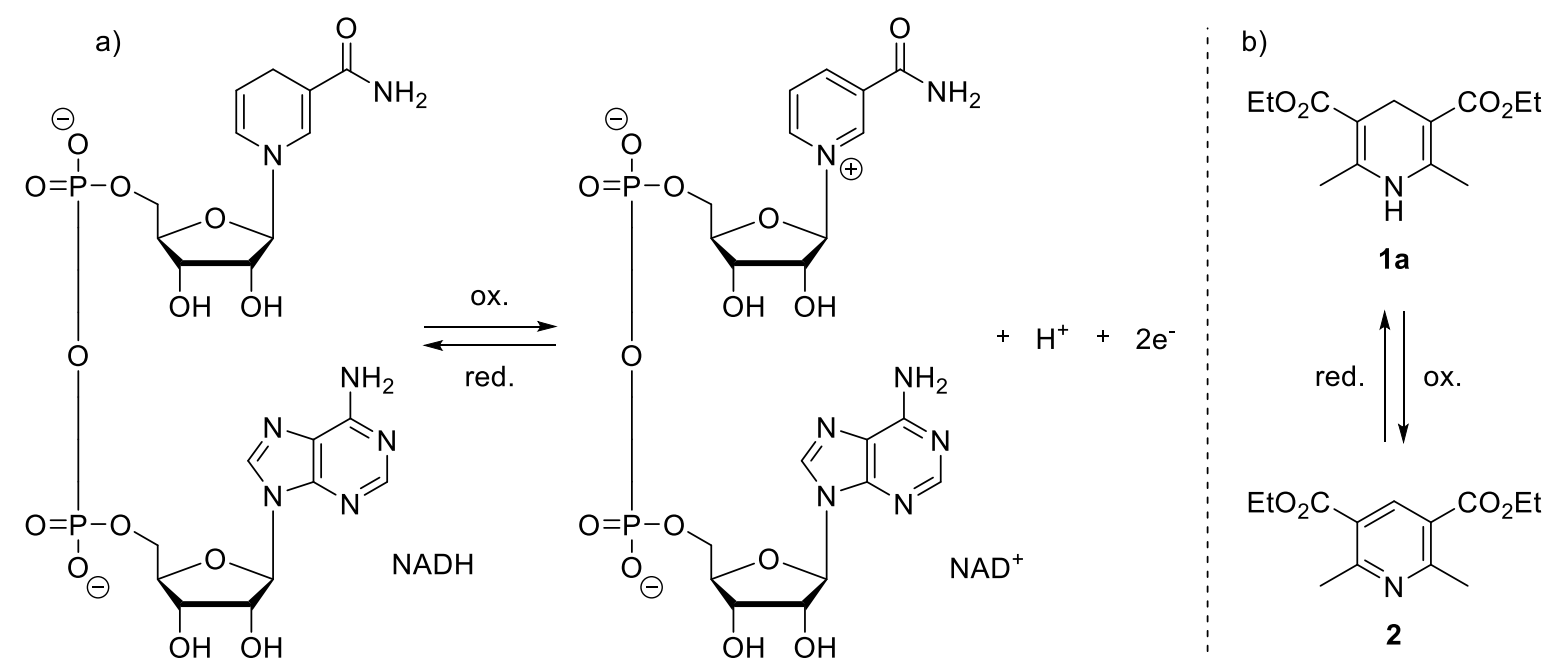

Scheme 1: Redox transformations of (a) NADH and $\mathrm{NAD}^{+}$and (b) Hantzsch ester $\mathbf{1 a}$ and its oxidized form 2. 
Apart from this example, other biomimetic approaches, i.e. the application of artificial technology imitating the efficient systems utilized by nature, can be found across different scientific disciplines: Inspired by the superhydrophobicity of Lotus plants, well recognized as the Lotus effect, the visibility through e.g. car windshields has been improved. ${ }^{[4]}$ Thousands of birds, unable to recognize the physical barrier of transparent glass, die every year from collisions with common glass fronts. This could be averted by using new types of glass fronts that draw inspiration from UV reflective spiderwebs, which birds are able to recognize and consequently avoid. ${ }^{[5]}$ Scientists around the world also pursue the goal of mimicking enzymes, the biological catalysts working inside cells.

One approach thereof can be found in supramolecular chemistry. Due to the complex structure of enzymes, the rational design of enzyme-mimicking catalytically active systems is highly challenging. Supramolecular chemists therefore envisage synthesizing easily accessible supramolecular cages aiming at reproducing similar characteristics observed in the enzymatic reaction pockets: In these, substrates are taken up into the hydrophobic cavity and bound with high affinity due to stabilization via non-covalent interactions. Owing to the restricted internal volume and the defined cavity structure of the enzyme, the substrates are forced to adopt reactive conformations that highly resemble the corresponding transition states. This results in a reduction of the activation energy, and facilitates the transformation. After conversion of the substrate to a product of lower affinity to the enzyme, the latter is expelled from the catalytically active site to enable a new turnover. Similar to enzymes, compartmentalization is a crucial aspect for the utilization of supramolecular containers as reaction hosts. Inside their cavities, the segregation from the bulk solution, higher local concentration and host-induced preorientation of substrates may lead to previously unseen reaction rate accelerations and unexpected selectivities compared to other "man-made" catalysts.

This dissertation describes the first example of utilizing a self-assembled, hydrogen-bonded and easily accessible supramolecular nanoreactor to modulate the stereospecific outcome of an organocatalytic reaction using Hantzsch esters as hydride donors. 


\section{Organocatalysis}

Ever since the Contergan tragedy, ${ }^{[6]}$ which caused thousands of children to be born with multiple deformities, the necessity of delivering molecules with the highest degree of optical purity became the focus of attention for chemists around the world. For a long time, only transition metal catalysis ${ }^{[7]}$ and enzymatic catalysis ${ }^{[8]}$ were demonstrated to fulfill these requirements. Organocatalysts on the other hand, where the catalytically active species is comprised of a small organic molecule consisting of, mainly, carbon, hydrogen, oxygen, sulfur and phosphorus atoms, did not receive as much attention. Interestingly, the first report of an asymmetric organocatalytic reaction was already documented in 1912 (Bredig and Fiske reported the addition of $\mathrm{HCN}$ to benzaldehyde accelerated by quinine and quinidine and the opposing optical activity of the formed cyanohydrins ${ }^{[9]}$ ), but no large effort was put into the further expansion of this reaction pathway for many years. Other reports followed, ${ }^{[10]}$ but only the seminal publications of List, Lerner and Barbas ${ }^{[1]}$ as well as Ahrendt, Borth and MacMillan $^{[12]}$ in 2000 on a proline-catalyzed asymmetric aldol reaction and a highly enantioselective organocatalytic Diels-Alder reaction, respectively, led to the so-called gold rush of organocatalysis. ${ }^{[13]}$ Today, organocatalysts are widely used and their relevance to the scientific community is increasing, as can be concluded from the rise in numbers of publications on organocatalytic transformations presented each year. ${ }^{[14]}$ Organocatalysts are able to draw upon multiple advantages: Increased stability towards water and oxygen allow less demanding reaction setups. Often derived from the chiral pool, organocatalysts are usually readily available and inexpensive. Organocatalysis also gains importance in the pharmaceutical industry where metal contamination of products, a result of the usage of metal-based catalysts, is problematic. ${ }^{[15]}$ Furthermore, organocatalysts are considered to be less toxic than metal catalysts. $^{[15]}$

Two main approaches exist in organocatalysis: In non-covalent organocatalysis, the formation of the substrate-catalyst complex is mainly facilitated by hydrogen bonding using e.g. ureas, ${ }^{[16]}$ thioureas $^{[16-17]}$ and diols. ${ }^{[18]}$ In covalent organocatalysis, the substrate reacts at first with the catalyst to form a reactive intermediate. The two main modes of activation of this approach, enamine and iminium catalysis, are highlighted in the following two chapters. 


\subsection{Enamine Catalysis}

One of the most important activation modes in covalent organocatalysis is enamine catalysis (Scheme 2): ${ }^{[19]}$ In an acid-induced condensation reaction between carbonyl compound $\mathbf{3}$ (ketone or aldehyde) and cyclic secondary amine $\mathbf{4}$, the positively charged iminium ion $\mathbf{5}$ is formed, which exists in equilibrium with enamine 6. This nucleophilic intermediate is the reactive species in the enamine catalytic cycle and is able to attack an electrophile from its $\alpha$-position to form iminium ion 7. After hydrolysis, a $\alpha$-functionalized carbonyl compound $\mathbf{8}$ and catalyst $\mathbf{4}$ are liberated to close the catalytic cycle.
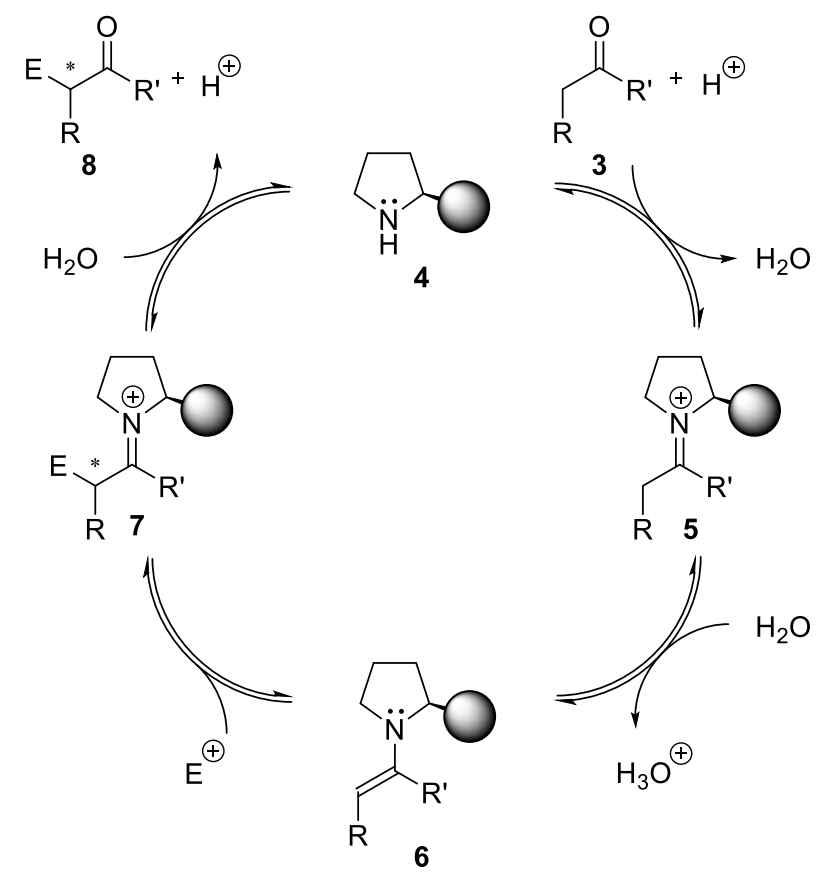

Scheme 2: Catalytic cycle of enamine catalysis with aminocatalyst 4.

The activation via enamine formation can be explained by a change in orbital energies (Scheme 3). Induced by a higher intrinsic energy of the nitrogen lone pair of enamine 6 in comparison to the oxygen lone pair of enol $\mathbf{9}$ (formed by tautomerization from carbonyl compound 3), the Highest Occupied Molecular Orbital (HOMO) of enamine 6 is raised compared to the HOMO of the starting carbonyl compound. The energy gap between the HOMO of the nucleophile and the Lowest Unoccupied Molecular Orbital (LUMO) of the electrophile is therefore lowered, facilitating the formation of a new bond. 


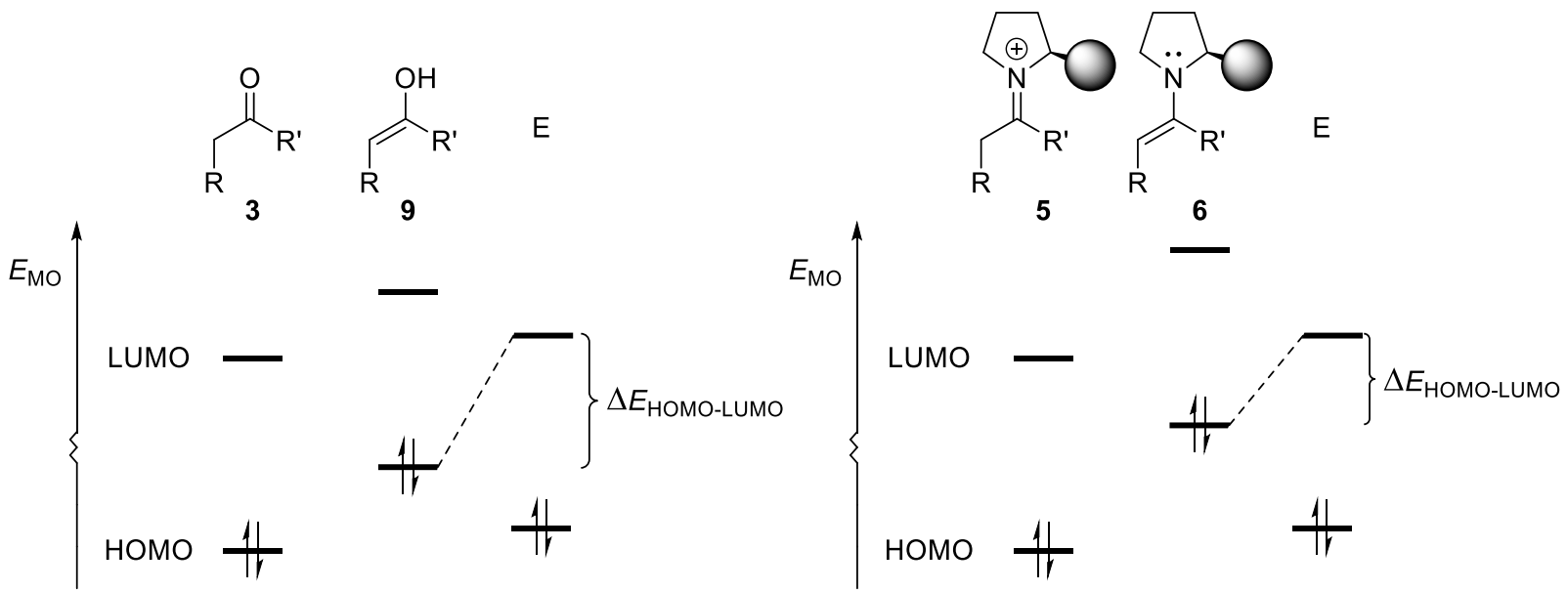

Scheme 3: With the formation of enamine 6, the corresponding HOMO is elevated in comparison to the carbonyl compound. A smaller HOMO-LUMO gap translates to a more facile reaction.

Since the pioneering work of List, Lerner and Barbas, ${ }^{[11]}$ enamine catalysis has turned into a powerful tool for asymmetric synthesis. ${ }^{[19]}$ Various $\alpha$-functionalizations of aldehydes utilizing this strategy were developed in the following years, including aldol reactions, ${ }^{[20]}$ Mannich reactions ${ }^{[21]}$ and Michael reactions. ${ }^{[22]}$ Using the concept of vinylogy, ${ }^{[23]}$ the focus later turned to the functionalization of the more remote $\gamma$ - and $\varepsilon$-positions giving rise to dienamine ${ }^{[24]}$ and trienamine ${ }^{[25]}$ chemistry.

\subsection{Iminium Catalysis}

Of similar relevance to the scientific community is iminium catalysis, in which iminium ions act as the reactive intermediates in the catalytic cycle (Scheme 4). ${ }^{[26]}$ Mechanistically identical to the first step in enamine catalysis, the cycle starts with an acid-induced condensation of an $\alpha, \beta$-unsaturated carbonyl compound $\mathbf{1 0}$ (aldehyde or ketone) with the secondary amine $\mathbf{4}$, forming the positively charged iminium ion 11. This highly electrophilic species is then attacked by a nucleophile in its $\beta$-position forming enamine 12. Protonation of 12 and hydrolysis of $\mathbf{1 3}$ releases product $\mathbf{1 4}$ and regenerates the secondary amine $\mathbf{4}$, which then can undergo another catalytic cycle. 


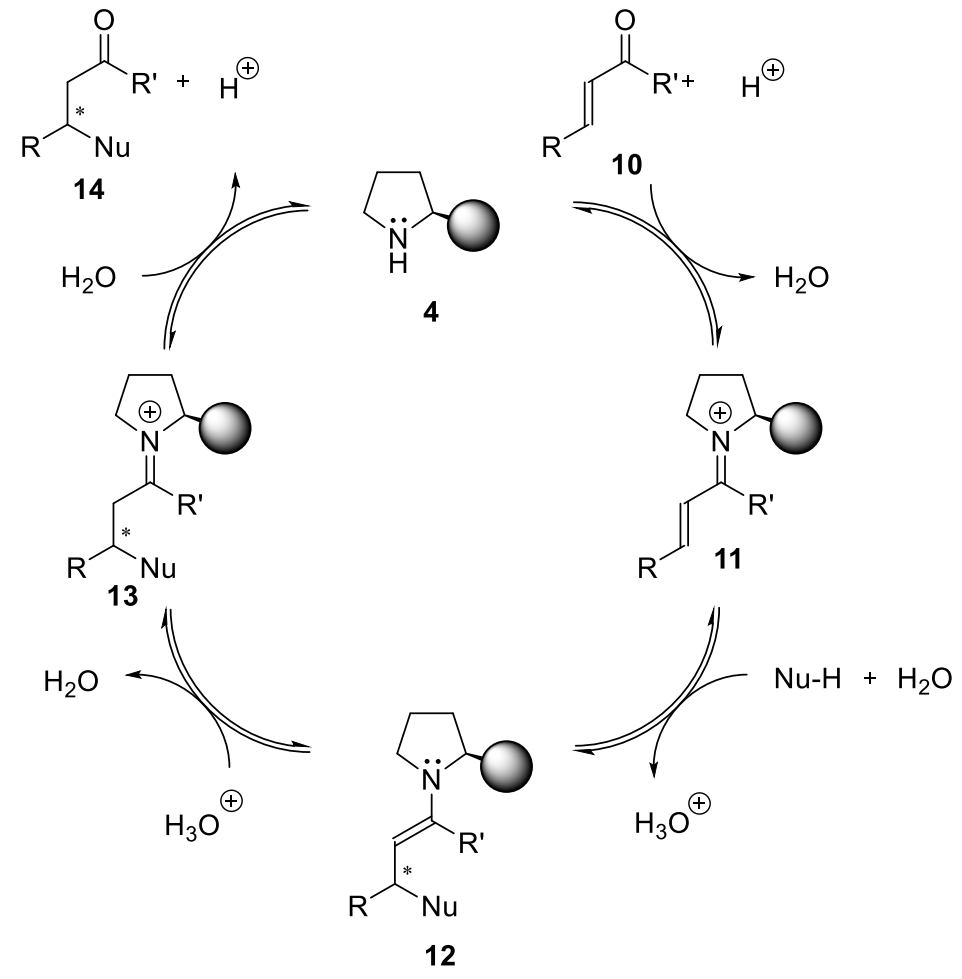

Scheme 4: General catalytic cycle of iminium catalysis with aminocatalyst 4.

In analogy to enamine catalysis, iminium catalysis is facilitated due to the lowering of the HOMO-LUMO gap (Scheme 5): Whereas an ordinary $\alpha, \beta$-unsaturated carbonyl compound 10 is less reactive towards a nucleophilic attack, an activation by the formation of iminium ion $\mathbf{1 1}$ results in the lowering of the LUMO, making the electrophile more reactive to approaching nucleophiles. Another mode of activation of $\alpha, \beta$-unsaturated carbonyl compounds can be found in the coordination of Lewis acids (see complex 15, Scheme 5).
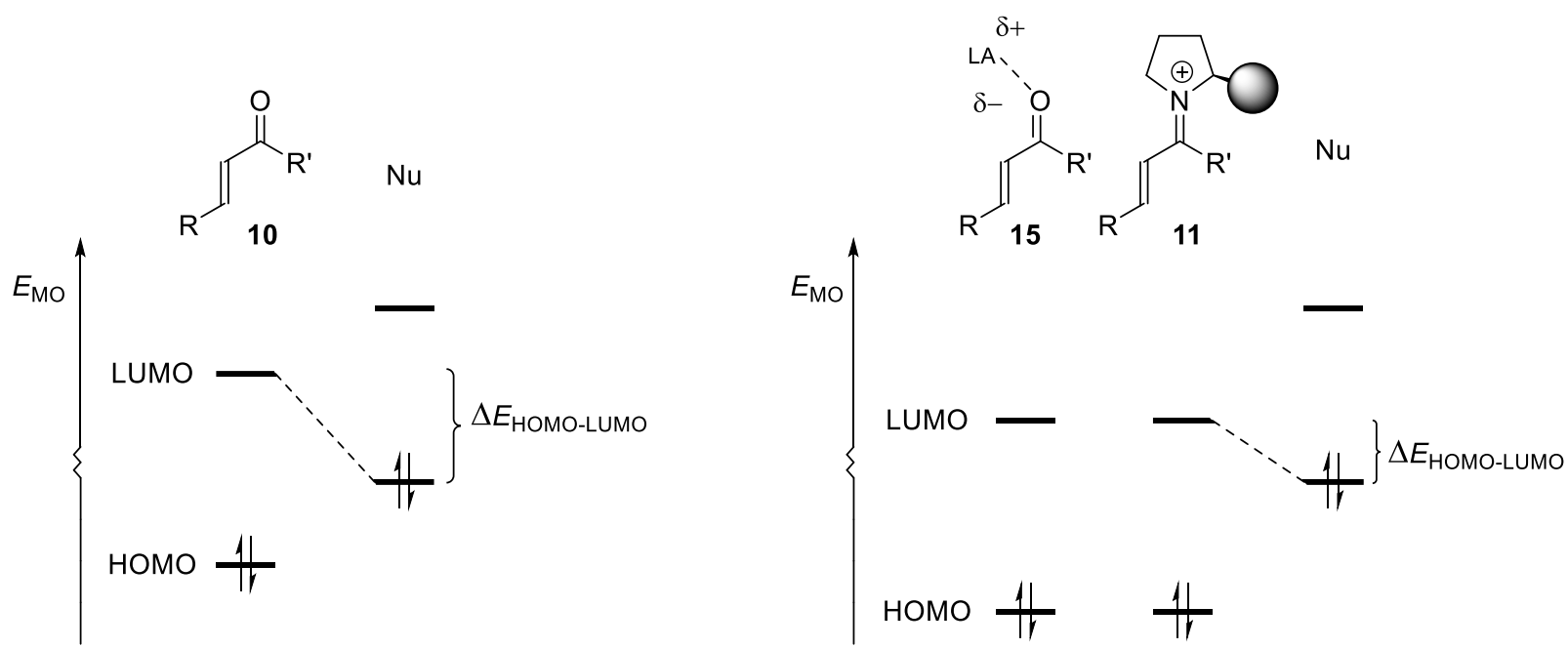

Scheme 5: With the formation of iminium ion 11, the corresponding LUMO is lowered in comparison to the carbonyl compound facilitating the nucleophilic attack. Coordination of a Lewis acid to carbonyl compound 15 lowers the HOMOLUMO gap in the same manner. 
The Diels-Alder reaction published by Ahrendt, Borth and MacMillan ${ }^{[12]}$ served as trailblazer. Reports of other Diels-Alder ${ }^{[27]}$ and aza-Diels-Alder ${ }^{[28]}$ reactions followed. Additionally, iminium catalysis also proved to be a versatile tool for a variety of enantioselective functionalizations on the $\beta$-position of aldehydes and ketones. Conjugate additions of carbon, ${ }^{[29]}$ hydrogen, ${ }^{[30]}$ sulphur, ${ }^{[31]}$ phosphorus, ${ }^{[32]}$ nitrogen ${ }^{[33]}$ and oxygen ${ }^{[34]}$ nucleophiles on $\alpha, \beta-$ unsaturated carbonyl compounds were reported. Diarylprolinol silyl ethers proved to be a versatile tool in this regard. ${ }^{[35]}$ Similar to enamine catalysis, the extension of the reactivity to more remote positions in iminium catalysis challenged the scientific community for a long time. ${ }^{[36]}$ It was only in 2013 that the first report of vinylogous functionalization via classical iminium ion activation was published. ${ }^{[37]}$

In summary, organocatalysis has flourished over the course of the past years, establishing a new and fascinating methodology that opened up innumerable possibilities for organic synthesis with usually excellent control of stereoselectivities. However, the focus of attention already turned to the functionalization of more remote positions. Therefore, it can be expected that future organocatalytic reports will expand upon this development and present unprecedented reactivities and selectivities. 


\section{Supramolecular Hosts and Their Application in Catalysis}

In contrast to the dominating field of molecular chemistry dealing with covalent bonds, supramolecular chemistry addresses the non-covalent interactions between molecules and is therefore often described as the chemistry beyond the molecule. ${ }^{[38]}$ It also covers metal coordination, hydrophobic forces, $\pi-\pi$ interactions and electrostatic effects. The functionality of enzymes as paragon, self-organization, molecular recognition and host-guest chemistry are the key concepts underlying this research area.

The prospect of mimicking these highly sophisticated biological catalysts motivated many chemists to develop man-made supramolecular structures, investigate the encapsulation of substrates in such hosts and elucidate their potential as reaction chambers or catalysts. ${ }^{[39]}$ Similar to the substrate binding in the pocket of a natural enzyme, encapsulation of guests in artificial supramolecular structures results in an increased local concentration and, in some cases, in a favorable preorganization of the bound substrate to facilitate a chemical transformation. There are three possible benefits of performing catalytic reactions in supramolecular nanocontainers: ${ }^{[40]}$ Substrate selectivity can be achieved, when a specific substrate is encapsulated in a supramolecular container and selectively converted, while others with a similar reactivity but a different size and shape do not react. Product selectivity can occur when the product distribution varies in the reactions in the absence and the presence of a nanoreactor, as encapsulation by a supramolecular structure may favor alternative reaction pathways. Furthermore, the development of multicatalytic tandem reactions, where a multitude of steps is conducted consecutively, may be facilitated by supramolecular catalysts. The timeconsuming processes of reaction setup, workup and purification for each step could therefore be avoided. Furthermore, low product selectivity, often encountered when a multitude of steps is performed in bulk solution, could be circumvented.

Early attempts of constructing supramolecular structures concentrated on covalently linked structures, such as cyclophanes, ${ }^{[41]}$ cucurbiturils $^{[42]}$ and spherands. ${ }^{[43]}$ Furthermore, cyclodextrins, which are now widely used in industrial applications, ${ }^{[44]}$ have been investigated thoroughly. ${ }^{[45]}$ However, most of the covalently linked systems possess the noteworthy disadvantage of non-trivial and step-intensive syntheses. 18 steps were, for instance, necessary for the synthesis of a catalytically active cyclophane host structure reported by Diederich. ${ }^{[41]}$ Besides, inefficient guest exchange as well as the inability of one specific system to 
accommodate variously sized guests led to a decreased interest in this type of supramolecular hosts.

\subsection{Mechanically Interlocked Supramolecular Structures}

Another potent class of supramolecular structures are rotaxanes, mechanically interlocked aggregates consisting of an axle with bulky end groups threaded through a macrocycle. After the first synthesis of a rotaxane by Harrison in the $1960 \mathrm{~s},{ }^{[46]}$ a large number of chemists put their focus to this new and exciting research area. The topic drew even more attention from the scientific community when the Nobel Prize 2016 in Chemistry was awarded to Stoddart for his contributions to this field of supramolecular chemistry. ${ }^{[47]}$ Whereas early developments focused on the synthesis via high-yielding routes and the description of the topology of such systems, ${ }^{[48]}$ rotaxanes and rotaxane-based molecular shuttles later - due to their possibility of switching between "on" and "off" states ${ }^{[49]}$ - proved to be potentially useful tools for information storage, ${ }^{[50]}$ fluorescence switching ${ }^{[51]}$ and to control binding events ${ }^{[52]}$. The concept of using rotaxanes as switchable organocatalysts by concealing ("off") and revealing ("on") the active organocatalytic site was introduced by the Leigh group (Scheme 6). ${ }^{[53]}$ Inspired by a motif developed by Coutrot ${ }^{[54]}$ Leigh et al. synthesized switchable rotaxane $\mathbf{I}$, which features a dibenzo[24]crown-8 macrocycle surrounding an axle comprised of two triazolium rings and a dibenzylamine/ammonium moiety. By tuning the acidity of the system, the position of the macrocycle on the axle in $\mathbf{I}$ can be controlled: In its non-protonated form (Ia), the triazolium groups are the favored binding sites for the macrocycle leaving the catalytic site exposed and active. Upon protonation (Ib) of the secondary amine (e.g. by the addition of TFA), the macrocycle moves to the middle of the chain blocking access of reactants to the catalytic center. The authors investigated the efficacy of this system as a switchable organocatalyst in the Michael addition of aliphatic thiols, e.g. thiol 16, to trans-cinnamaldehyde (17). They found that the neutral form of rotaxane was able to catalyze the reaction via the formation of an iminium ion ( $5 \mathrm{~d}, 83 \%$ yield), whereas the starting material remained unreacted when the protonated form of the rotaxane was used ( $0 \%$ yield). In a subsequent publication, Leigh et al. demonstrated the generality of their system by utilizing the rotaxane in iminium catalysis, in enamine catalysis, in tandem iminium-enamine reactions and in trienamine catalysis. ${ }^{[55]}$ Research in rotaxane-based switchable organocatalysts was also presented by the group of Leung in 2016. ${ }^{[56]}$ 
a)

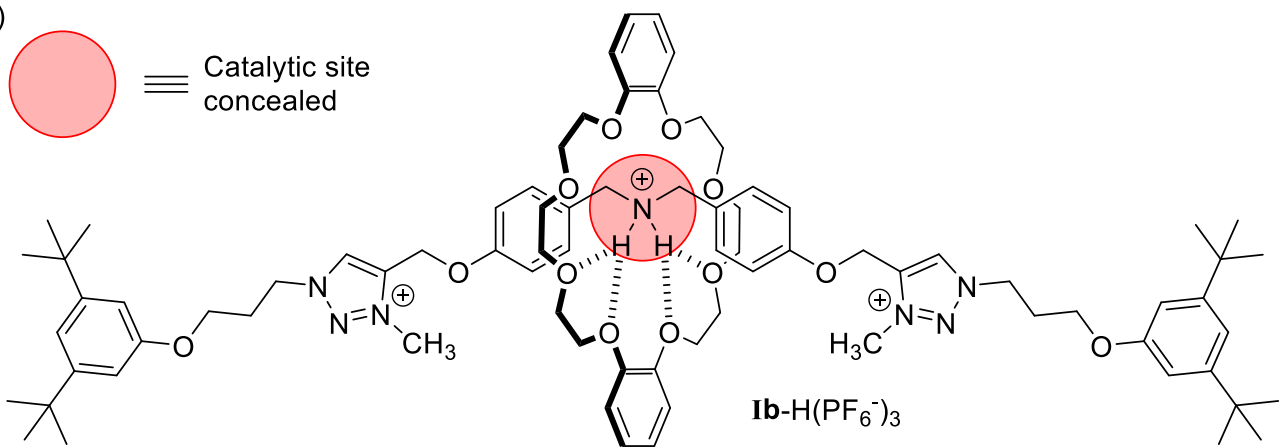

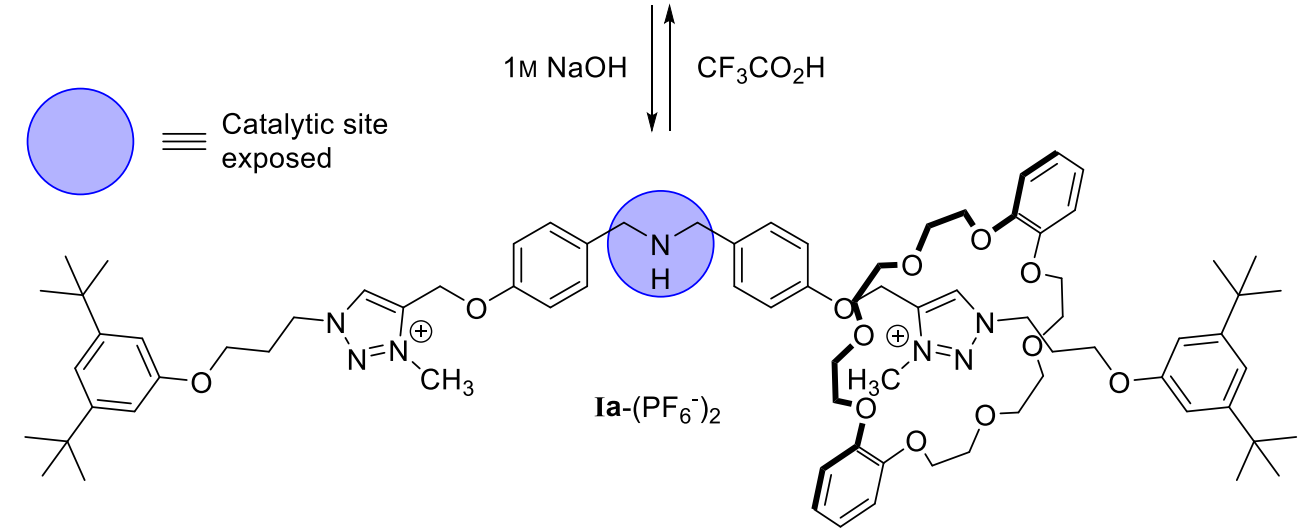

b)

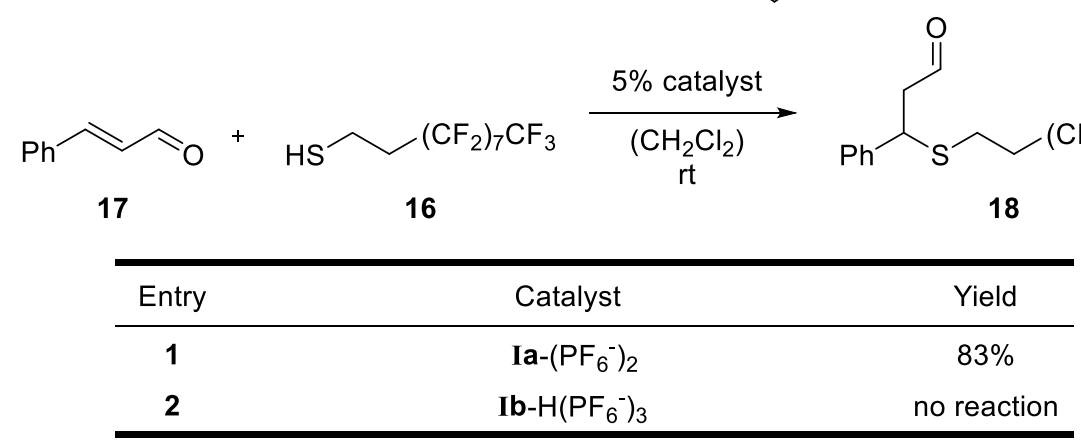

Scheme 6: (a) Rotaxanes Ib-H( $\left(\mathrm{PF}_{6}^{-}\right)_{3}$ and $\mathbf{I a}-\left(\mathrm{PF}_{6}^{-}\right)_{2}$; (b) Investigation of the catalytic properties of rotaxanes $\mathbf{I b}-\mathrm{H}\left(\mathrm{PF}_{6}^{-}\right)_{3}$ and Ia- $\left(\mathrm{PF}_{6}^{-}\right)_{2}$ on the Michael addition of thiol 16 to trans-cinnamaldehyde (17).

Besides rotaxanes, catenanes, which consist of two or more interlocked macrocycles, have recently been utilized as supramolecular catalysts. The Niemeyer group reported the first application of a catenane-based catalyst for asymmetric organocatalysis (Scheme 7). ${ }^{[57]}$ After having synthesized the interlocked [2]catenane $(S, S)$-II featuring two chiral 1,1'-binaphthylphosphoric acids, ${ }^{[58]}$ the authors envisaged to employ this system in catalysis since 1,1'-binaphthyl-phosphoric acids are widely used in asymmetric organocatalysis. ${ }^{[59]}$ Using a protocol initially established by the Rueping group, ${ }^{[60]}$ the authors performed a transfer hydrogenation reaction of 2-substituted quinolines with $(S, S)$-II using Hantzsch esters as the reducing agent. The best result was achieved with 2-(4-methoxyphenyl)quinoline 19a as the substrate. With catalytic amounts of $(S, S)$-II $(2.5 \mathrm{~mol} \%)$, 19a was selectively converted to $(R)$ 2-(4-methoxyphenyl)-1,2,3,4-tetrahydroquinoline

20a $(87 \%$ yield, $97 \%$ ee $)$. The 
stereoselectivity was greatly attenuated with either the macrocyclic, non-catenated catalyst $(S)$-21 (ee of 47\% $(R))$ or the acyclic derivative $(S)$-22 (ee of 58\% $(R))$. Extensive computational studies indicated that the higher stereoselectivity observed with catalyst $(S, S)$-II is attributed to the formation of a sandwich-like transition state with this catalyst. Compared to the systems with only one phosphoric acid $\left(1.1 \mathrm{kcal} \mathrm{mol}^{-1}\right)$, the transition state resulting from the dual phosphoric acid motif offers a higher energetic differentiation $\left(3.9 \mathrm{kcal} \mathrm{mol}^{-1}\right)$, which ultimately favors the formation of one enantiomer over the other.
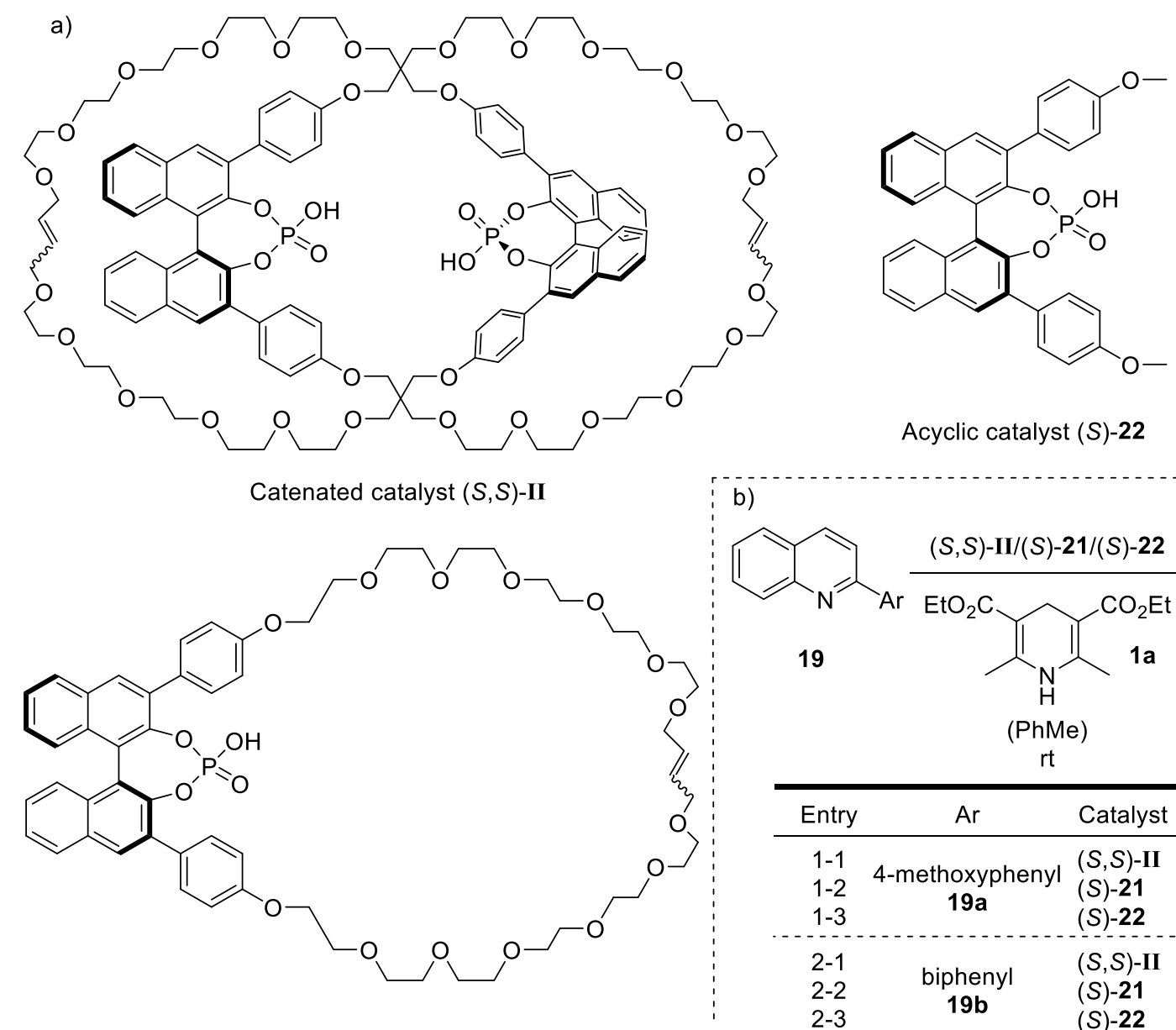

b)

Non-interlocked macrocycle (S)-21

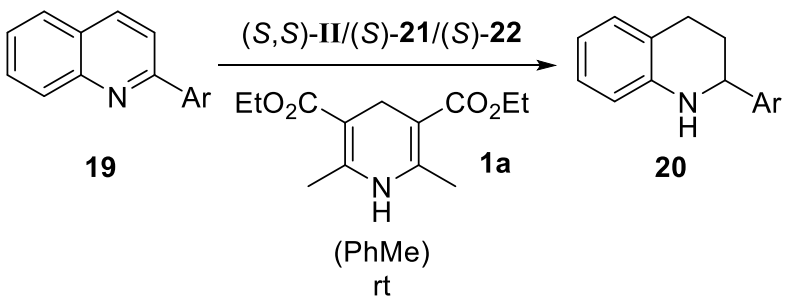

\begin{tabular}{|c|c|c|c|c|}
\hline Entry & $\mathrm{Ar}$ & Catalyst & Yield [\%] & ee $[\%]$ \\
\hline $\begin{array}{l}1-1 \\
1-2 \\
1-3\end{array}$ & $\begin{array}{c}\text { 4-methoxyphenyl } \\
\text { 19a }\end{array}$ & $\begin{array}{l}(S, S)-\mathbf{I I} \\
(S)-21 \\
(S)-22\end{array}$ & $\begin{array}{l}87 \\
90 \\
89\end{array}$ & $\begin{array}{l}97 \\
47 \\
58\end{array}$ \\
\hline $\begin{array}{l}2-1 \\
2-2 \\
2-3\end{array}$ & $\begin{array}{c}\text { biphenyl } \\
19 \mathrm{~b}\end{array}$ & $\begin{array}{l}(S, S)-\mathbf{I I} \\
(S)-21 \\
(S)-22\end{array}$ & $\begin{array}{l}89 \\
94 \\
87\end{array}$ & $\begin{array}{l}98 \\
59 \\
76\end{array}$ \\
\hline
\end{tabular}

Scheme 7: (a) Catenated catalyst $(S, S)$-II, acyclic catalyst (S)-22 and non-interlocked catalyst (S)-21; (b) Results for the transfer hydrogenation of different 2-aryl-quinolines 19.

Similar to covalently linked supramolecular structures, a large effort has to be devoted to the synthesis of these mechanically interlocked hosts. The switchable rotaxane I by Leigh et al., for instance, was obtained in a time-consuming 11-step sequence and involved the usage of cancerogenic reactants. ${ }^{[53]}$ To bypass this issue, chemists envisioned to utilize the more readily accessible non-covalently linked supramolecular structures as alternatives. 


\subsection{Self-Assembled Supramolecular Structures}

In this approach, smaller and synthetically readily available subunits spontaneously selfassemble to form highly ordered supramolecular structures. The types of connections enabling such self-assembled structures include metal-ligand interactions, ${ }^{[61]}$ hydrogen bonding, ${ }^{[62]}$ and hydrophobic interactions. ${ }^{[63]}$ Although these types of interaction are much weaker than covalent bonds, the accumulation of a multitude of such weak interactions renders the assemblies thermodynamically stable. However, supramolecular structures based on non-covalent interactions have not been widely used in catalysis. So far, hydrogen-bonded and, to a larger extent, metal-ligand systems have successfully been exploited to perform catalysis. The following examples shall give a brief overview over the utilized systems.

\subsubsection{Metal-Ligand Supramolecular Structures}

The by far most important self-assembled supramolecular host displaying catalytic activity is the metal-ligand [Ga4 $\left.\mathrm{L}_{6}\right]^{12-}$-cluster IIIa, established by the group of Raymond in 1998 (Scheme 8) ${ }^{[64]}$ Four Gallium(III) metal ions and six naphthalene-based catecholamide ligands define the vertices and edges of this tetrahedral assembly. As a consequence of the tris-bidentate coordination of the Gallium(III) atoms, the individual $\left[\mathrm{Ga}_{4} \mathrm{~L}_{6}\right]^{12-}$-clusters show a helical chirality. Of a variety of theoretically possible stereoisomers, the homochiral $\Delta \Delta \Delta \Delta$ - and $\Lambda \Lambda \Lambda \Lambda$-assemblies are formed exclusively since the chiral information around the metal atoms is transferred by mechanical coupling. ${ }^{[65]}$ Host-guest chemistry is performed in the $450 \AA^{3}$ sized hydrophobic interior, whereas the cage itself is water-soluble. Its solubility in water is due to the negative charge of III, which is also the driving force for the encapsulation of cationic guests that experience strong coulombic interactions inside the cavity. Additionally, cationic guests are also stabilized via cation- $\pi$ interactions with the naphthalene walls of the host. However, owing to the hydrophobic effect, encapsulation of neutral guests is also observed. ${ }^{[66]}$ Uptake and release of guests occurs via a non-dissociative mechanism that involves partial deformation of the cluster. ${ }^{[67]}$ The encapsulation process is entropy-driven, since the uptake of one guest molecule results in the expulsion of several pre-encapsulated solvent molecules. ${ }^{[68]}$ Guests being encapsulated and stabilized by the nanovessel include amines, ${ }^{[69]}$ diamines $^{[70]}$ and phosphonium species. ${ }^{[71]}$ 
a)

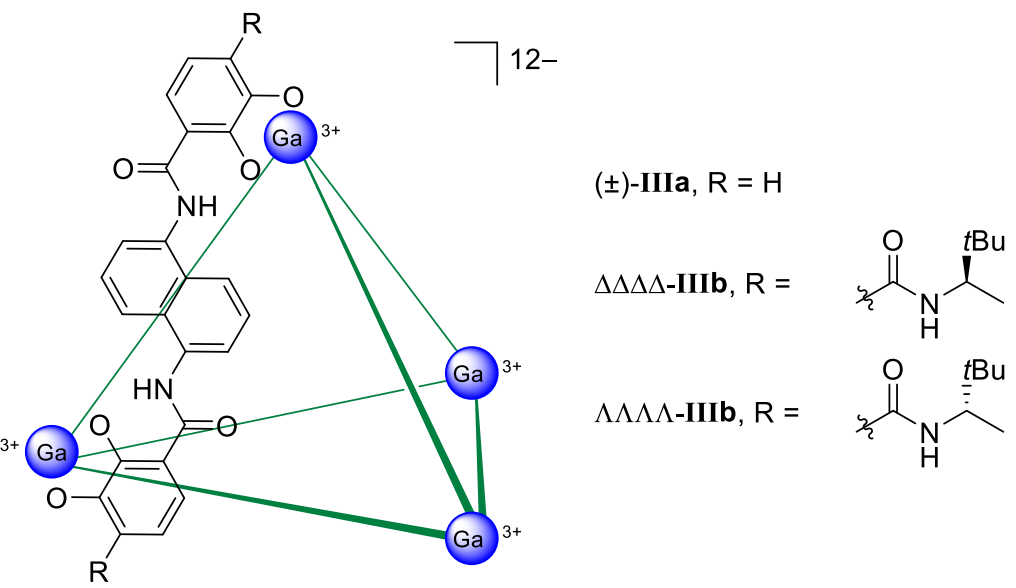

b)

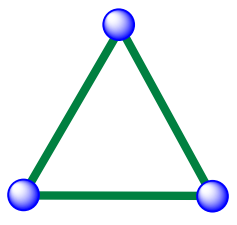

Scheme 8: (a) Self-assembled metal-ligand $\left[\mathrm{Ga}_{4} \mathrm{~L}_{6}\right]^{12-}$ cluster III established by the Raymond group; (b) simplified symbolic representation of the cluster.

Being aware of the affinity of cluster IIIa for cationic species, the groups of Raymond and Bergman also envisioned to trap iminium ions (Scheme 9), ${ }^{[72]}$ which are susceptible to hydrolysis in bulk solution. To test their hypothesis, a mixture of pyrrolidine (23) and acetone (24) in $\mathrm{D}_{2} \mathrm{O}$ was treated with IIIa. No formation of the iminium adduct could be detected by ${ }^{1} \mathrm{H}$ NMR analysis in the absence of cage IIIa. However, the formation of the complex $[\text { IIIa } \subset \mathbf{2 5}]^{11-}$ was unambiguously confirmed by the characteristic ${ }^{1} \mathrm{H}$ NMR resonances for the iminium species (63\% binding efficiency, the binding efficiency represents the ratio between the concentration of occupied host to overall host concentration). This confirmed the stabilization of the positively charged iminium ion by IIIa via encapsulation. The authors then investigated the binding efficiency of differently sized iminium species. The highest binding efficiency $(82 \%)$ was observed with the iminium species derived from 2-pentanone. This was rationalized with the optimal fit of the formed iminium ion, which is able to arrange its alkyl chain in a fully extended conformation in the cavity of IIIa. Substrates with longer alkyl chains are also encapsulated, however, they have to adopt folded conformations for longer chain lengths. This resulted in a less pronounced binding affinity. Using 2-nonanone as ketone, a binding efficiency of only $28 \%$ was detected. No iminium ion formation at all was observed when 2-undecanone was utilized, indicating that the respective iminium cation is too large to fit into the cavity of host IIIa. 


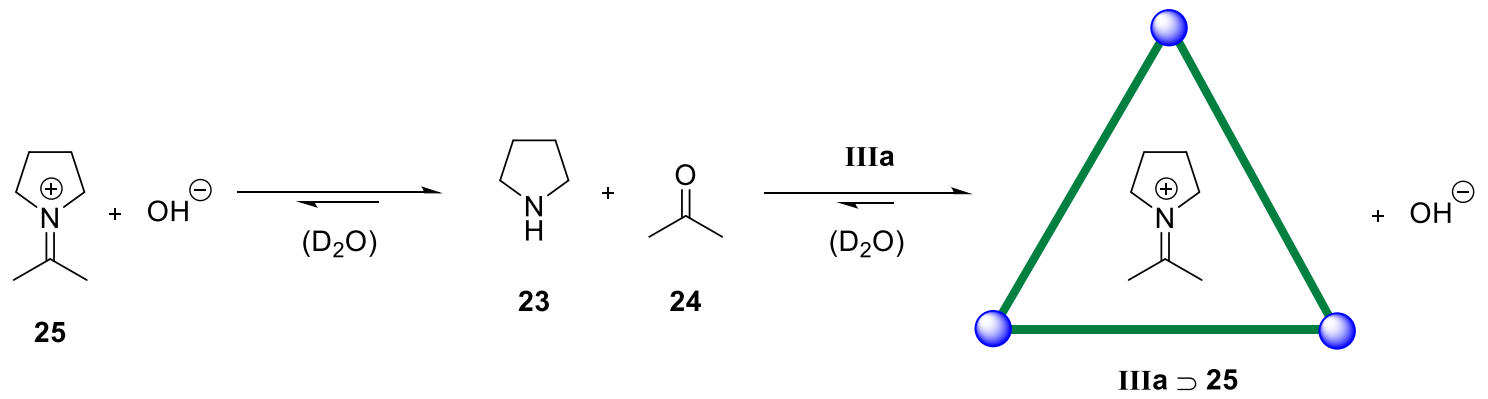

Scheme 9: Molecular recognition and stabilization of iminium ion 25 in cage IIIa.

Besides the research of complexation of various species, cluster IIIa was demonstrated to be capable of catalyzing chemical transformations. In a first example, a rate acceleration in an azaCope rearrangement of allylenammonium salts was described. ${ }^{[73]}$ In a Nazarov cyclization of tertiary alcohols a rate enhancement of $10^{6}$ was observed, rivaling the values typically achieved in enzymatic catalysis. ${ }^{[7]}$ In other investigations, orthoformates ${ }^{[75]}$ as well as acetals ${ }^{[76]}$ were hydrolyzed in basic media. In bulk solution, these species are remarkably stable under neutral and basic conditions. However, the stabilization of the cationic intermediates upon encapsulation by host IIIa enabled their smooth hydrolysis.

Having ascertained the ability of capsule IIIa to stabilize iminium species, the groups of Raymond and Bergman continued to investigate reactions involving iminium ions. An impressive example of how the particular microenvironment of nanovessel IIIa can influence the product selectivity of reactions was shown in 2015, when the collaborative effort of the groups of Raymond, Bergman and Toste reported the aza-Prins cyclization of iminium ions (Scheme 10). ${ }^{[77]}$ In the absence of capsule IIIa, when amine 26 was reacted with formaldehyde (27), alcohol 28 is obtained. The in situ formed iminium ion 29 prefers the energetically more favorable all equatorial transition state. After annulation and formation of carbenium ion 30, a water molecule can easily attack to form $\mathbf{2 8}$. In the presence of host IIIa, however, substituted piperidine $\mathbf{3 1}$ was unexpectedly obtained. The authors explain the unusual outcome by the different conformation of iminium intermediate $\mathbf{3 2}$ formed inside the confined space of capsule IIIa. After cyclization to $\mathbf{3 3}$ in a first step of the reaction sequence, the more compact conformation with the isopropyl group in the axial position results in a close proximity of the isopropyl cation to the $\mathrm{N}$-methyl C-H bonds group, facilitating a 1,5-through-space hydride transfer. The authors verified this hypothesis by deuterium labeling studies. 


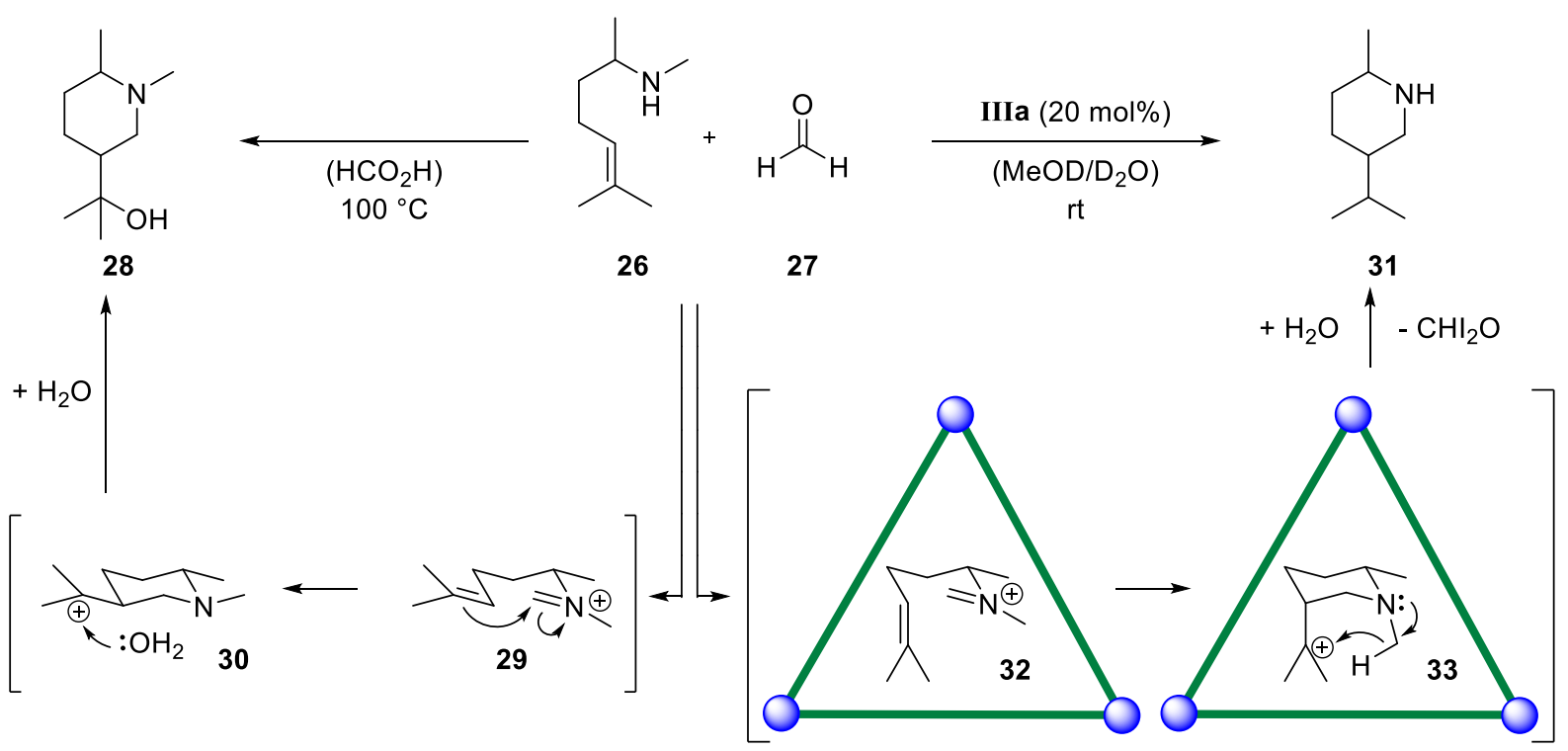

Scheme 10: Different reaction pathways of an aza-Prins reaction in the presence and absence of host IIIa leading to different reaction products.

\subsubsection{Hydrogen-Bonded Supramolecular Structures}

Besides structures held together by metal-ligand interactions, a large number of hydrogen bondbased supramolecular assemblies have also been described in literature. ${ }^{[39 c, 78]}$ In contrast to most metal-ligand supramolecular structures, which operate in aqueous solution, they possess the advantage of being soluble in organic media.

Interesting examples of this class of structures are the hexameric resorcin[4]arene capsules developed by the Atwood group in 1997. ${ }^{[79]}$ Capsule IVa self-assembles in apolar solvents such as chloroform or toluene from six molecules of the respective resorcin[4]arene $\mathbf{3 4}$ and eight water molecules (Scheme 11). The subunit resorcin[4] arene itself is readily available in multi-gram scale from resorcinol (35a) and, for instance for capsule IVa, from dodecanal (36a). The capsule assembles via 60 hydrogen bonds, making it thermodynamically stable in the solid $^{[79]}$ and liquid ${ }^{[80]}$ state. The hydrophobic cavity, filled with solvent molecules when no other guests are present, has a volume of about $1400 \AA^{3}$, establishing capsules IV as one of the largest hydrogen-bonded supramolecular systems known in literature. Encapsulation studies revealed that cationic guests, such as alkylammonium ions, ${ }^{[81]}$ are bound with high affinity due to enthalpic (the guest experiences strong stabilizing cation- $\pi$ interactions) and entropic (stabilization through release of encapsulated solvent molecules) reasons. ${ }^{[80,82]}$ Other species encapsulated include tertiary amines ${ }^{[83]}$ and metal complexes. ${ }^{[84]}$ Alcohols can be encapsulated either as other guests or replace the water molecules which are part of the hexameric assembly. ${ }^{[85]}$ The encapsulation of carboxylic acids relies on their capability to form hydrogen 
bonds with the hexameric host. ${ }^{[62 b]}$ Guest exchange is facile and likely occurs via the dissociation of one resorcin[4] arene unit generating a transient portal for the encapsulation or the release of guest molecules. ${ }^{[82]}$ An interesting finding was reported by Tiefenbacher and coworkers: A series of experiments with various amines revealed that resorcin[4]arene assembly IVa behaves as a moderate Brønsted acid with a $\mathrm{p} K_{\mathrm{a}}$ value of 5.5-6 (the individual resorcinol has a $\mathrm{p} K_{\mathrm{a}}$ of about 9.15). ${ }^{[86]}$ This also explains the high affinity of tertiary amines towards capsule IVa: Tertiary amines are protonated and encapsulated as ammonium ions by capsule IVa, thus encountering strong cation- $\pi$ interactions inside the cavity.

Another member of self-assembled supramolecular containers is the pyrogallol[4]arene hexamer IVb (Scheme 11). ${ }^{[87]}$ It differs from IVa by having four additional hydroxyl groups in its subunit pyrogallol[4]arene 34c. In the case of hexamer $\mathbf{I V b}$, the capsule is held together by 72 hydrogen bonds (and no water molecules) with an internal volume ranging from 1200 to $1520 \AA^{3} .^{[88]}$ Despite being structurally closely related to resorcin[4] arene capsule IVa, hexamer IVb shows a different encapsulation behavior: Tetraalkylammonium ions, for instance, are weakly bound to IVb. ${ }^{[83]}$ For capsule IVa, it was demonstrated that the ammonium salts are encapsulated as an ion pair. ${ }^{[89]}$ In case of capsule $\mathbf{I V b}$, the cations are only encapsulated to a small extent, whereas the counteranions remain on the outside of the cavity. ${ }^{[89]}$ Puzzling for a long time, ESP calculations now confirm that the absence of the bound water molecules, present in capsule IVa, is responsible for a lower stabilization of counteranions, being unfavorable for an encapsulation inside IVb. ${ }^{[89]}$ Recent findings, however, show that quarternary alkylammoniums can indeed be encapsulated using benzene as solvent. ${ }^{[90]}$ Neutral amines are taken up, but expelled from the cavity upon the formation of corresponding ammonium species via protonation. ${ }^{\left[{ }^{[3]}\right.}$ In a similar study as for capsule IVa, a $\mathrm{p} K_{\mathrm{a}}$ value of $9.5-10$ was measured for the pyrogallol[4]arene hexamer IVb. ${ }^{[89]}$ 


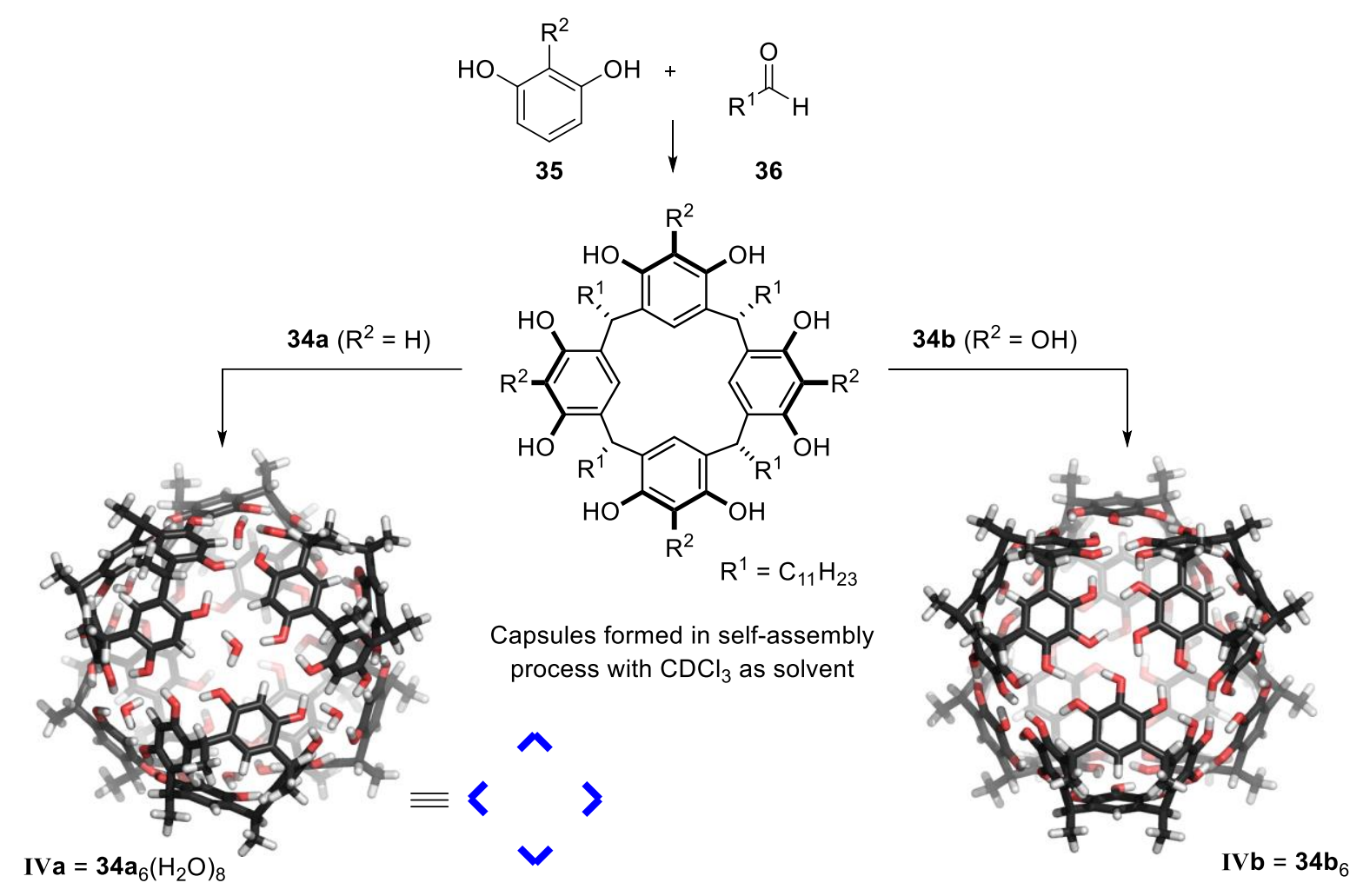

Scheme 11: Synthesis of the resorcin[4]arene hexamer IVa and the pyrogallol[4]arene hexamer IVb.

Until a few years ago, hydrogen-bonded capsules were sparsely investigated as reaction chambers or as catalysts. In an early attempt, Rebek et al. reported a Diels-Alder reaction between para-benzoquinone and cyclohexadiene that was accelerated some 200 -fold over the background reaction utilizing a dimeric cage. ${ }^{[91]}$ Stoichiometric amounts of the host were necessary as product inhibition occurred due to a strong binding of the Diels-Alder adduct in the cavity of the cage. True catalysis with a 7-fold rate acceleration was later achieved in a Diels-Alder system utilizing a thiophene dioxide derivative as diene. ${ }^{[92]}$ In this system, product inhibition was no longer an issue as the dimeric cage preferentially accommodates the substrates of the reaction.

The hexameric resorcin[4]arene capsule IVa was first employed in 2011 in an international cooperation of the groups of Strukul and Reek who reported the encapsulation of gold(I)catalyst 37. OTf (Scheme 12). ${ }^{[39 b]}$ NMR studies hereby confirmed the complete uptake of the catalytically active cationic species, but also indicated that the triflate anion remains on the outside of the assembly. The hydration of tertiary alkynes was chosen to examine the influence of the assembly on the activity and selectivity of catalyst 37 . In solution, a smooth conversion of terminal alkyne 38 to methyl ketone 39 was observed. Interestingly, the encapsulated catalyst delivers a different product distribution than the free catalyst: Besides $\mathbf{3 9}$ (43\% product ratio), the respective terminal aldehyde $\mathbf{4 0}$ (12\% product ratio) and 1,2-dihydronaphthalene (41, 43\% 
product ratio) were also formed. The formation of the ring-closed product $\mathbf{4 1}$ can be explained by the unusual folding of the substrate, a direct result of the confined space within the cavity. Furthermore, this product is usually exclusively formed in the absence of water. This can be attributed to the hydrophobic environment within capsule IVa. The formation of the antiMarkovnikov product $\mathbf{4 0}$ is, presumably, likewise a direct consequence of the restricted cavity space giving access to the branched and more compact intermediate $\mathbf{4 2}$ in contrast to the linear intermediate 43 delivering 39. Intriguingly, the reaction with assembly IVa is significantly slower. The authors suppose that the kinetic barrier imposed by the capsule limits the reaction rate, as the substrate has to enter the cavity prior to its interaction with the bound catalyst. When the cavity of IVa was blocked with strongly binding guest $\left(\mathrm{Et}_{4} \mathrm{NBF}_{4}\right)$, the reaction occurred exclusively in the bulk solution, delivering $\mathbf{3 9}$ as the single product.

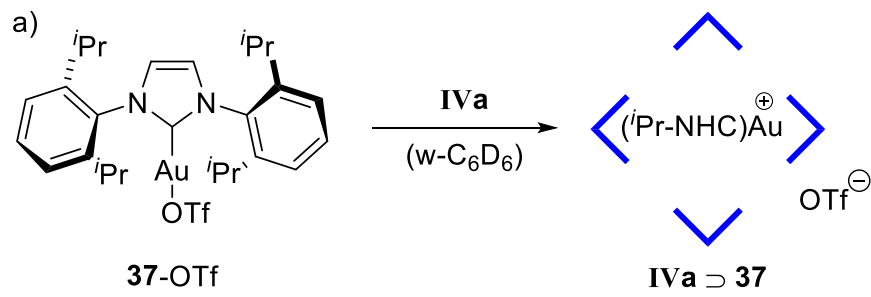

b)

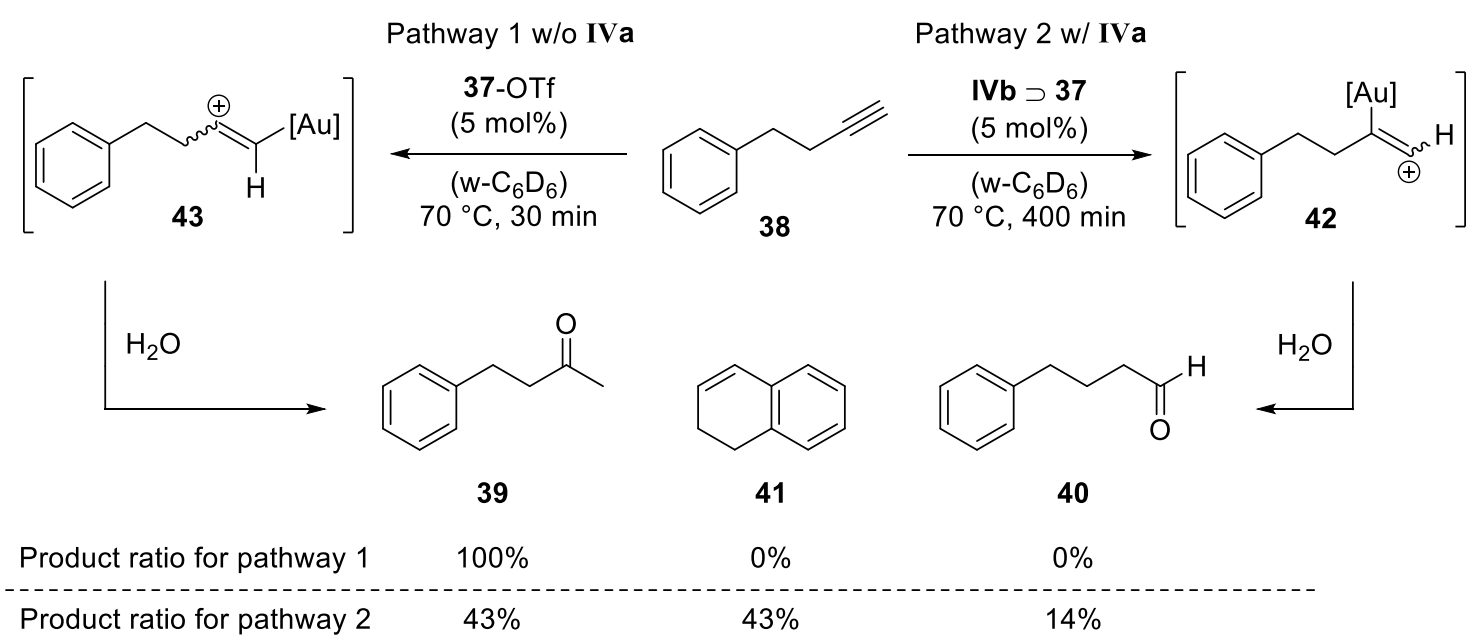

Scheme 12: (a) Gold(I)-catalyst 37-OTf and its encapsulation into IVa; (b) the different reaction pathways of the gold(I)catalyst-mediated conversion of $\mathbf{3 8}$ and the varying product distribution in presence and absence of capsule IVa. Note: ${ }_{w}-\mathrm{C}_{6} \mathrm{D}_{6}$ stands for water-saturated deuterated benzene.

After having revealed that assembly IVa is prone binding positively charged guests, the group of Tiefenbacher further explored organic reactions involving positively charged intermediates in the cavity of IVa. An acetal hydrolysis reaction was chosen to test the potential use of IVa as a selective enzyme-like catalyst (Scheme 13a). ${ }^{[86]}$ In the presence of catalytic amounts of capsule IVa, a large number of variously sized $n$-alkyl acetals $\mathbf{4 4}$ were successfully hydrolyzed to the corresponding aldehydes $\mathbf{4 5}$. Hereby, the authors observe a decreased reaction rate for 
longer alkyl acetals, which is at first sight unexpected since even the largest acetal utilized does not reach the optimum of occupancy for the cavity (22\% occupancy of IVa vs. 55\% optimal guest occupancy $\left.{ }^{[93]}\right)$. It was demonstrated that the larger species are encapsulated less efficiently into the cavity of IVa resulting in a slower hydrolysis. In a control experiment, no conversion was observed when the capsule cavity is blocked by tetrabutylammonium bromide. The same is true when the reaction was performed in the absence of the capsule under otherwise identical conditions. Since water is needed for the hydrolysis, the results also indicate that water is able to enter the cavity of IVa. These results taken together provide strong evidence that the presented reaction occurs inside the cavity of IVa. In a competition reaction, the capsule was treated with a 1:1-mixture of acetal $\mathbf{4 4 a}$ and its longer analogue $\mathbf{4 4 g}$. The reaction occurred in a highly size-selective fashion, favoring the cleavage of the smaller acetal $(\mathbf{4 5 a}: \mathbf{4 5 g}=98: 2)$. In solution, both products are approximately formed in equal amounts.

a)<smiles>[R]C(OCC)OCC</smiles>

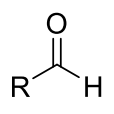

45

\begin{tabular}{|c|c|c|c|}
\hline substrate & $\begin{array}{l}\text { conversion } \\
(60 \mathrm{~min})\end{array}$ & substrate & $\begin{array}{l}\text { conversion } \\
\text { (60 min) }\end{array}$ \\
\hline 44a $\left(\mathrm{R}=\mathrm{CH}_{3}\right)$ & $85 \%$ & $44 \mathrm{e}\left(\mathrm{R}=n-\mathrm{C}_{5} \mathrm{H}_{11}\right)$ & $30 \%$ \\
\hline 44b $\left(\mathrm{R}=n-\mathrm{C}_{2} \mathrm{H}_{5}\right)$ & $86 \%$ & $44 f\left(\mathrm{R}=n-\mathrm{C}_{7} \mathrm{H}_{15}\right)$ & $13 \%$ \\
\hline $44 \mathrm{c}\left(\mathrm{R}=n-\mathrm{C}_{3} \mathrm{H}_{7}\right)$ & $62 \%$ & $\mathbf{4 4 g}\left(\mathrm{R}=n-\mathrm{C}_{11} \mathrm{H}_{23}\right)$ & $3.4 \%$ \\
\hline 44d $\left(\mathrm{R}=n-\mathrm{C}_{4} \mathrm{H}_{9}\right)$ & $44 \%$ & $44 b+\mathrm{Bu}_{4} \mathrm{NBr}$ & $1 \%$ \\
\hline
\end{tabular}

b)

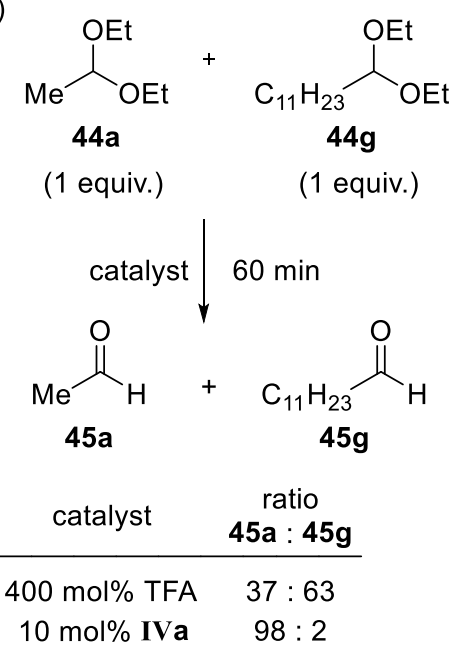

Scheme 13: (a) Hydrolysis of acetals 44 to the corresponding aldehydes 45 catalyzed by nanovessel IVa; (b) size-selective competition experiment of substrates $44 \mathbf{a}$ and $\mathbf{4 4 g}$. Note: $\mathrm{w}-\mathrm{CDCl}_{3}$ stands for water-saturated deuterated chloroform.

Encouraged by these results, the Tiefenbacher group further investigated capsule IVa in reactions involving cationic intermediates or transition states. The by far most impressive example is the capsule-catalyzed tail-to-head terpene (THT) cyclization (Scheme 14). ${ }^{\text {[94] }}$ Whereas nature produces tens of thousands of terpene products efficiently from only few simple building blocks using highly selective enzymes, chemists all over the world still lack effective tools for the synthesis of complex terpenes. ${ }^{[95]}$ Tiefenbacher and co-workers reported the first example of a biomimetic THT cyclization utilizing an artificial enzyme-like system. In the presence of $10 \mathrm{~mol} \%$ IVa, nerol (46) cyclizes via $\alpha$-terpineol (47) in an intramolecular hydroalkoxylation mechanism to eucalyptol (48) in 39\% yield (the main side products were $\alpha$-terpinene (49) and terpinolene (50), Scheme 14a). Such a selective THT cyclization had not 
been described previously using man-made catalysts. ${ }^{[96]}$ To avoid the premature interception of the cationic intermediate by water, acetate was investigated as a less nucleophilic leaving group. Indeed, the interception of cation $\mathbf{5 1}$ became less prominent. The most selective cyclization was observed with geranyl acetate (52) (Scheme 14b): The reactive $\alpha$-terpinyl cation $\mathbf{5 1}$ is not intercepted, as evidenced by the disappearance of $\mathbf{4 7}$, but is able to undergo a non-stop reaction mechanism including a 1,2-H shift to cation $\mathbf{5 3}$ and a subsequent elimination to the final product $\alpha$-terpinene (49). The non-stop transfer of the positive charge likely relies on the stabilization of the cationic intermediates by the capsule. No cyclization was observed in control experiments omitting IVa or with the high affinity ammonium guest $n-\mathrm{Bu}_{4} \mathrm{NBr}$ blocking the cavity of IVa, delivering evidence that the reaction takes place inside nanovessel IVa. Based on the different reactivity displayed by geranyl acetate and linalyl acetate, ${ }^{[96]}$ the authors conclude that the direct isomerization of transoid conformer 54a to cisoid cation $\mathbf{5 4 b}$ should be considered in the biosynthesis of terpenes.

a)

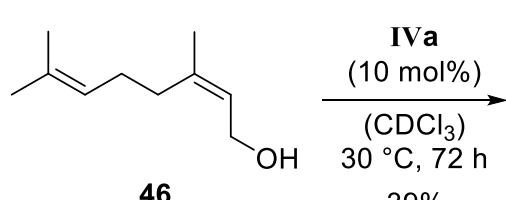

46

$39 \%$

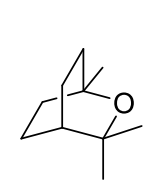

48 b)

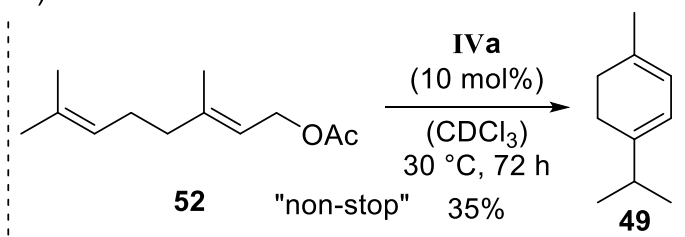

c)<smiles>[R]OCC=C(C)CCC=C(C)C</smiles><smiles>[R]C(C)(C=C)CCC=C(C)C</smiles><smiles>CC(C)=CCCC(C)C</smiles>

$\mathrm{R}=\mathrm{H}$ : geraniol (55)

$\mathrm{R}=\mathrm{H}$ : linalool (56) $\mathrm{R}=\mathrm{H}$ : nerol (46) $\mathrm{OR}$

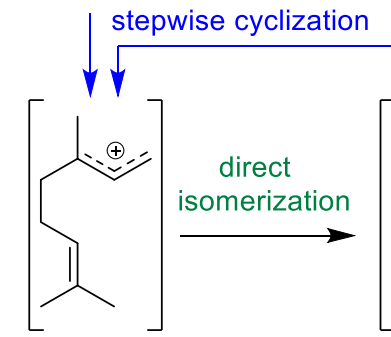
direct cyclization

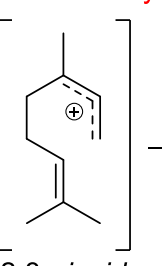

2,3-transoid cation 54a

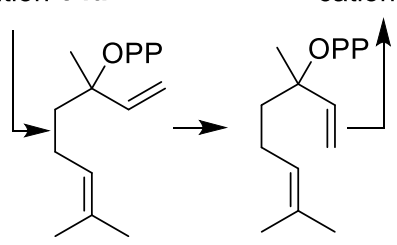

linalyl-PP (57a) linalyl-PP (57b) (transoid) (cisoid)

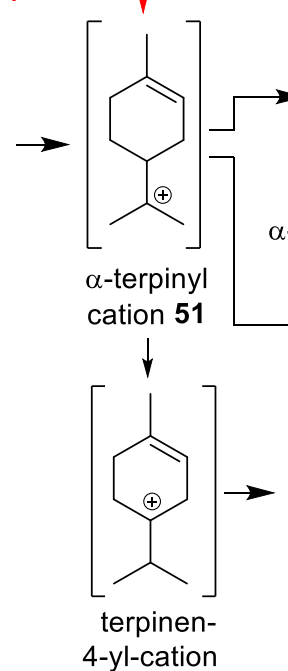

(53)

Scheme 14: Schematic overview over the various reaction pathways of the monoterpene cyclization within hexamer IVa in comparison to the biosynthesis $(\mathbf{5 7} \mathbf{a} / \mathbf{5 7} \mathbf{b})$ : Geranyl acetate cyclizes stepwise, nerol acetate cyclizes directly and linalyl acetate displays a mixed case. 
Intrigued by the observation of an intramolecular hydroalkoxylation in the synthesis of eucalyptol (48) in the THT cyclization, the group of Tiefenbacher further investigated this topic. In a separate report, ${ }^{[97]}$ further details of the capsule-catalyzed hydroalkoxylation were described. A large number of variously sized hydroxyl olefins $\mathbf{5 9}$ were transformed to the corresponding tetrahydropyrans 60 and oxepanes $\mathbf{6 1}$ in the presence of catalytic amounts of capsule IVa (Scheme 15a). In contrast to using capsule IVa $\left(\mathrm{p} K_{\mathrm{a}}=5.5-6\right)$ as the catalyst, related transformations in bulk solution often require harsh acidic condition. ${ }^{[98]}$ The mild conditions using IVa as the catalyst are likely enabled by the ability of hexamer IVa to stabilize cationic intermediates or transition states inside its cavity. Compared to the alcohol substrates, the products (cyclic ethers 60 and 61) show a low affinity to the capsule interior, permitting catalytic turnover and thereby making the utilization of nanovessel IVa valuable. Evidence for the participation of capsule IVa in this reaction was shown in a size-selective competition experiment: A strong tendency towards the formation of $\mathbf{6 0 a}$ was observed in the cyclization of a 1:1 mixture of hydroxyl olefin 59a and its larger derivative 59d in the presence of IVa. In contrast, no noteworthy size-selectivity was noticed, when the reaction was performed in solution using TfOH (Scheme 15b).

a)

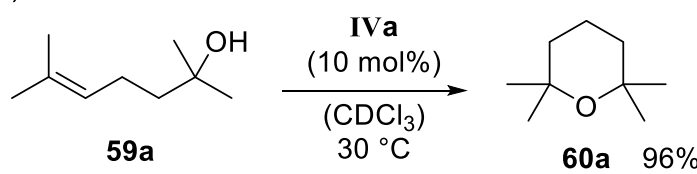

b)
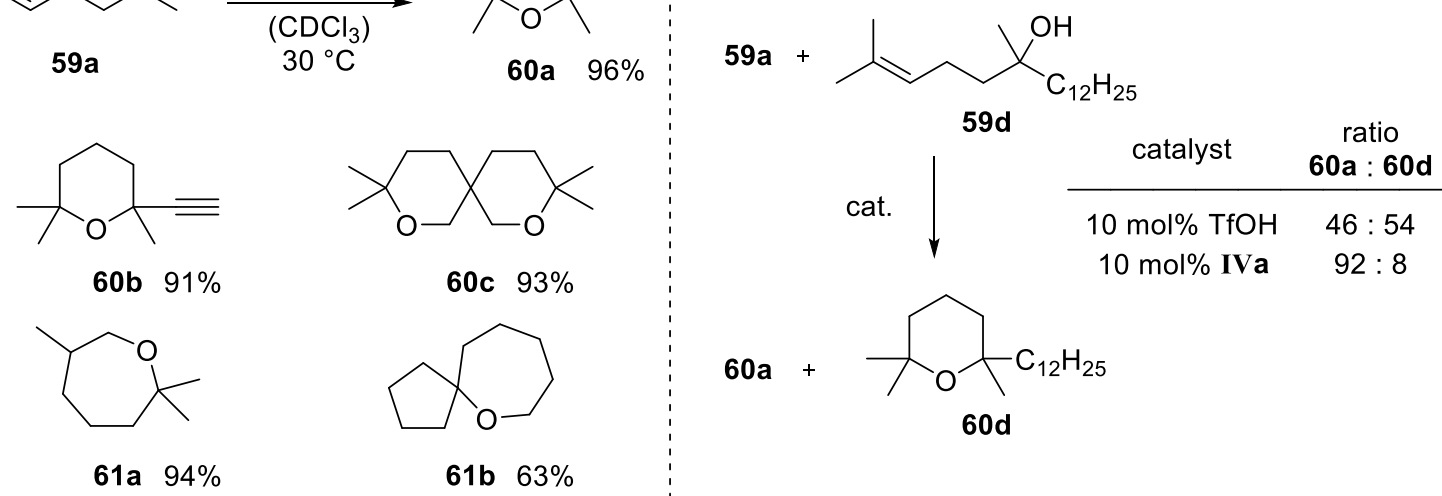

Scheme 15: (a) Intramolecular hydroalkoxylation of hydroxyl olefins achieved with hexamer IVa; (b) size-selectivity competition experiment.

The ability of capsule IVa to promote chemical transformations in its confined interior was also exploited by the group of Scarso. In a report from 2013, his group describes the encapsulation of various isonitriles 62 in IVa, which is evidenced by ${ }^{1} \mathrm{H}$ NMR (Scheme 16). ${ }^{[99]}$ Mediated by $10 \mathrm{~mol} \%$ of the supramolecular nanovessel and in the absence of strong Brønsted acids, the authors observe the hydration of $\mathbf{6 2}$ forming $N$-formylamides 63 . The cationic intermediate, obtained after protonation of the isonitrile carbon atom, is likely stabilized in the cavity of IVa 
and then attacked by a water molecule to form the products. In control experiments, no conversion of the substrate was observed in the absence of hexamer and with blocked hexamer using $\mathrm{NEt}_{4} \mathrm{OTf}$ as competitive guest. These results indicate that the encapsulation of substrates is crucial for the observed catalytic activity of host IVa.

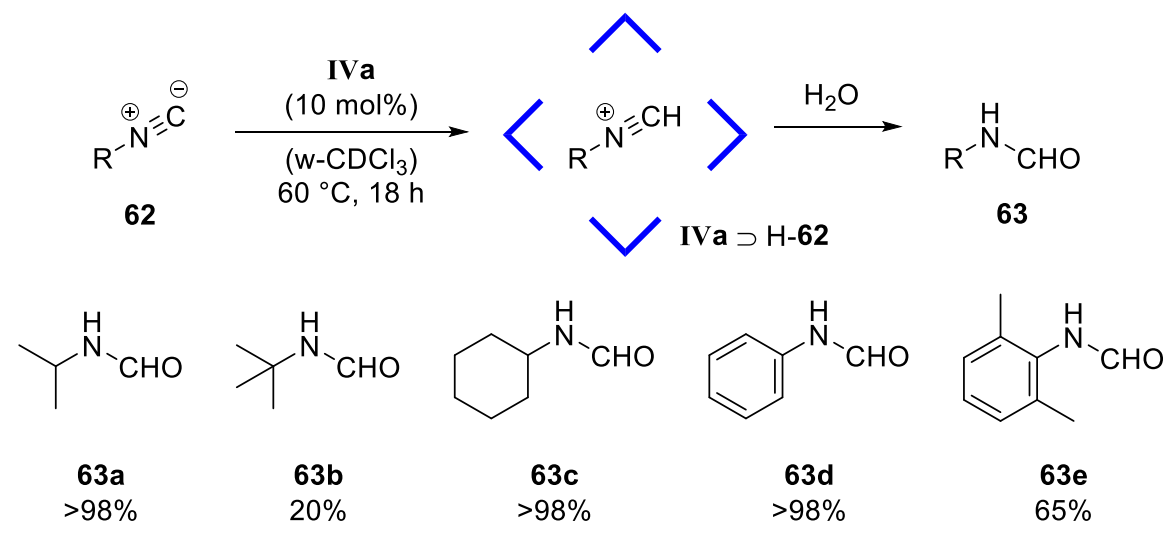

Scheme 16: Isonitrile hydration reaction in hexamer IVa reported by the group of Scarso. Note: w-CDCl 3 stands for watersaturated deuterated chloroform.

Having ascertained that isonitriles are well encapsulated inside IVa, the group of Scarso further investigated reactions involving these species. The intermolecular $[2+3]$-cycloaddition of isonitriles with trimethylsilyl azide $\left(\mathrm{TMSN}_{3}, 64\right)$ was described in 2015 (Scheme 17). ${ }^{[00]}$ Whereas no spontaneous reaction between cyclohexyl isonitrile (62c) and $\mathrm{TMSN}_{3}(\mathbf{6 4})$ was observed even after $5 \mathrm{~h}$ at $60{ }^{\circ} \mathrm{C}$ in the absence of capsule IVa, smooth conversion ( $>98 \%$ yield) to 1-cyclohexyl-1H-tetrazole (65c) occurred in the presence of $10 \mathrm{~mol} \%$ of nanoreactor IVa. The catalyzed reaction displayed a wide substrate scope: Aliphatic and aromatic isonitriles were converted to the corresponding $1 H$-tetrazoles in moderate to excellent yields. Interestingly, the catalytic activity was not fully suppressed when the cavity was blocked by $\mathrm{Et}_{4} \mathrm{NBF}_{4}$. This may indicate that the remaining space is still sufficient to perform catalysis. No conversion, however, could be observed when acetic acid $\left(\mathrm{p} K_{\mathrm{a}}=4.8\right)$ was employed instead of IVa. It may be concluded that the catalytic activity of capsule IVa is not reliant on its Brønsted acidity. The authors also rule out substrate activation via hydrogen bonding, since control experiments using resorcinol units showed no product formation. On top of this, the ability of IVa to stabilize cationic intermediates and establish higher local concentrations of reactants becomes clear in this reaction. Harsh conditions ${ }^{[101]}$ and the involvement of toxic reagents ${ }^{[102]}$ can therefore be circumvented. 


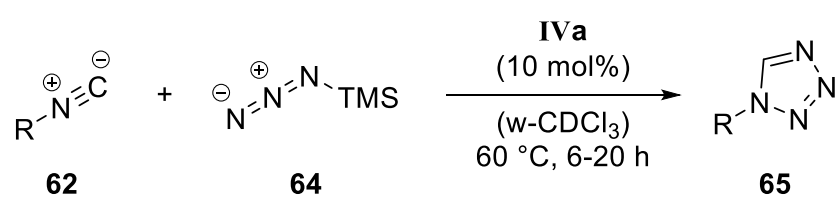

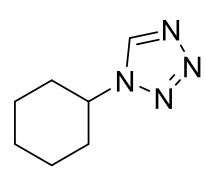

65c

$87 \%$<smiles>CC(C)n1cnnn1</smiles>

$65 a$

$87 \%$<smiles>CC(C)(C)n1cnnn1</smiles>

65b<smiles>c1ccc(Cn2cnnn2)cc1</smiles>

$65 f$

$93 \%$<smiles>Cc1cccc(C)c1-n1cnnn1</smiles>

$65 \mathrm{e}$ $40 \%$<smiles>c1ccc2cc(-n3cnnn3)ccc2c1</smiles>

65g

Scheme 17: Intermolecular [2+3] cycloaddition of various isonitriles 62 with trimethylsilyl azide (64) using the hexameric resorcin[4] arene assembly IVa. Note: $\mathrm{w}_{-} \mathrm{CDCl}_{3}$ stands for water-saturated deuterated chloroform.

The Scarso group also reported the oxidation of thioethers 66 to sulfoxides 67 promoted by nanovessel IVa under mild conditions (Scheme 18). ${ }^{[103]}$ In analogy to the previous example, the reaction is not induced by the intrinsic acidity of IVa: In the electrophilic oxidation reaction of thioethers using $\mathrm{H}_{2} \mathrm{O}_{2}$, it is known that the oxidant is activated by metal catalysts ${ }^{[104]}$ or organic molecules such as phenols. ${ }^{[105]}$ In the presented reaction, activation is believed to occur through the displacement of bridging water molecules in the $\mathrm{H}$-bond network by $\mathrm{H}_{2} \mathrm{O}_{2}$ which thereby becomes more electrophilic. As the polar transition state of the reaction is furthermore well stabilized in the interior of host IVa by interactions with its electron-rich surface, the authors observe a rate acceleration for a large number of substrates. The scope of the reaction comprises bis-aliphatic thioethers (>95\%), alkyl aryl sulfides (70\% to >98\%), a diaryl $(67 \%)$ as well as a disulfide derivative (51\%). As observed in the intermolecular [2+3]-cycloaddition, the addition of a competitive ammonium guest did not completely suppress the catalytic reactivity of capsule IVa. It is argued that substrates of suitable size can still be co-encapsulated by hexamer IVa in the presence of an inhibitor.

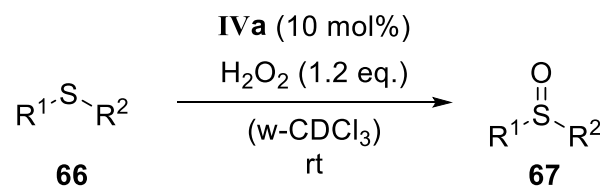

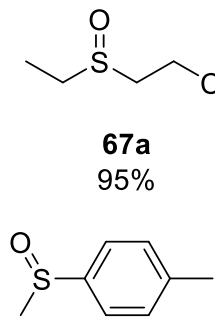

$67 f$

$>98 \%$

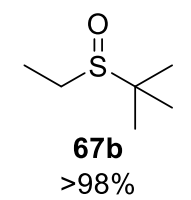<smiles>CS(=O)c1ccc(Br)cc1</smiles>

$67 \mathrm{~g}$

$90 \%$
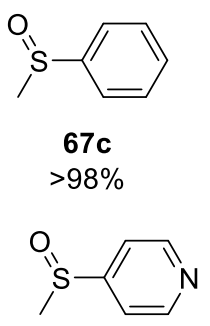

67h

$70 \%$
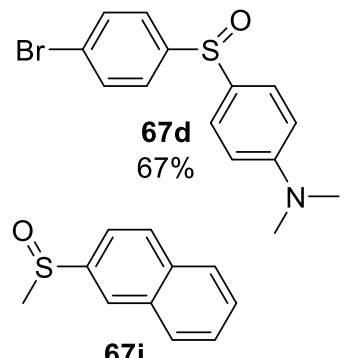

$80 \%$

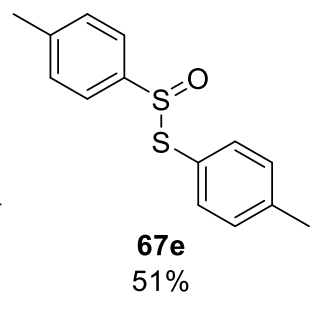

$51 \%$

Scheme 18: Thioether oxidation achieved by hexamer IVa. Note: w- $\mathrm{CDCl}_{3}$ stands for water-saturated deuterated chloroform. 
Other examples of chemical transformations catalyzed by capsule IVa include an epoxide isomerization reaction, ${ }^{[106]}$ a hydration reaction of aromatic alkynes ${ }^{[107]}$ and a cyclodehydration-rearrangement cascade reaction of unsaturated tertiary alcohols. ${ }^{[108]} \mathrm{A}$ 1,3-dipolar cycloaddition reaction between neutral diazoacetate esters and electron-poor alkenes leading to 4,5-dihydro- $1 H$-pyrazoles was achieved using stoichiometric amounts of capsule IVa. ${ }^{[109]}$ 


\section{Objective of This Thesis}

Whereas metal-ligand supramolecular structures have been employed successfully as catalysts in numerous chemical transformations, the number of uses of supramolecular capsules based on hydrogen bonding was, at the outset of this dissertation, still low. The investigation of such systems as reaction host and/or catalyst becomes more appealing after gaining awareness of their solubility in organic media whereas metal-ligand assemblies are mostly only watersoluble. In the few known procedures at that time, hexamer IVa emerged as interesting motif (see chapter 3.2.2). However, in spite of the disclosure of its Brønsted acidity and its effectiveness as cation-stabilizing assembly, the origin of the catalytic activity of hexamer IVa was still elusive. To gain further insight into the system, we pressed on exploring further reactions involving cationic intermediates and transition states.

Our interest turned to iminium catalysis. Since the iminium ion is positively charged, we expected it to be encapsulated and stabilized by hexamer IVa via strong cation- $\pi$ interactions (see chapter 2.2). Therefore, this thesis aims at exploring iminium catalysis in the cavity of IVa. As an outset of our investigation, literature-known reactions will be performed in the presence of hexamer IVa. Since the reactions are expected to proceed in the confined cavity of IVa, we are going to investigate the impact of the capsule on the reaction outcome such as substrate/product selectivity and stereoselectivity (Scheme 19).

a) Substrate selectivity

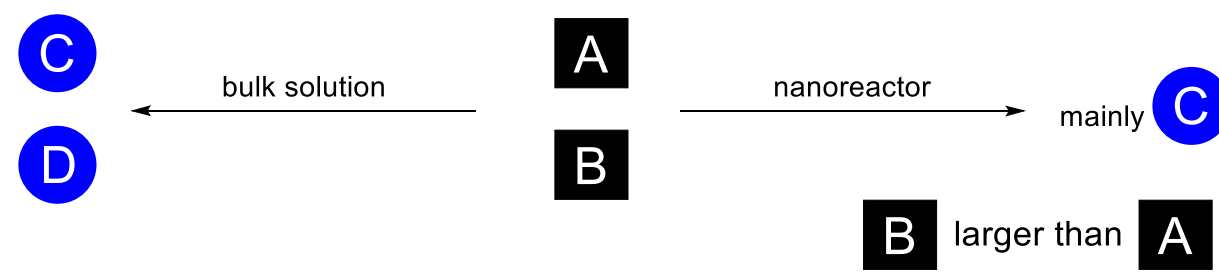

b) Product selectivity/Stereoselectivity

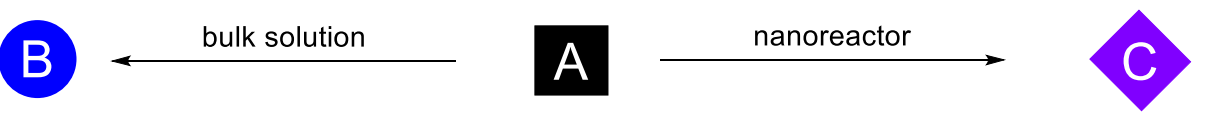

Scheme 19: Schematic representation of a) size-selectivity and b) product selectivity/stereoselectivity obtained in a reaction performed in a nanoreactor. 


\section{Publication Summaries}

The following pages of this chapter function as a short summary of the publications (excluding reviews) that were prepared during the course of this dissertation.

\subsection{Iminium Catalysis Inside a Self-Assembled Supramolecular Capsule: Modulation of Enantiomeric Excess}

At the outset of the investigation, a large number of literature-known organocatalytic transformations were screened to investigate the influence of capsule IVa on the reaction outcome. In a Diels-Alder reaction between ethyl (E)-4-oxobut-2-enoate and dienes such as isoprene and cyclohexadiene, the reaction was accelerated by a factor of 4 in the presence of catalytic amounts of capsule IVa. In addition, a moderate product selectivity was observed in a competition reaction, favoring the formation of the less bulky product. However, the system suffered from a relatively fast background reaction occurring outside the capsule. This impeded the further improvement of the product selectivity.

Subsequently, we investigated the organocatalytic 1,4-reduction reaction of $\alpha, \beta$-unsaturated aldehydes ${ }^{[30,110]}$ with and without catalytic amounts $\left(26\right.$ mol\%) of capsule IVa. ${ }^{[111]}$ In the 1,4reduction reaction of $(E)$-3-phenylbut-2-enal (68a), utilizing 69a as the catalyst, product 70a was formed with an enantiomeric excess of 9\% $(S)$ in the absence of capsule IVa. Surprisingly, the reaction with capsule IVa revealed a greatly increased enantioselectivity $(74 \%(S), \Delta e e$ of $65 \%$ ) under otherwise identical conditions. To test the generality of this effect, the reaction was performed with other organocatalysts. Catalysts 69b, carrying a sterically shielding residue, displayed a less pronounced modulation effect on the enantiomeric excess. However, catalysts featuring directing groups $(69 \mathrm{c}, 69 \mathrm{~d}$ and 69e) delivered comparable results to catalyst 69a. 
a)<smiles>CCOC(=O)C1=C(C)NC(C)=C(C(=O)OCC)C1</smiles>

$68 a$

$1 \mathrm{a}$

$70 a$

b)<smiles>O=C(O)C1CCCN1</smiles>

$69 a$

$\Delta e e=65 \%$<smiles>CN1C(=O)CNC1C(C)(C)[I+]#[V]</smiles>

$69 b$

$\Delta e e=4 \%$<smiles>NC(=O)C1CCCN1</smiles>

$69 c$

$\Delta e e=45 \%$<smiles>O=C(O)C1CSCN1</smiles>

69d

$\Delta e e=43 \%$

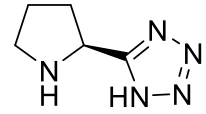

$69 e$

$\Delta e e=51 \%$

Scheme 20: (a) Analyzed 1,4-reduction of $\alpha, \beta$-unsaturated aldehyde 68a using Hantzsch ester 1a as hydride donors; (b) excerpt of the catalyst scope. Note: The term $\Delta e e$ indicates the difference in the enantioselectivity of the reactions in the presence and absence of capsule IVa. Note: w- $\mathrm{CDCl}_{3}$ stands for water-saturated deuterated chloroform.

We attribute this unprecedented modulation effect to the stereoselective binding of the encapsulated iminium intermediate to the capsule wall. It is highly likely that the bound iminium ion preferentially interacts with the capsule with its less hindered side experiencing stronger cation- $\pi$ interactions. Consequently, the Hantzsch ester selectively approaches the iminium ion syn to the group Y, delivering the $(S)$-enantiomer as the favored product. When the reaction occurs in solution, the group $\mathrm{Y}$ serves as the sole biasing element for the stereochemical outcome of the reaction.

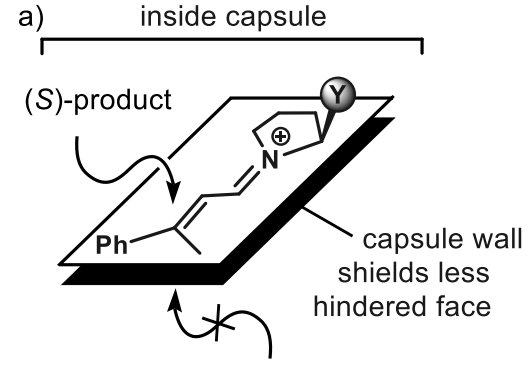

$(R)$-product
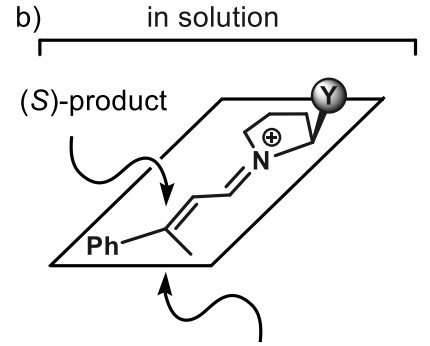

$(R)$-product

Scheme 21: Hypothesis for the different selectivity inside capsule IVa: (a) The capsule wall shields the originally less hindered side allowing the $s y n$-attack forming preferentially the $(S)$-product; (b) in solution, the pathway towards the $(R)$-enantiomer is not impeded.

\subsection{Iminium Catalysis Inside a Self-Assembled Supramolecular Capsule: Scope and}

\section{Mechanistic Studies}

In a follow-up study, ${ }^{[112]}$ the aldehyde substrate scope was investigated (Scheme 22). The reduced $\Delta e e$ of the cyclohexyl derivative $\mathbf{6 8 b}$ in comparison to its phenyl counterpart $\mathbf{6 8 a}$ indicates that the aromatic moiety of the reactive iminium intermediate plays an important role in the binding of the active species within capsule IVa. Further investigations were performed 
with the ortho- $(\mathbf{6 8 e})$, meta- $(\mathbf{6 8 d})$ and para-methyl $(\mathbf{6 8 c})$ derivatives of the standard substrate 68a. A negligible $\Delta e e$ of $4 \%$ for $\mathbf{6 8 c}$ and a moderate $\Delta e e$ of $41 \%$ for $\mathbf{6 8 d}$ were obtained. The most significant modulation effect was observed with substrate $\mathbf{6 8 e}(\Delta e e$ of $92 \%)$. In an effort to further increase the modulation effect, substrates bearing electron-withdrawing substituents on the ortho-position were investigated. The fluorine derivative $68 \mathrm{f}$ and chlorine derivative $\mathbf{6 8 g}$ showed the best results.

a)

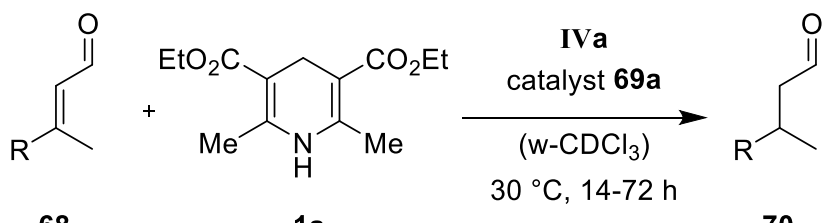

68

$1 \mathrm{a}$

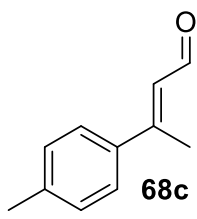

$\Delta e e=9 \%$

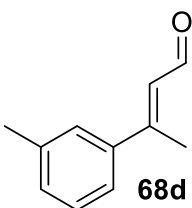

$\Delta e e=41 \%$

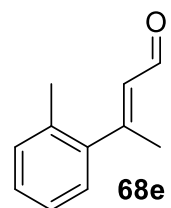

$\Delta e e=92 \%$
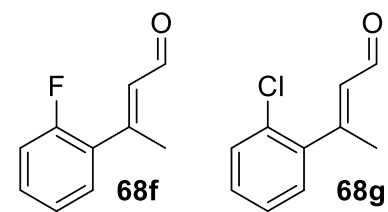

$\Delta e e=74 \%$

Scheme 22: (a) Analyzed 1,4-reduction of $\alpha, \beta$-unsaturated aldehydes using Hantzsch esters as hydride donors; (b) excerpt of the aldehyde scope. Note: $\mathrm{w}-\mathrm{CDCl}_{3}$ stands for water-saturated deuterated chloroform.

The experiment using D-proline (77\% ee $(R))$ as catalyst delivered the opposite result of the experiment using L-proline (see chapter 5.1), providing evidence that the observed enantioselectivities are exclusively induced by the organocatalyst. The reaction was also performed with the structurally related pyrogallol[4]arene hexamer IVb (Scheme 11). Capsule IVb displayed no influence on the enantioselectivity.

To obtain more evidence that the reaction indeed takes place inside the cavity of IVa, a series of control experiments were performed (Scheme 23). First, NMR studies indicate the inclusion of the iminium species by capsule IVa. Next, reactions were run with bulky derivatives of each reagent, which were too large to fit the cavity of IVa. Since the reactions had to take place on the outside of the capsule due to size limitation, negligible modulation effects were observed in these experiments. The same is true when the cavity of IVa was blocked by a strong inhibitor (71) or when the capsule was disassembled upon the addition of DMSO. Additional evidence was obtained from a size-selective competition reaction. Trans-2-hexenal (72a) was selectively converted with catalytic amounts of capsule IVa in the presence of its longer analogue featuring the same reactivity (Scheme 23b). 


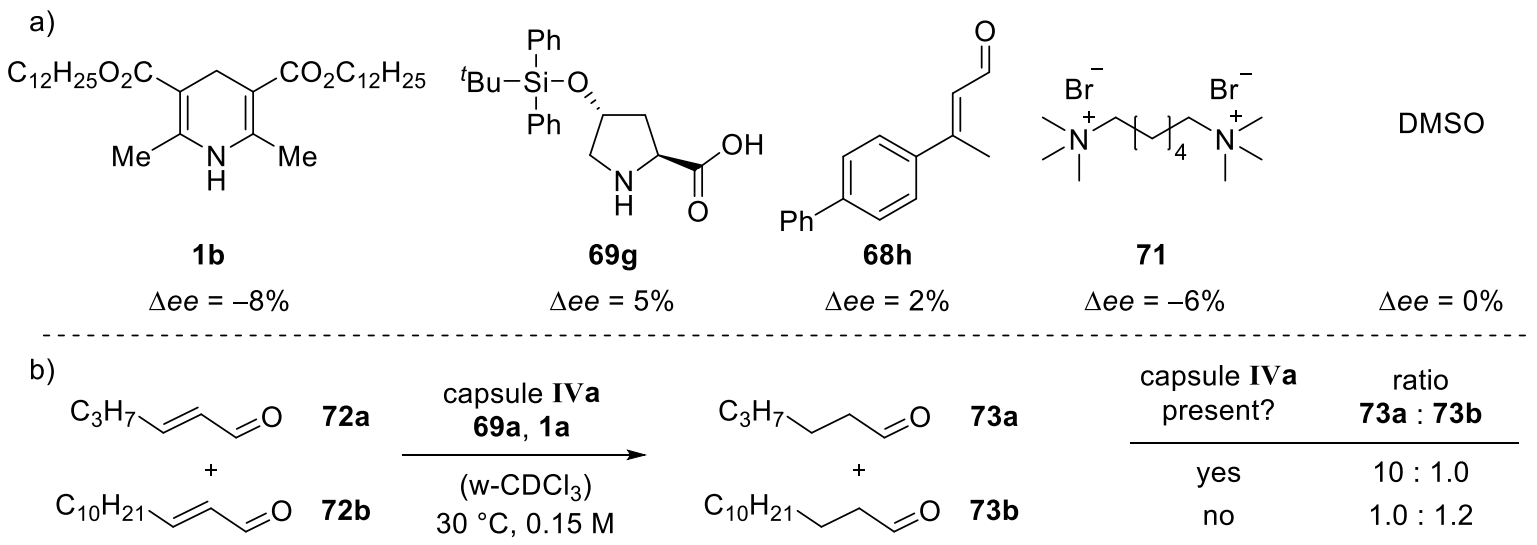

Scheme 23: (a) Control experiments utilizing large Hantzsch ester 1b, large catalyst 69g, large aldehyde 68h, hexamethonium bromide (71) and DMSO; (b) size-selective competition experiments reveal a substrate selectivity of IVa. Note: w-CDCl 3 stands for water-saturated deuterated chloroform.

To gain further insight into the reaction, kinetic experiments were performed. The kinetic parameters for enthalpy $\Delta H^{\neq}$, entropy $\Delta S^{\neq}$and free energy $\Delta G^{\neq}$were determined using the initial rate method. The obtained values are $\Delta H^{f}=21.10 \pm 0.16 \mathrm{kcal} \mathrm{mol}^{-1}, \Delta S^{\neq}=-9.57 \pm 0.49 \mathrm{~J} \mathrm{~mol}^{-1}$ and $\Delta G^{\neq}=24.00 \pm 0.02 \mathrm{kcal} \mathrm{mol}^{-1}$. In a competition reaction between Hantzsch ester 1a and its derivative 1c (deuterated at the methylene position), a normal kinetic isotope effect of $k_{\mathrm{H}} / k_{\mathrm{D}}=$ $1.90 \pm 0.05$ was determined. Taken together, these results indicated that the hydride transfer is the rate determining step.

We extended the study by utilizing benzothiazolines $\mathbf{7 4}$ as an alternative hydride source (Scheme 24). ${ }^{[113]}$ Surprisingly, the preferred formation of the $(R)$-enantiomer was observed for the first time in the presence of capsule IVa when phenyl benzothiazoline 74a was used as hydride donor. We hypothesize that additional interactions of the hydride donor with the aromatic walls of the host outcompete the proposed binding motif (see chapter 5.1) leading to this unusual observation. With $\mathbf{7 4 b}$ and $\mathbf{7 4 c}$ the familiar selectivity was observed.

a)<smiles>CC(=CC=O)c1ccccc1</smiles>

$68 \mathrm{a}$<smiles>[R]C1Nc2ccccc2S1</smiles>

74

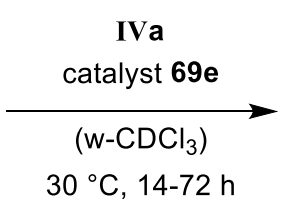

$30{ }^{\circ} \mathrm{C}, 14-72 \mathrm{~h}$

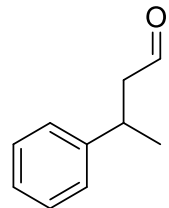

$70 a$

b)

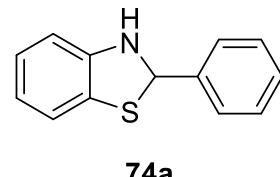

$\Delta e e=-73 \%$<smiles>CC1Nc2ccccc2S1</smiles>

74b

$\Delta e e=67 \%$

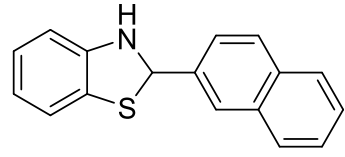

$74 c$

$\Delta e e=26 \%$

Scheme 24: (a) Investigated 1,4-reduction of $\alpha, \beta$-unsaturated aldehydes using phenyl-, methyl- and naphthyl-substituted benzothiazolines $\mathbf{7 4}$ as hydride donors. Note: $\mathrm{w}-\mathrm{CDCl}_{3}$ stands for water-saturated deuterated chloroform. 


\section{Summary and Outlook}

Since Lehn, Cram and Pedersen won the 1987 Nobel Prize in chemistry, supramolecular chemistry has become an increasingly popular research topic for the scientific community. Its role as an indispensable discipline of chemistry was reconfirmed with the awarding of the 2017 Nobel Prize in chemistry to Sauvage, Stoddart and Feringa. Over the course of the years, a number of supramolecular systems have been developed and some have been applied as catalysts in chemical transformations. Self-assembled supramolecular cages possess the advantage of ease of preparation, as their complex structure is spontaneously formed from readily available simple building blocks. The hydrogen-bonded supramolecular assembly IVa is an interesting member of this class of structures. It was shown to act as an efficient catalyst for a variety of chemical transformations.

In the studies leading to this dissertation, we disclosed the first example of iminium catalysis inside a supramolecular system. The 1,4-reduction of $\beta$-substituted $\alpha, \beta$-unsaturated aldehydes using simple Hantzsch ester $\mathbf{1}$ as reducing agent was thoroughly investigated. Size-selectivity experiments, but mainly stereochemical aspects confirmed that the reaction indeed takes place inside the cavity of IVa. It was found that the formation of the $(S)$-enantiomer is favored in the presence of capsule IVa. Intensive control reactions including detailed NMR studies and experiments with blocked cavity further confirmed that the reaction indeed takes place inside the cavity of IVa. This unusual modulation of enantiomeric excess was also observed for a series of organocatalysts and $\alpha, \beta$-unsaturated aldehydes. It is proposed that the encapsulated iminium species binds to the capsule from the sterically less hindered face. Consequently, hydride donors preferentially approaches the iminium intermediate from the other face, favoring the formation of the $(S)$-enantiomer. After having established the catalyst and substrate scope, benzothiazolines $\mathbf{7 4}$ were investigated as alternative hydride donors. Kinetic studies were performed to gain further insight into the reaction. The results obtained show that the delivery of the hydride is the rate-determining step of the catalytic cycle. 


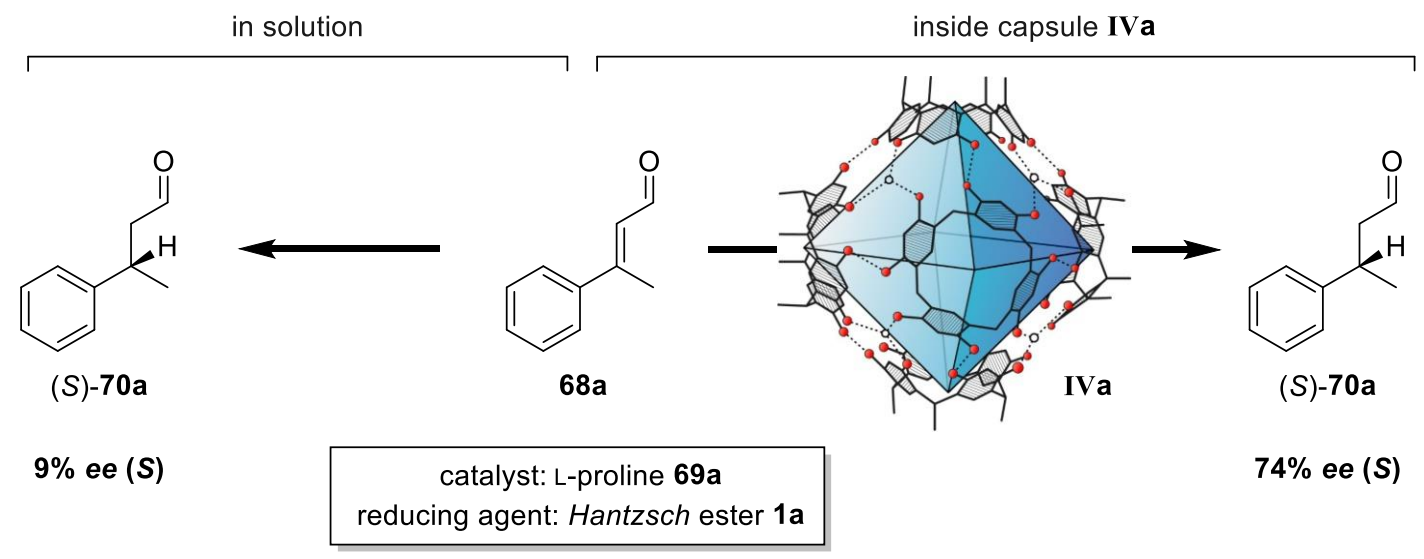

Scheme 25: Modulation of the enantiomeric excess in the organocatalytic 1,4-reduction of $\beta$-substituted $\alpha, \beta$-unsaturated aldehydes using Hantzsch esters as the reducing agent in the presence and absence of IVa.

To suppress the background reaction, under the standard reaction conditions, capsule IVa is added in a slight excess (26 mol\%, compared to $20 \mathrm{~mol} \%$ organocatalyst) to ensure the complete encapsulation of the iminium intermediate. In a later study (unpublished results), it was found that the modulation effect on the enantioselectivity can be maintained when reducing the amount of hexamer IVa to $8 \mathrm{~mol} \%$. However, a further reduction of the capsule loading to $4 \mathrm{~mol} \%$ resulted in a significantly diminished modulation effect. Since the iminium ion is not quantitatively formed in bulk solution, the conceivable explanation for these observations is that the formed iminium ion undergoes rapid encapsulation prior to the further transformation. Further investigations shall be performed to identify the optimal capsule concentration.

Recently, it has been demonstrated that ammonium salts are encapsulated as ion pairs by the resorcin[4]arene capsule IVa. ${ }^{[89]}$ This finding raised another possibility to modulate the enantioselectivity. In the present examples, the stereoinformation stems from the chiral iminium species, whereas its counter ion (chloride or trifluoroacetate) is achiral. It would be of high interest to probe the influence of chiral anions on the enantioselectivity in the presence of a chiral iminium species. However, preliminary experiments with camphor sulfonate as the chiral counter ion displayed no modulation effect for the enantioselectivity. Due to the restricted size in IVa, larger chiral anions have to be excluded from the investigation. 


\section{Index of Abbreviations}

$\begin{array}{ll}\mathrm{A} \supset \mathrm{B} & \text { B encapsulated within A } \\ \AA & \text { Angström } \\ \mathrm{aq.} & \text { aqueous } \\ \mathrm{Ar} & \text { aryl } \\ \mathrm{Bu} & \text { butyl } \\ \mathrm{C} & \text { Celsius } \\ \text { cat. } & \text { catalyst }\end{array}$

DMSO dimethyl sulfoxide

$\Delta \mathrm{H}^{\ddagger}$

standard enthalpy of activation

$\Delta S^{\neq}$

standard entropy of activation

$\Delta G^{\neq}$

Gibbs free energy of activation

$\mathrm{E}$

electrophile

$\mathrm{E}$

energy

e

electron

$e e$

enantiomeric excess

e.g.

lat. exempli gratia, for example

equiv.

equivalents

Et

ethyl

$\mathrm{h}$

hours

HOMO

Highest Occupied Molecular Orbital

i.e.

lat. id est, that is to say

$k$

reaction rate

kcal

kilocalorie

$\mathrm{L}$

ligand

LA

Lewis acid

LUMO

Lowest Unoccupied Molecular Orbital

M

molarity, mol

$\mathrm{Me}$

methyl

$\min$

minutes

MO

molecular orbital

$\mathrm{NADH} / \mathrm{NAD}^{+}$

Nicotinamide adenine dinucleotide 


$\begin{array}{ll}\text { NHC } & N \text {-heterocyclic carbene } \\ \text { NMR } & \text { nuclear magnetic resonance } \\ \mathrm{Nu} & \text { nucleophile } \\ \text { ox. } & \text { oxidized } \\ \mathrm{Ph} & \text { phenyl } \\ \mathrm{p} K_{\mathrm{a}} & \text { negative base-10 logarithm of the acid dissociation constant }\left(K_{\mathrm{a}}\right) \\ & \text { of a solution } \\ \mathrm{PP} & \text { pyrophosphate } \\ \mathrm{Pr} & \text { propyl } \\ \text { red. } & \text { reduced } \\ \text { rt } & \text { room temperature } \\ t & \text { tert } \\ \text { OTf } & \text { triflate } \\ \text { TFA } & \text { trifluoroacetic acid } \\ \text { THT } & \text { tail-to-head terpene } \\ \text { TMS } & \text { trimethylsilyl } \\ \text { UV } & \text { Ultra violet } \\ \text { w } & \text { water-saturated } \\ \text { w/ } & \text { with } \\ \text { w/o } & \text { without } \\ & \end{array}$




\section{References}

[1] C. Cantó, K. J. Menzies, J. Auwerx, Cell Metab. 2015, 22, 31-53.

[2] A. Hantzsch, Ber. Dtsch. Chem. Ges. 1881, 14, 1637-1638.

[3] C. Zheng, S.-L. You, Chem. Soc. Rev. 2012, 41, 2498-2518.

[4] a) I. P. Parkin, R. G. Palgrave, J. Mater. Chem. 2005, 15, 1689-1695; b) V. A. Ganesh, H. K. Raut, A. S. Nair, S. Ramakrishna, J. Mater. Chem. 2011, 21, 16304-16322.

[5] http://www.ornilux.com/birds-glass.html, (10.01.2018).

[6] S. J. Matthews, C. McCoy, Clin. Ther. 2003, 25, 342-395.

[7] M. Beller, C. Bolm, Transition Metals for Organic Synthesis, Wiley-VCH Verlag GmbH, Weilheim, 2008.

[8] T. C. Bruice, Acc. Chem. Res. 2002, 35, 139-148.

[9] P. S. Fiske, G. Bredig, Biochem. Z. 1913, 46, 7-23.

[10] a) W. Langenbeck, R. Sauerbier, Ber. Dtsch. Chem. Ges. 1937, 70, 1540-1541; b) M. Yamaguchi, N. Yokota, T. Minami, J. Chem. Soc., Chem. Commun. 1991, 1088-1089.

[11] B. List, R. A. Lerner, C. F. Barbas, J. Am. Chem. Soc. 2000, 122, 2395-2396.

[12] K. A. Ahrendt, C. J. Borths, D. W. C. MacMillan, J. Am. Chem. Soc. 2000, 122, 4243-4244.

[13] a) P. Melchiorre, M. Marigo, A. Carlone, G. Bartoli, Angew. Chem. Int. Ed. 2008, 47, 61386171; b) S. Bertelsen, K. A. Jørgensen, Chem. Soc. Rev. 2009, 38, 2178-2189.

[14] B. List, Chem. Rev. 2007, 107, 5413-5415.

[15] C. A. Busacca, D. R. Fandrick, J. J. Song, C. H. Senanayake, Adv. Synth. Catal. 2011, 353, 1825-1864.

[16] Z. Zhang, P. R. Schreiner, Chem. Soc. Rev. 2009, 38, 1187-1198.

[17] R. P. Herrera, V. Sgarzani, L. Bernardi, A. Ricci, Angew. Chem. Int. Ed. 2005, 44, 6576-6579.

[18] A. K. Unni, N. Takenaka, H. Yamamoto, V. H. Rawal, J. Am. Chem. Soc. 2005, 127, 13361337.

[19] S. Mukherjee, J. W. Yang, S. Hoffmann, B. List, Chem. Rev. 2007, 107, 5471-5569.

[20] Q. Pan, B. Zou, Y. Wang, D. Ma, Org. Lett. 2004, 6, 1009-1012.

[21] I. Ibrahem, J. Casas, A. Córdova, Angew. Chem. Int. Ed. 2004, 43, 6528-6531.

[22] N. Mase, R. Thayumanavan, F. Tanaka, C. F. Barbas, Org. Lett. 2004, 6, 2527-2530.

[23] R. C. Fuson, Chem. Rev. 1935, 16, 1-27.

[24] D. B. Ramachary, Y. V. Reddy, Eur. J. Org. Chem. 2012, 2012, 865-887.

[25] I. Kumar, P. Ramaraju, N. A. Mir, Org. Biomol. Chem. 2013, 11, 709-716.

[26] A. Erkkilä, I. Majander, P. M. Pihko, Chem. Rev. 2007, 107, 5416-5470.

[27] A. B. Northrup, D. W. C. MacMillan, J. Am. Chem. Soc. 2002, 124, 2458-2460.

[28] M. G. Memeo, P. Quadrelli, Chem. Eur. J. 2012, 18, 12554-12582. 
[29] S. Brandau, A. Landa, J. Franzén, M. Marigo, K. A. Jørgensen, Angew. Chem. Int. Ed. 2006, 45, 4305-4309.

[30] S. G. Ouellet, J. B. Tuttle, D. W. C. MacMillan, J. Am. Chem. Soc. 2005, 127, 32-33.

[31] M. Marigo, T. Schulte, J. Franzén, K. A. Jørgensen, J. Am. Chem. Soc. 2005, 127, 15710-15711.

[32] A. Carlone, G. Bartoli, M. Bosco, L. Sambri, P. Melchiorre, Angew. Chem. Int. Ed. 2007, 46, 4504-4506.

[33] K. Takasu, S. Maiti, M. Ihara, Heterocycles 2003, 59, 51-55.

[34] D. B. Ramachary, R. Mondal, Tetrahedron Lett. 2006, 47, 7689-7693.

[35] B. S. Donslund, T. K. Johansen, P. H. Poulsen, K. S. Halskov, K. A. Jørgensen, Angew. Chem. Int. Ed. 2015, 54, 13860-13874.

[36] Y. Hayashi, D. Okamura, S. Umemiya, T. Uchimaru, ChemCatChem 2012, 4, 959-962.

[37] L. Dell'Amico, Ł. Albrecht, T. Naicker, P. H. Poulsen, K. A. Jørgensen, J. Am. Chem. Soc. 2013, 135, 8063-8070.

[38] J.-M. Lehn, Angew. Chem. Int. Ed. 1990, 29, 1304-1319.

[39] a) D. M. Vriezema, M. Comellas Aragonès, J. A. A. W. Elemans, J. J. L. M. Cornelissen, A. E. Rowan, R. J. M. Nolte, Chem. Rev. 2005, 105, 1445-1490; b) A. Cavarzan, A. Scarso, P. Sgarbossa, G. Strukul, J. N. H. Reek, J. Am. Chem. Soc. 2011, 133, 2848-2851; c) T. S. Koblenz, J. Wassenaar, J. N. H. Reek, Chem. Soc. Rev. 2008, 37, 247-262.

[40] L. Catti, Q. Zhang, K. Tiefenbacher, Chem. Eur. J. 2016, 22, 9060-9066.

[41] P. Mattei, F. Diederich, Helv. Chim. Acta 1997, 80, 1555-1588.

[42] K. I. Assaf, W. M. Nau, Chem. Soc. Rev. 2015, 44, 394-418.

[43] D. J. Cram, H. E. Katz, I. B. Dicker, J. Am. Chem. Soc. 1984, 106, 4987-5000.

[44] S. Amiri, S. Amiri, in Cyclodextrins: Properties and Industrial Applications, John Wiley \& Sons, Ltd, Chichester, 2017, 269-300.

[45] I. Tabushi, Acc. Chem. Res. 1982, 15, 66-72.

[46] I. T. Harrison, S. Harrison, J. Am. Chem. Soc. 1967, 89, 5723-5724.

[47] D. A. Leigh, Angew. Chem. Int. Ed. 2016, 55, 14506-14508.

[48] a) F. M. Raymo, J. F. Stoddart, in Molecular Catenanes, Rotaxanes and Knots, Wiley-VCH Verlag GmbH, Weilheim, 2007, 143-176; b) E. Wassennan, in Molecular Catenanes, Rotaxanes and Knots, Wiley-VCH Verlag GmbH, Weilheim, 2007, 1-6.

[49] P. R. Ashton, R. Ballardini, V. Balzani, I. Baxter, A. Credi, M. C. T. Fyfe, M. T. Gandolfi, M. Gómez-López, M. V. Martínez-Díaz, A. Piersanti, N. Spencer, J. F. Stoddart, M. Venturi, A. J. P. White, D. J. Williams, J. Am. Chem. Soc. 1998, 120, 11932-11942.

[50] C. P. Collier, E. W. Wong, M. Belohradský, F. M. Raymo, J. F. Stoddart, P. J. Kuekes, R. S. Williams, J. R. Heath, Science 1999, 285, 391-394.

[51] E. M. Pérez, D. T. F. Dryden, D. A. Leigh, G. Teobaldi, F. Zerbetto, J. Am. Chem. Soc. 2004, $126,12210-12211$. 
[52] C. J. Serpell, R. Chall, A. L. Thompson, P. D. Beer, Dalton Trans. 2011, 40, 12052-12055.

[53] V. Blanco, A. Carlone, K. D. Hänni, D. A. Leigh, B. Lewandowski, Angew. Chem. Int. Ed. 2012, 51, 5166-5169.

[54] F. Coutrot, C. Romuald, E. Busseron, Org. Lett. 2008, 10, 3741-3744.

[55] V. Blanco, D. A. Leigh, U. Lewandowska, B. Lewandowski, V. Marcos, J. Am. Chem. Soc. 2014, 136, 15775-15780.

[56] C.-S. Kwan, A. S. C. Chan, K. C.-F. Leung, Org. Lett. 2016, 18, 976-979.

[57] R. Mitra, H. Zhu, S. Grimme, J. Niemeyer, Angew. Chem. Int. Ed. 2017, 56, 11456-11459.

[58] R. Mitra, M. Thiele, F. Octa-Smolin, M. C. Letzel, J. Niemeyer, Chem. Comm. 2016, 52, 59775980.

[59] D. Parmar, E. Sugiono, S. Raja, M. Rueping, Chem. Rev. 2014, 114, 9047-9153.

[60] M. Rueping, A. P. Antonchick, T. Theissmann, Angew. Chem. Int. Ed. 2006, 45, 3683-3686.

[61] a) M. D. Pluth, R. G. Bergman, K. N. Raymond, Acc. Chem. Res. 2009, 42, 1650-1659; b) Y. Michito, F. Makoto, Bull. Chem. Soc. Jpn. 2010, 83, 609-618; c) T. K. Ronson, S. Zarra, S. P. Black, J. R. Nitschke, Chem. Comm. 2013, 49, 2476-2490; d) M. Han, D. M. Engelhard, G. H. Clever, Chem. Soc. Rev. 2014, 43, 1848-1860.

[62] a) F. Hof, S. L. Craig, C. Nuckolls, J. J. Rebek, Angew. Chem. Int. Ed. 2002, 41, 1488-1508; b) T. Evan-Salem, I. Baruch, L. Avram, Y. Cohen, L. C. Palmer, J. Rebek, Proc. Natl. Acad. Sci. USA 2006, 103, 12296-12300.

[63] J. H. Jordan, B. C. Gibb, Chem. Soc. Rev. 2015, 44, 547-585.

[64] D. L. Caulder, R. E. Powers, T. N. Parac, K. N. Raymond, Angew. Chem. Int. Ed. 1998, 37, 1840-1843.

[65] C. Zhao, Q.-F. Sun, W. M. Hart-Cooper, A. G. DiPasquale, F. D. Toste, R. G. Bergman, K. N. Raymond, J. Am. Chem. Soc. 2013, 135, 18802-18805.

[66] S. M. Biros, R. G. Bergman, K. N. Raymond, J. Am. Chem. Soc. 2007, 129, 12094-12095.

[67] A. V. Davis, K. N. Raymond, J. Am. Chem. Soc. 2005, 127, 7912-7919.

[68] C. Sgarlata, J. S. Mugridge, M. D. Pluth, B. E. F. Tiedemann, V. Zito, G. Arena, K. N. Raymond, J. Am. Chem. Soc. 2010, 132, 1005-1009.

[69] M. D. Pluth, R. G. Bergman, K. N. Raymond, J. Am. Chem. Soc. 2007, 129, 11459-11467.

[70] M. D. Pluth, R. G. Bergman, K. N. Raymond, J. Am. Chem. Soc. 2008, 130, 6362-6366.

[71] J. L. Brumaghim, M. Michels, K. N. Raymond, Eur. J. Org. Chem. 2004, 2004, 4552-4559.

[72] V. M. Dong, D. Fiedler, B. Carl, R. G. Bergman, K. N. Raymond, J. Am. Chem. Soc. 2006, 128, 14464-14465.

[73] D. Fiedler, R. G. Bergman, K. N. Raymond, Angew. Chem. Int. Ed. 2004, 43, 6748-6751.

[74] C. J. Hastings, M. D. Pluth, R. G. Bergman, K. N. Raymond, J. Am. Chem. Soc. 2010, 132, 6938-6940.

[75] M. D. Pluth, R. G. Bergman, K. N. Raymond, Science 2007, 316, 85-88. 
[76] M. D. Pluth, R. G. Bergman, K. N. Raymond, Angew. Chem. Int. Ed. 2007, 46, 8587-8589.

[77] D. M. Kaphan, F. D. Toste, R. G. Bergman, K. N. Raymond, J. Am. Chem. Soc. 2015, 137, 9202-9205.

[78] a) J. Rebek, Acc. Chem. Res. 2009, 42, 1660-1668; b) D. Ajami, J. Rebek, Acc. Chem. Res. 2013, 46, 990-999.

[79] L. R. MacGillivray, J. L. Atwood, Nature 1997, 389, 469-472.

[80] L. Avram, Y. Cohen, J. Am. Chem. Soc. 2002, 124, 15148-15149.

[81] a) A. Shivanyuk, J. Rebek, Proc. Natl. Acad. Sci. USA 2001, 98, 7662-7665; b) L. Avram, Y. Cohen, Org. Lett. 2003, 5, 1099-1102.

[82] M. Yamanaka, A. Shivanyuk, J. Rebek, J. Am. Chem. Soc. 2004, 126, 2939-2943.

[83] L. Avram, Y. Cohen, J. Am. Chem. Soc. 2003, 125, 16180-16181.

[84] S. Horiuchi, H. Tanaka, E. Sakuda, Y. Arikawa, K. Umakoshi, Chem. Eur. J. 2016, 22, 1753317537.

[85] a) O. Ugono, K. T. Holman, Chem. Comm. 2006, 2144-2146; b) S. Slovak, Y. Cohen, Chem. Eur. J. 2012, 18, 8515-8520.

[86] Q. Zhang, K. Tiefenbacher, J. Am. Chem. Soc. 2013, 135, 16213-16219.

[87] T. Gerkensmeier, W. Iwanek, C. Agena, R. Fröhlich, S. Kotila, C. Näther, J. Mattay, Eur. J. Org. Chem. 1999, 1999, 2257-2262.

[88] L. C. Palmer, J. Rebek, Org. Lett. 2005, 7, 787-789.

[89] Q. Zhang, L. Catti, V. R. I. Kaila, K. Tiefenbacher, Chem. Sci. 2017, 8, 1653-1657.

[90] S. Yariv-Shoushan, Y. Cohen, Org. Lett. 2016, 18, 936-939.

[91] J. Kang, J. Rebek Jr, Nature 1997, 385, 50-52.

[92] J. Kang, J. Santamaría, G. Hilmersson, J. Rebek, J. Am. Chem. Soc. 1998, 120, 7389-7390.

[93] S. Mecozzi, J. J. Rebek, Chem. Eur. J. 1998, 4, 1016-1022.

[94] Q. Zhang, K. Tiefenbacher, Nat. Chem. 2015, 7, 197-202.

[95] S. J. Danishefsky, J. J. Masters, W. B. Young, J. T. Link, L. B. Snyder, T. V. Magee, D. K. Jung, R. C. A. Isaacs, W. G. Bornmann, C. A. Alaimo, C. A. Coburn, M. J. Di Grandi, J. Am. Chem. Soc. 1996, 118, 2843-2859.

[96] R. Croteau, Chem. Rev. 1987, 87, 929-954.

[97] L. Catti, K. Tiefenbacher, Chem. Comm. 2015, 51, 892-894.

[98] D. C. Rosenfeld, S. Shekhar, A. Takemiya, M. Utsunomiya, J. F. Hartwig, Org. Lett. 2006, 8, 4179-4182.

[99] G. Bianchini, G. L. Sorella, N. Canever, A. Scarso, G. Strukul, Chem. Comm. 2013, 49, 53225324.

[100] S. Giust, G. La Sorella, L. Sperni, F. Fabris, G. Strukul, A. Scarso, Asian J. Org. Chem. 2015, 4, 217-220.

[101] T. Jin, S. Kamijo, Y. Yamamoto, Tetrahedron Lett. 2004, 45, 9435-9437. 
[102] a) F. G. Fallon, R. M. Herbst, J. Org. Chem. 1957, 22, 933-936; b) D. M. Zimmerman, R. A. Olofson, Tetrahedron Lett. 1969, 10, 5081-5084.

[103] G. La Sorella, L. Sperni, G. Strukul, A. Scarso, Adv. Synth. Catal. 2016, 358, 3443-3449.

[104] M. Mba, L. J. Prins, G. Licini, Org. Lett. 2007, 9, 21-24.

[105] W. L. Xu, Y. Z. Li, Q. S. Zhang, H. S. Zhu, Synthesis 2004, 2004, 227-232.

[106] T. Caneva, L. Sperni, G. Strukul, A. Scarso, RSC Adv. 2016, 6, 83505-83509.

[107] G. La Sorella, L. Sperni, P. Ballester, G. Strukul, A. Scarso, Catal. Sci. Technol. 2016, 6, 60316036.

[108] L. Catti, A. Pöthig, K. Tiefenbacher, Adv. Synth. Catal. 2017, 359, 1331-1338.

[109] G. La Sorella, L. Sperni, G. Strukul, A. Scarso, ChemCatChem 2015, 7, 291-296.

[110] J. W. Yang, M. T. Hechavarria Fonseca, B. List, Angew. Chem. Int. Ed. 2004, 43, 6660-6662.

[111] T. M. Bräuer, Q. Zhang, K. Tiefenbacher, Angew. Chem. Int. Ed. 2016, 55, 7698-7701.

[112] T. M. Bräuer, Q. Zhang, K. Tiefenbacher, J. Am. Chem. Soc. 2017, 139, 17500-17507.

[113] a) C. Zhu, T. Akiyama, Org. Lett. 2009, 11, 4180-4183; b) A. Henseler, M. Kato, K. Mori, T. Akiyama, Angew. Chem. Int. Ed. 2011, 50, 8180-8183. 


\section{Bibliographic Data of Complete Publications}

This chapter provides the bibliographic details of the publications summarized in chapters 5.1 and 5.2 of this thesis to facilitate the retrieval of the complete manuscripts and supporting information.

\subsection{Iminium Catalysis Inside a Self-Assembled Supramolecular Capsule: Modulation of Enantiomeric Excess}

Thomas M. Bräuer, ${ }^{[\mathrm{a}]}$ Qi Zhang ${ }^{[\mathrm{a}]}$ and Konrad Tiefenbacher ${ }^{[\mathrm{b}] *}$

[a] Department of Chemistry, Technical University of Munich, Lichtenbergstraße 4, 85747 Garching, Germany

[b] Department of Chemistry, University of Basel, St. Johanns-Ring 19, 4056 Basel, Switzerland

E-Mail: konrad.tiefenbacher@unibas.ch/tkonrad@ethz.ch

Originally published in: Angew. Chem. Int. Ed. 2016, 55, 7698-7701.

DOI: $10.1002 /$ anie.201602382

Hyperlink: http://onlinelibrary.wiley.com/wol1/doi/10.1002/anie.201602382/abstract

9.2 Iminium Catalysis Inside a Self-Assembled Supramolecular Capsule: Scope and Mechanistic Studies

Thomas M. Bräuer, ${ }^{[\mathrm{a}]}$ Qi Zhang ${ }^{[\mathrm{a}]}$ and Konrad Tiefenbacher ${ }^{[\mathrm{a}, \mathrm{b}] *}$

[a] Department of Chemistry, University of Basel, BPR 1096, Postfach 3350, Mattenstrasse 24a, 4002 Basel, Switzerland

[b] Department of Biosystems Science and Engineering, ETH Zürich, Mattenstrasse 26, 4058 Basel, Switzerland

E-Mail: konrad.tiefenbacher@unibas.ch/tkonrad@ethz.ch

Originally published in: J. Am. Chem. Soc. 2017, 139, 17500-17507.

DOI: $10.1021 /$ jacs.7b08976

Hyperlink: http://pubs.acs.org/doi/abs/10.1021/jacs.7b08976 


\section{Reprint Permissions and Reprints}

\subsection{John Wiley and Sons}

10.1.1 Reprint Permission of the Manuscript "Iminium Catalysis Inside a Self-Assembled Supramolecular Capsule: Modulation of Enantiomeric Excess"

The manuscript published in Angewandte Chemie International Edition ${ }^{[111]}$ was reproduced with permission of John Wiley and Sons. 


\section{JOHN WILEY AND SONS LICENSE TERMS AND CONDITIONS}

This Agreement between Mr. Thomas Bräuer ("You") and John Wiley and Sons ("John Wiley and Sons") consists of your license details and the terms and conditions provided by John Wiley and Sons and Copyright Clearance Center.

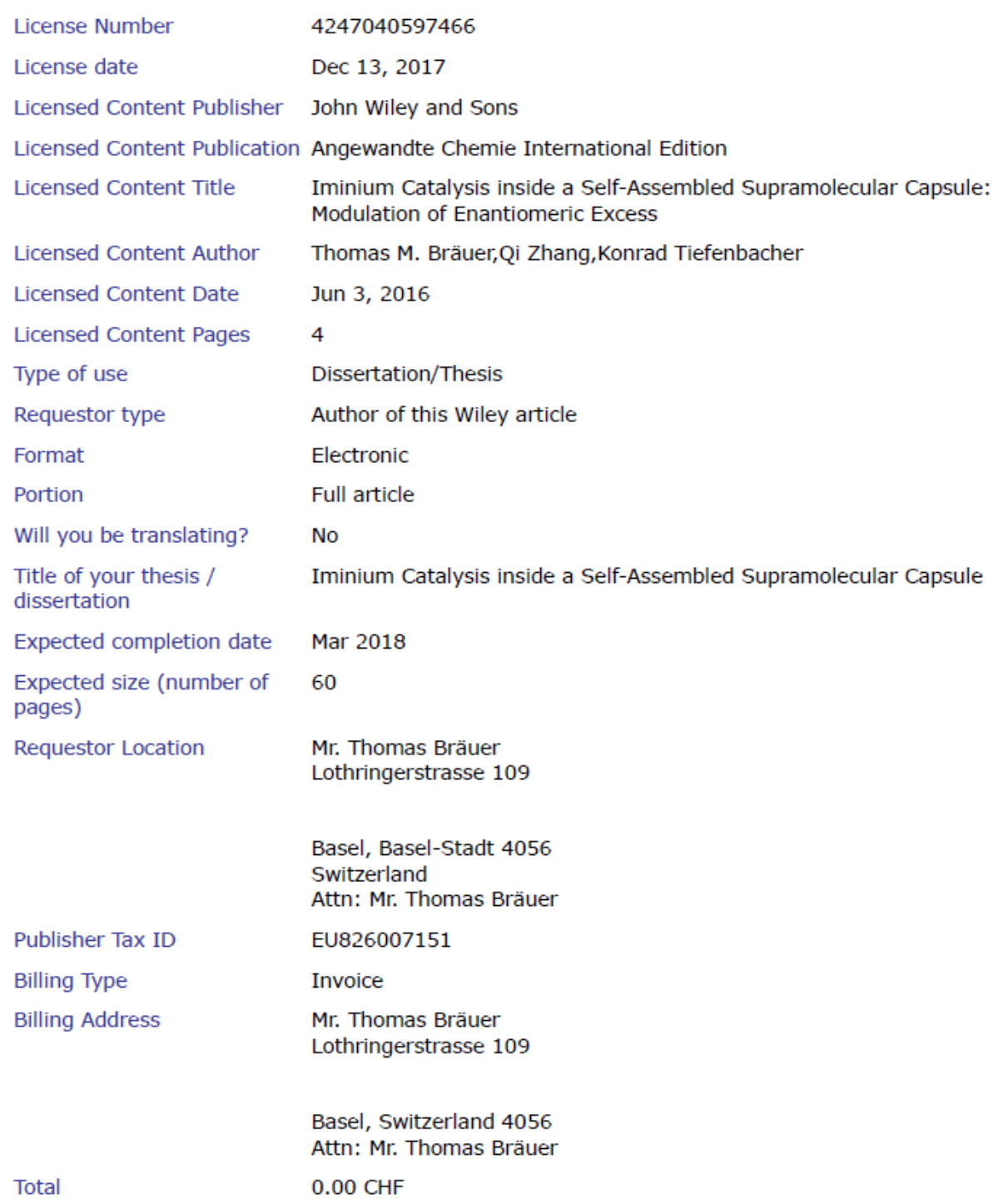

Terms and Conditions

TERMS AND CONDITIONS

This copyrighted material is owned by or exclusively licensed to John Wiley \& Sons, Inc. or one of its group companies (each a"Wiley Company") or handled on behalf of a society with 
which a Wiley Company has exclusive publishing rights in relation to a particular work (collectively "WILEY"). By clicking "accept" in connection with completing this licensing transaction, you agree that the following terms and conditions apply to this transaction (along with the billing and payment terms and conditions established by the Copyright Clearance Center Inc., ("CCC's Billing and Payment terms and conditions"), at the time that you opened your RightsLink account (these are available at any time at http://myaccount.copyright.com).

\section{Terms and Conditions}

- The materials you have requested permission to reproduce or reuse (the "Wiley Materials") are protected by copyright.

- You are hereby granted a personal, non-exclusive, non-sub licensable (on a standalone basis), non-transferable, worldwide, limited license to reproduce the Wiley Materials for the purpose specified in the licensing process. This license, and any CONTENT (PDF or image file) purchased as part of your order, is for a one-time use only and limited to any maximum distribution number specified in the license. The first instance of republication or reuse granted by this license must be completed within two years of the date of the grant of this license (although copies prepared before the end date may be distributed thereafter). The Wiley Materials shall not be used in any other manner or for any other purpose, beyond what is granted in the license. Permission is granted subject to an appropriate acknowledgement given to the author, title of the material/book/journal and the publisher. You shall also duplicate the copyright notice that appears in the Wiley publication in your use of the Wiley Material. Permission is also granted on the understanding that nowhere in the text is a previously published source acknowledged for all or part of this Wiley Material. Any third party content is expressly excluded from this permission.

- With respect to the Wiley Materials, all rights are reserved. Except as expressly granted by the terms of the license, no part of the Wiley Materials may be copied, modified, adapted (except for minor reformatting required by the new Publication), translated, reproduced, transferred or distributed, in any form or by any means, and no derivative works may be made based on the Wiley Materials without the prior permission of the respective copyright owner.For STM Signatory Publishers clearing permission under the terms of the STM Permissions Guidelines only, the terms of the license are extended to include subsequent editions and for editions in other languages, provided such editions are for the work as a whole in situ and does not involve the separate exploitation of the permitted figures or extracts, You may not alter, remove or suppress in any manner any copyright, trademark or other notices displayed by the Wiley Materials. You may not license, rent, sell, loan, lease, pledge, offer as security, transfer or assign the Wiley Materials on a stand-alone basis, or any of the rights granted to you hereunder to any other person.

- The Wiley Materials and all of the intellectual property rights therein shall at all times remain the exclusive property of John Wiley \& Sons Inc, the Wiley Companies, or their respective licensors, and your interest therein is only that of having possession of and the right to reproduce the Wiley Materials pursuant to Section 2 herein during the continuance of this Agreement. You agree that you own no right, title or interest in or to the Wiley Materials or any of the intellectual property rights therein. You shall have no rights hereunder other than the license as provided for above in Section 2. No right, 
license or interest to any trademark, trade name, service mark or other branding ("Marks") of WILEY or its licensors is granted hereunder, and you agree that you shall not assert any such right, license or interest with respect thereto

- NEITHER WILEY NOR ITS LICENSORS MAKES ANY WARRANTY OR REPRESENTATION OF ANY KIND TO YOU OR ANY THIRD PARTY, EXPRESS, IMPLIED OR STATUTORY, WITH RESPECT TO THE MATERIALS OR THE ACCURACY OF ANY INFORMATION CONTAINED IN THE MATERIALS, INCLUDING, WITHOUT LIMITATION, ANY IMPLIED WARRANTY OF MERCHANTABILITY, ACCURACY, SATISFACTORY QUALITY, FITNESS FOR A PARTICULAR PURPOSE, USABILITY, INTEGRATION OR NON-INFRINGEMENT AND ALL SUCH WARRANTIES ARE HEREBY EXCLUDED BY WILEY AND ITS LICENSORS AND WAIVED BY YOU.

- WILEY shall have the right to terminate this Agreement immediately upon breach of this Agreement by you.

- You shall indemnify, defend and hold harmless WILEY, its Licensors and their respective directors, officers, agents and employees, from and against any actual or threatened claims, demands, causes of action or proceedings arising from any breach of this Agreement by you.

- IN NO EVENT SHALL WILEY OR ITS LICENSORS BE LIABLE TO YOU OR ANY OTHER PARTY OR ANY OTHER PERSON OR ENTITY FOR ANY SPECIAL, CONSEQUENTIAL, INCIDENTAL, INDIRECT, EXEMPLARY OR PUNITIVE DAMAGES, HOWEVER CAUSED, ARISING OUT OF OR IN CONNECTION WITH THE DOWNLOADING, PROVISIONING, VIEWING OR USE OF THE MATERIALS REGARDLESS OF THE FORM OF ACTION, WHETHER FOR BREACH OF CONTRACT, BREACH OF WARRANTY, TORT, NEGLIGENCE, INFRINGEMENT OR OTHERWISE (INCLUDING, WITHOUT LIMITATION, DAMAGES BASED ON LOSS OF PROFITS, DATA, FILES, USE, BUSINESS OPPORTUNITY OR CLAIMS OF THIRD PARTIES), AND WHETHER OR NOT THE PARTY HAS BEEN ADVISED OF THE POSSIBILITY OF SUCH DAMAGES. THIS LIMITATION SHALL APPLY NOTWITHSTANDING ANY FAILURE OF ESSENTIAL PURPOSE OF ANY LIMITED REMEDY PROVIDED HEREIN.

- Should any provision of this Agreement be held by a court of competent jurisdiction to be illegal, invalid, or unenforceable, that provision shall be deemed amended to achieve as nearly as possible the same economic effect as the original provision, and the legality, validity and enforceability of the remaining provisions of this Agreement shall not be affected or impaired thereby.

- The failure of either party to enforce any term or condition of this Agreement shall not constitute a waiver of either party's right to enforce each and every term and condition of this Agreement. No breach under this agreement shall be deemed waived or excused by either party unless such waiver or consent is in writing signed by the party granting such waiver or consent. The waiver by or consent of a party to a breach of any provision of this Agreement shall not operate or be construed as a waiver of or 
consent to any other or subsequent breach by such other party.

- This Agreement may not be assigned (including by operation of law or otherwise) by you without WILEY's prior written consent.

- Any fee required for this permission shall be non-refundable after thirty (30) days from receipt by the $\mathrm{CCC}$.

- These terms and conditions together with CCC's Billing and Payment terms and conditions (which are incorporated herein) form the entire agreement between you and WILEY concerning this licensing transaction and (in the absence of fraud) supersedes all prior agreements and representations of the parties, oral or written. This Agreement may not be amended except in writing signed by both parties. This Agreement shall be binding upon and inure to the benefit of the parties' successors, legal representatives, and authorized assigns.

- In the event of any conflict between your obligations established by these terms and conditions and those established by CCC's Billing and Payment terms and conditions, these terms and conditions shall prevail.

- WILEY expressly reserves all rights not specifically granted in the combination of (i) the license details provided by you and accepted in the course of this licensing transaction, (ii) these terms and conditions and (iii) CCC's Billing and Payment terms and conditions.

- This Agreement will be void if the Type of Use, Format, Circulation, or Requestor Type was misrepresented during the licensing process.

- This Agreement shall be governed by and construed in accordance with the laws of the State of New York, USA, without regards to such state's conflict of law rules. Any legal action, suit or proceeding arising out of or relating to these Terms and Conditions or the breach thereof shall be instituted in a court of competent jurisdiction in New York County in the State of New York in the United States of America and each party hereby consents and submits to the personal jurisdiction of such court, waives any objection to venue in such court and consents to service of process by registered or certified mail, return receipt requested, at the last known address of such party.

\section{WILEY OPEN ACCESS TERMS AND CONDITIONS}

Wiley Publishes Open Access Articles in fully Open Access Journals and in Subscription journals offering Online Open. Although most of the fully Open Access journals publish open access articles under the terms of the Creative Commons Attribution (CC BY) License only, the subscription journals and a few of the Open Access Journals offer a choice of Creative Commons Licenses. The license type is clearly identified on the article.

\section{The Creative Commons Attribution License}

The Creative Commons Attribution License (CC-BY) allows users to copy, distribute and transmit an article, adapt the article and make commercial use of the article. The CC-BY license permits commercial and non-

Creative Commons Attribution Non-Commercial License

The Creative Commons Attribution Non-Commercial (CC-BY-NC)License permits use, distribution and reproduction in any medium, provided the original work is properly cited 
and is not used for commercial purposes.(see below)

Creative Commons Attribution-Non-Commercial-NoDerivs License

The Creative Commons Attribution Non-Commercial-NoDerivs License (CC-BY-NC-ND) permits use, distribution and reproduction in any medium, provided the original work is properly cited, is not used for commercial purposes and no modifications or adaptations are made. (see below)

Use by commercial "for-profit" organizations

Use of Wiley Open Access articles for commercial, promotional, or marketing purposes requires further explicit permission from Wiley and will be subject to a fee.

Further details can be found on Wiley Online Library http://olabout.wiley.com/WileyCDA /Section/id-410895.html

Other Terms and Conditions:

v1.10 Last updated September 2015

Questions? customercare@copyright.com or +1-855-239-3415 (toll free in the US) or +1-978-646-2777.

10.1.2 Manuscript "Iminium Catalysis Inside a Self-Assembled Supramolecular Capsule: Modulation of Enantiomeric Excess" 


\section{Communications}

\section{Angewandte}

International Edition: DOI: 10.1002/anie.201602382

Host-Guest Systems Hot Paper

German Edition: DOI: 10.1002/ange.201602382

\section{Iminium Catalysis inside a Self-Assembled Supramolecular Capsule: Modulation of Enantiomeric Excess}

Thomas M. Bräuer, Qi Zhang, and Konrad Tiefenbacher*

Abstract: The noncovalent combination of a supramolecular host with iminium organocatalysis is described. Due to cation$\pi$ interactions the reactive iminium species is held inside the host and reacts in this confined environment. The product. formed differ up to $92 \%$ ee from the control experiments without added host. A model rationalizing the observed difference is presented.

$\boldsymbol{C}_{\text {atalysis in self-assembled supramolecular structures has }}$ attracted great interest. ${ }^{[1]}$ Chemists are intrigued by the possibility of performing reactions in small spaces $\left(\mathrm{nm}^{3}\right.$ scale), in which the reactivities and selectivities differ from those in solution. ${ }^{[2]}$ In artificial systems, product inhibition poses a great challenge. Nevertheless, a variety of reactions including hydroformylations, ${ }^{[3]}$ hydrolysis, ${ }^{[4]}$ hydrations ${ }^{[5]}$ hydroalkoxylations ${ }^{[6]}$ aza-Cope rearrangements, ${ }^{[7]}$ Diels-Alder reactions, Nazarov ${ }^{[8]}$ and, Prins ${ }^{[9]}$ cyclizations, isomerizations ${ }^{[10]}$ and terpene cyclizations ${ }^{[1]}$ were catalyzed successfully. The majority of these examples involve monomolecular reactions or reactions catalyzed by an encapsulated metal catalyst. We herein report the catalysis of a complex multimolecular reaction inside the supramolecular host I. Capsule I, first reported by the Atwood group, ${ }^{[12]}$ self-assembles from six resorcinarene units 1 and eight water molecules (Figure 1). ${ }^{[13]}$ Its behavior in solution was studied extensively. ${ }^{[14]}$

Recently, we reported that I acts as a Brønsted acid ${ }^{[\operatorname{Ag}]}$ and is able to catalyze cationic reactions ${ }^{[6,11]}$ We now explored the possibility of controlling iminium reactions ${ }^{[15]}$ inside this host. If the reaction is to occur inside the cavity of $\mathbf{I}$, rapid encapsulation of the reactive iminium species 4 (Figure 2) is essential. Since capsule I displays a high affinity towards ammonium ions due to cation- $\pi$ interactions ${ }^{[14 \mathrm{~h}, \mathrm{c}, \mathrm{e}-\mathrm{h}, \mathrm{m}]}$ we speculated that a suitably sized iminium species would also be an excellent guest to yield complex $\mathbf{A}$. After uptake of a nucleophile (complex B) and reaction (complex C), hydrolysis would regenerate the catalysts amine $\mathbf{2}$ and capsule I.

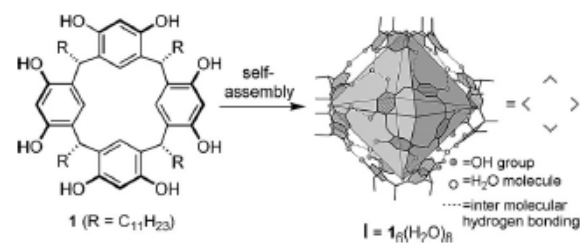

Figure 1. Structure of resorcinarene 1 and capsule $\mathbf{I}$

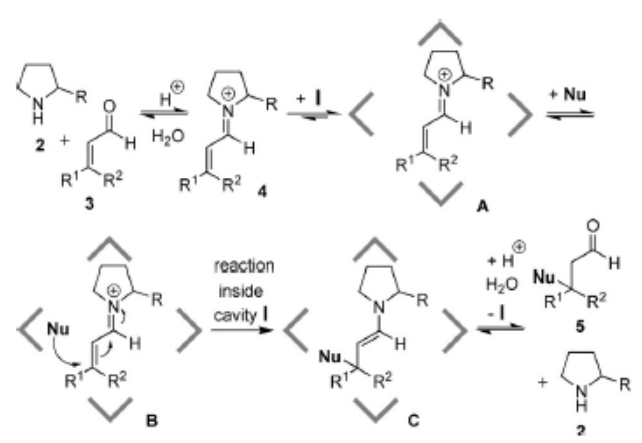

Figure 2. Proposed pathway of the iminium-catalyzed reaction inside capsule I.

To the best of our knowledge, no iminium catalysis has been reported inside supramolecular structures. The Rebek group reported the acceleration of a Knoevenagel reaction by an amine catalyst bound to a cavitand, where the reaction took place outside of the open cavity. ${ }^{[16]}$ The Bergman and Raymond groups reported the stabilization of an iminium ion inside a supramolecular container but no conversion. ${ }^{[17]}$ The fact that intramolecular cation- $\pi$ interactions can play a significant role in iminium catalysis was demonstrated by the Gilmour group. ${ }^{[18]}$ We herein show that intermolecular cation- $\pi$ stabilization and the resulting encapsulation inside a supramolecular host can dramatically influence the reaction.

[*] M. Sc. T. M. Brăuer, M. Sc. Q. Zhan Department of Chemistry, Technical University of Munich Lichtenbergstrasse 4, 85747 Garching (Germany) Prof. Dr. K. Tiefenbacher

Department of Chemistry, University of Basel St. Johannsring 19, CH-4056 Basel (Switzerland) E-mail: konrad.tiefenbacher@unibas.ch

(1) Supporting information and the ORCID identification number(s) for the author(s) of this article can be found under http://dx.doi.org/10 1002/anie.201602382.

As a model reaction, the organocatalytic reduction of $\alpha, \beta$ unsaturated aldehyde 3a (Figure 3) was investigated ${ }^{[19]}$ The

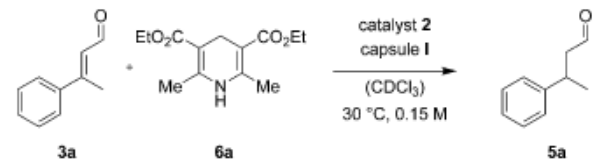

Figure 3. Iminium-catalyzed 1,4-reduction investigated. 
reactions were carried out with and without $26 \mathrm{~mol} \%$ capsule I. Reactions with catalysts carrying a sterically shielding group in $\alpha$-position (entries 1 and 2, Table 1) did not display significant differences when capsule I was present. However, catalysts with hydrogen-bond acceptor groups (entries 3-5, Table 1) provided products with different enantiomeric excess when the capsule was present. For instance, with proline benzyl ester 2 e a $\Delta e e$ value of $32 \%$ was observed. Employing catalysts with hydrogen-bond acceptor and donor functionalities (entries 6 and 7, Table 1), resulted in even higher $\Delta e e$ values. In the case of proline $2 \mathrm{~g}$ (entry 7 , Table 1), $67 \% \mathrm{ee}(S)$ was obtained in the presence of I, while only $23 \% e e(S)$ were observed in its absence.

Control experiments (Supporting Information (SI) chapters 8.1-8.6) with a very large Hantzsch ester, amine catalyst, and aldehyde were performed. Due to their size, the formation of the reactive complex B (Figure 2) is prevented and, therefore, the reaction has to occur outside in solution.

Table 1: Results of the iminium-catalyzed 1,4-reduction of aldehyde 3 a utilizing different catalysts.

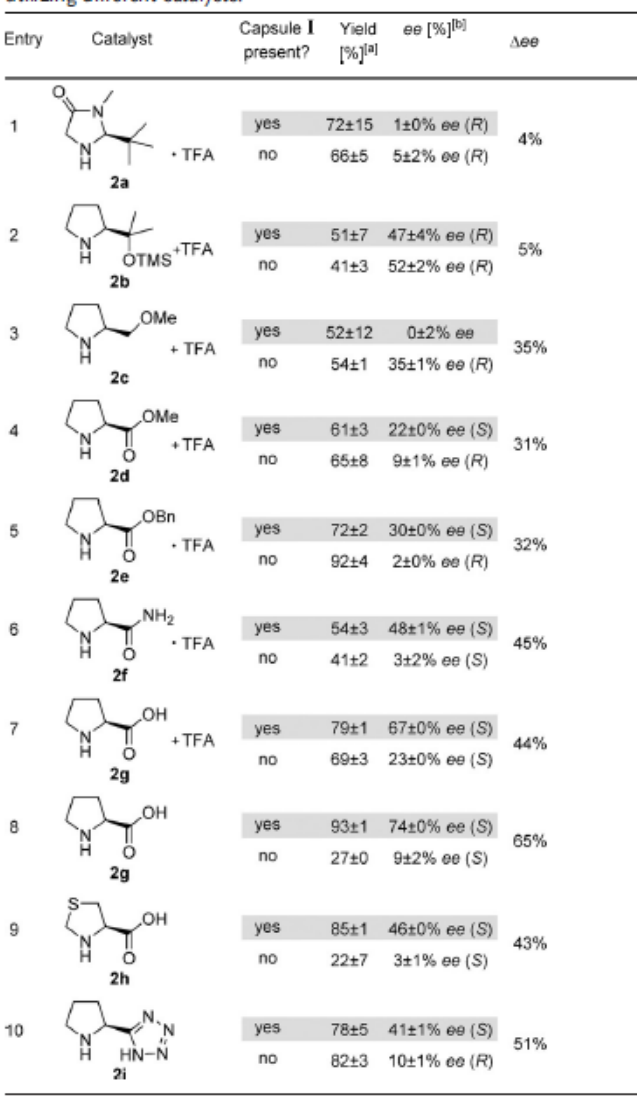

[a] Determined by CC analysis. [b] Determined by CC analysis on a chira stationary phase. $\mathrm{Bn}=$ benzyl, TFA = trifluoroacetic acid, TMS = trime thylsilyl.

(c) 2016 Wiley-VCH Verlag GmbH \& Co. KGaA, Weinheim

No significant $\Delta e e$ values were observed in these cases, providing strong evidence that encapsulation is indeed responsible for the strong modulation of the ee. Further evidence is provided by a control experiment, in which the cavity was blocked by a strongly binding inhibitor. Evidence for the encapsulation of an iminium species of $\mathbf{2} \mathrm{g}$ was obtained by NMR spectroscopy (SI chapters $8.7-8.10$ ).

Furthermore, we found that in the case of the carboxylic acid $2 \mathrm{~g}$ the addition of acid additive is not necessary. Without TFA, even a higher modulating effect of capsule I was observed ( $\Delta e e$ of $65 \%$ ). Also other catalysts with acidic protons thioproline $(\mathbf{2} \mathbf{h})$ and proline tetrazole $\mathbf{2} \mathbf{i}^{[20]}$ exhibited relatively large see values ( $43 \%$ and $51 \%$, respectively).

Inside the confined environment of $\mathbf{I}$, strong substrate selectivity is to be expected. Therefore, a series of unsaturated aldehydes were investigated with $\mathbf{2} \mathbf{g}$ as the catalyst (Table 2).

Table 2: Results of the iminium catalyzed 1,4-reduction of different aldehydes 3 utilizing proline $(\mathbf{2 g})$

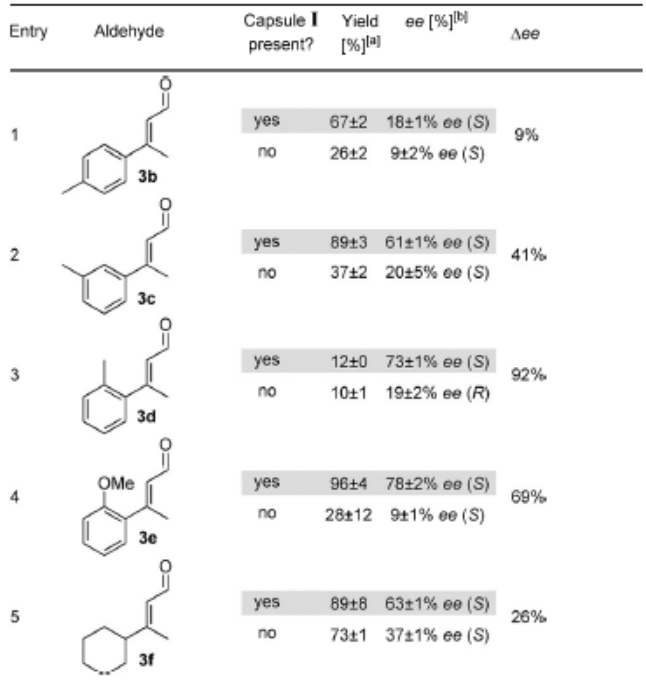

a] Deter mined by CC analysis. [b] Determined by CC analysis on a chiral stationary phase.

The addition of a methyl group at different positions of the phenyl substituent of the substrate (entries 1-3, Table 2) had a pronounced influence on the reaction inside the capsule: the $\Delta e e$ value observed increased from $9 \%$ (para-) to $92 \%$ (ortho-substitution). Similarly, the ortho-methoxy substrate was also converted much more selectively in the presence of capsule (Aee of $69 \%$ ). To gauge the influence of the phenyl group, the cyclohexyl derivative was investigated. Only a reduced modulating effect of capsule I was observed ( $\Delta e e$ of $26 \%$ ), indicating that interactions of the phenyl ring contribute to the phenomenon observed.

Inspection of all experiments reveals that the enantiomeric distribution of the product tends towards an $S$ configuration inside $\mathbf{I}$, when compared to the corresponding results in

\footnotetext{
Angew. Chem. Int. Ed. 2016, 55, 7698-7701
} 


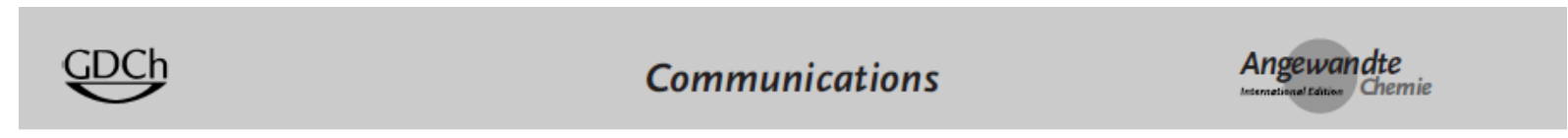

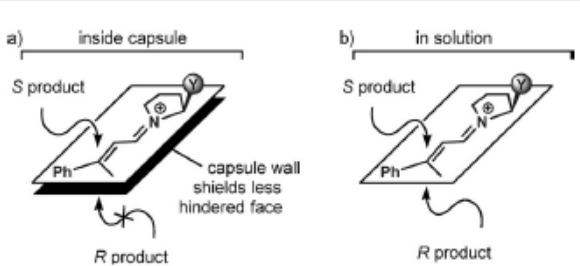

Figure 4 Hypothesis for the different selectivity inside capsule I.

solution. We propose that the iminium species binds to the interior wall of the cavity via cation- $\pi$ interactions from the less hindered side (Figure $4 \mathrm{a}$ ). Therefore, the hydride is preferentially delivered $s y n$ to group Y. In the case of directing groups ${ }^{[15 a, 21]}$ (groups that can act as hydrogen-bond donors, Table 1 entries 6-10), modest to good selectivities for the $S$ enantiomer were obtained inside capsule $\mathbf{I}$. In the case of a sterically shielding group $\mathrm{Y}$, the orientation of the substrate inside capsule I reduces the selectivity for the $R$ configured product. It is further noteworthy that the described reactions differ from catalysis observed previous-

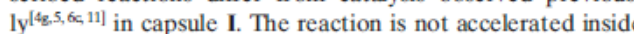
the container (SI chapter 6.2). This is due to the fact that the reactive iminium species is sequestered from the nucleophile by encapsulation.

In summary, it has been demonstrated that an iminiumcatalyzed 1,4-reduction can be performed inside a supramolecular host. The intermolecular, noncovalent interactions inside the host system dramatically improve the enantiose lectivity for several amine catalysts. As expected for a reaction inside a confined environment, a high substrate selectivity was observed. To some extent, the presented system mimics natural amine reductases, in which $\mathrm{NADH}$ binds as a reducing cofactor inside an enzyme pocket. Conceptually, this novel approach opens up new avenues for organocatalysis.

\section{Acknowledgements}

We thank Prof. Thorsten Bach for his support. T.M.B. thanks the National Research Fund, Luxembourg for an AFR fellowship. Further support was provided by the Bayerische A kademie der Wissenschaften, Fonds der Chemischen Industrie, and the TUM Junior Fellow Fund. We thank M.Sc Johannes Richers for graphical design.

Keywords: enantioselectivity · host-guest systems iminium catalysis - organocatalysis - supramolecular chemistry

How to cite: Angew. Chem. Int. Ed. 2016, 55, 7698-7701 Angew. Chem. 2016, 128, 7829-7832

[1] a) M. Yoshizawa, J. K. Klosterman, M. Fujita, Angew. Chem. In Ed. 2009, 48, 3418-3438; Angew. Chem. 2009, 121, 3470-3490; b) J. Meeuwissen, J. N. H. Reek, Nat. Chem. 2010, 2, 615-621; c) L. Marchetti, M. Levine, ACS Catal. 2011, 1, 1090-1118; d) M. J. Wiester, P. A. Ulmann, C. A. Mirkin, Angew. Chem. Int. Ed. 2011, 50,114-137; Angew. Chem. 2011, 123, 118-142; e) M. Raynal, P. Ballester, A. Vidal-Ferran, P. W. N. M. van Leeuwen,
Chem. Soc. Rev. 2014, 43, 1734-1787; f) C. J. Brown, F. D. Toste, R. G. Bergman, K. N. Raymond, Chem. Rev. 2015, 115, 3012 3035 ; g) S. H. A. M. Leenders, R. Gramage-Doria, B. de Bruin, J. N. H. Reek, Chem. Soc. Rev. 2015, 44, 433-448; h) S. Zarra, D. M. Wood, D. A. Roberts, J. R. Nitschke, Chem. Soc. Rev. 2015, 44, 419-432; i) L. Catti, Q. Zhang, K. Tiefenbacher, Synthesis 2016, 48, 313-328.

[2] a) D. Ajami, L. Liu, J. Rebek, Jr., Chem. Soc. Rev. 2015, 44, 490 499; b) K. I. Assaf, W. M. Nau, Chem. Soc. Rev. 2015, 44, 394 418; c) K. Hermann, Y. Ruan, A. M. Hardin, C. M. Hadad, J. D. Badjic, Chem. Soc. Rev. 2015, 44, 500-514; d) J. H. Jordan, B. C. Gibb, Chem. Soc. Rev. 2015, 44, 547-585; e) J.-N. Rebilly, B. Colasson, O. Bistri, D. Over, O. Reinaud, Chem. Soc. Rev. 2015, $44,467-489$.

[3] For recent examples see: a) P. Dydio, R. J. Detz, B. de Bruin, J. N. H. Reek, J. Am. Chem. Soc. 2014, 136, 8418-8429; b) C. García-Simón, R. Gramage-Doria, S. Raoufmoghaddam, T Parella, M. Costas, X. Ribas, J. N. H. Reek, J. Am. Chem. Soc. 2015, 137, 2680-2687.

[4] a) M. D. Pluth, R. G. Bergman, K. N. Raymond, Science 2007, $316,85-88$; b) M. D. Pluth, R. G. Bergman, K. N. Raymond, Angew. Chem. Int. Ed. 2007, 46, 8587-8589; Angew. Chem. 2007, 119,8741-8743; c) M. D. Pluth, R. G. Bergman, K. N. Raymond, J. Am. Chem. Soc. 2008, 130,11423-11429; d) M. D. Pluth, R. G. Bergman, K. N. Raymond, J. Org. Chem. 2009, 74, 58-63; e) J. L. Bolliger, A. M. Belenguer, J. R. Nitschke, Angew. Chem. Int. Ed. 2013, 52, 7958-7962; Angew. Chem. 2013, 125, $8116-8120$; f) A. G. Salles, S. Zarra, R. M. Tumer, J. R Nitschke, J. Am. Chem. Soc. 2013, 135, 19143-19146; g) Q. Zhang, K. Tiefenbacher, J. Am. Chem. Soc. 2013, 135, 1621316219.

[5] a) A. Cavarzan, A. Scarso, P. Sgarbossa, G. Strukul, J. N. H. Reek, J. Am. Chem. Soc. 2011, 133, 2848-2851; b) G. Bianchini, G. L. Sorella, N. Canever, A. Scarso, G. Strukul, Chem. Commun. 2013, 49, 5322-5324; c) A. Cavarzan, J. N. H. Reek, F. Trentin, A. Scarso, G. Strukul, Catal. Sci. Technol. 2013, 3, 2898-2901.

[6] a) Z. J. Wang C. J. Brown, R. G. Bergman, K. N. Raymond, F. D. Toste, J. Am. Chem. Soc. 2011, 133, 7358-7360; b) Z. J. Wang, K. N. Clary, R. G. Bergman, K. N. Raymond, F. D. Toste, Nat. Chem. 2013, 5, 100-103; c) L. Catti, K. Tiefenbacher, Chem. Commun. 2015, $51,892-894$.

[7] a) D. Fiedler, R. G. Bergman, K. N. Raymond, Angew. Chem. Int. Ed. 2004, 43, 6748-6751; Angew. Chem. 2004, 116, 69166919; b) D. Fiedler, H. van Halbeek, R. G. Bergman, K. N. Raymond, J. Am. Chem. Soc. 2006, 128, 10240-10252; c) C. J. Hastings, D. Fiedler, R. G. Bergman, K. N. Raymond, J. Am. Chem. Soc. 2008, 130, $10977-10983$; d) C. J. Brown, R. G. Bergman, K. N. Raymond, J. Am. Chem. Soc. 2009, 131, $17530-17531$.

[8] a) C. J.Hastings M. D. Pluth, R. G. Bergman, K. N. Raymond, J. Am. Chem. Soc. 2010, 132, 6938-6940; b) C. J. Hastings, M. P. Backlund, R. G. Bergman, K. N. Raymond, Angew. Chem. Int. Ed. 2011, 50, 10570-10573; Angew. Chem. 2011, 123, 10758 10761 ; c) C. J. Hastings, R. G. Bergman, K. N. Raymond, Chem. Eur. J. 2014, 20, 3966-3973.

[9] a) W. M. Hart-Cooper, K. N. Clary, F. D. Toste, R. G. Bergman, K. N. Raymond, J. Am. Chem. Soc. 2012, 134, 17873-17876; b) C. Zhao, Q.-F. Sun, W. M. Hart-Cooper, A. G. DiPasquale, F. D. Toste, R. G. Bergman, K. N. Raymond, J. Am. Chem. Soc. 2013, 135, 18802-18805; c) W. M. Hart-Cooper, C. Zhao, R. M. Triano, P. Yaghoubi, H. L. Ozores, K. N. Burford, F. D. Toste, R. G. Bergman, K. N. Raymond, Chem. Sci. 2015, 6, 1383-1393.

[10] D. H. Leung, R. G. Bergman, K. N. Raymond, J. Am. Chem. Soc. 2007, 129, 2746-2747.

[11] Q. Zhang, K. Tiefenbacher, Nat. Chem. 2015, 7, 197-202.

[12] L. R. MacGillivray, J. L. Atwood, Nature 1997, 389, 469-472. 
[13] a) J. L. Atwood, L. J. Barbour, A. Jerga, Chem. Commun. 2001, 0, 2376-2377; b) L. Avram, Y. Cohen, Org. Lett. 2002, 4, 4365 4368 .

[14] a) L. Avram, Y. Cohen, J. Rebek, Jr., Chem. Commun. 2011, 47, $5368-5375$; b) A. Shivanyuk, J. Rebek, Proc Natl. Acad. Sci USA 2001, 98, 7662-7665; c) L. Avram, Y. Cohen, J. Am. Chem. Soc. 2002, 124, 15148-15149; d) A. Shivanyuk, J. Rebek, J. Am Chem. Soc. 2003, 125,3432-3433; e) L. Avram, Y. Cohen, J. Am. Chem. Soc. 2003, 125,16180-16181; f) L. Avram, Y. Cohen, Org Lett. 2003, 5, 1099-1102; g) M. Yamanaka, A. Shivanyuk, J. Rebek, J. Am. Chem. Soc. 2004, 126, 2939-2943; h) L. Avram, Y Cohen, J. Am. Chem. Soc 2004, 126, 11556-11563; i) L. C. Palmer, A. Shivanyuk, M. Yamanaka, J. J. Rebek, Chem Commun 2005, 0, 857-858; j) T. Evan-Salem, I. Baruch, L. Avram, Y. Cohen, L. C. Palmer, J. Rebek, Proc. Natl. Acad. Sc USA 2006, 103, 12296-12300; k) E. S. Barrett, T. J. Dale, J. Rebek, J. Am. Chem. Soc. 2007, 129,3818-3819; I) E. S. Barrett, T. J. Dale, J. Rebek, J. Am. Chem. Soc 2008, 130, 2344-2350; m) L. Avram, Y. Cohen, Org. Lett. 2008, 10, 1505-1508; n) S Slovak, L. Avram, Y. Cohen, Angew. Chem. Int. Ed. 2010, 49 428-431; Angew. Chem. 2010, 122, 438-441; o) S. Slovak, Y Cohen, Supramol. Chem. 2010, 22, 803-807; p) S. Slovak, Y. Cohen, Chem. Eur. J. 2012, 18, 8515-8520.

[15] a) A. Erkkilä, I. Majander, P. M. Pihko, Chem. Rev. 2007, 107, 5416-5470; b) M. Mahlau, B. List, Angew. Chem. Int. Ed. 2013, 52, 518-533; Angew. Chem. 2013, 125, 540-556.
[16] O. B. Benryman, A. C. Sather, A. Lledó, J. Rebek, Angew. Chem. Int. Ed. 2011, 50, 9400-9403; Angew. Chem. 2011, 123, $9572-$ 9575.

[17] V. M. Dong, D. Fiedler, B. Carl, R. G. Bergman, K. N. Raymond, J. Am. Chem. Soc 2006, 128, 14464-14465.

[18] a) M. C. Holland, S. Paul, W. B Schweizer, K. Bergander, C Mück-Lichtenfeld, S. Lakhdar, H. Mayr, R. Gilmour, Angew. Chem. Int. Ed. 2013, 52, 7967-7971; Angew. Chem. 2013, 125, $8125-8129$; b) M. C. Holland, J. B. Metternich, C. Muck-Lichtenfeld, R. Gilmour, Chem. Commun. 2015, 51, 5322-5325.

[19] a) J. W. Yang, M. T. H. Fonseca, B. List, Angew. Chem Int. Ed. 2004, 43, 6660-6662; Angew. Chem 2004, 116, 6829-6832; b) J. W. Yang, M. T. H. Fonseca, N. Vignola, B. List, Angew. Chem. Int. Ed. 2005, 44, 108-110; Angew. Chem. 2005, 117, $110-$ 112 ; c) S. G. Ouellet, J. B. Tuttle, D. W. C. MacMillan, J. Am. Chem. Soc. 2005, 127, 32-33.

[20] A. J. A. Cobb, D. M. Shaw, S. V. Ley, Synlett 2004, 2004, 558 560.

[21] B. List, R. A. Lemer, C. F. Barbas, J. Am. Chem. Soc. 2000, 122, $2395-2396$.

Received: March 8, 2016

Revised: April 22, 2016

Published online: June 3, 2016

\subsection{American Chemical Society}

10.2.1 Reprint Permission of the Manuscript "Iminium Catalysis Inside a Self-Assembled Supramolecular Capsule: Scope and Mechanistic Studies" 
The manuscript published in Journal of the American Chemical Society ${ }^{[112]}$ was reproduced with permission of the American Chemical Society.

\section{Copyright Clearance \\ Center

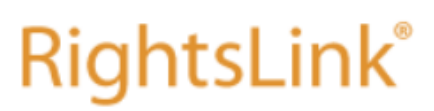

Home

ACS Publications Title: most Trusted. Most Cited. Most Read.
Iminium Catalysis inside a SelfAssembled Supramolecular Capsule: Scope and Mechanistic Studies

Author:

Thomas M. Bräuer, Qi Zhang, Konrad Tiefenbacher

Publication: Journal of the American Chemical Society

Publisher: American Chemical Society

Date: Dec 1, 2017

Copyright @ 2017, American Chemical Society

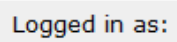

\section{PERMISSION/LICENSE IS GRANTED FOR YOUR ORDER AT NO CHARGE}

This type of permission/license, instead of the standard Terms \& Conditions, is sent to you because no fee is being charged for your order. Please note the following:

- Permission is granted for your request in both print and electronic formats, and translations.

- If figures and/or tables were requested, they may be adapted or used in part.

- Please print this page for your records and send a copy of it to your publisher/graduate school.

- Appropriate credit for the requested material should be given as follows: "Reprinted (adapted) with permission from (COMPLETE REFERENCE CITATION). Copyright (YEAR) American Chemical Society." Insert appropriate information in place of the capitalized words.

- One-time permission is granted only for the use specified in your request. No additional uses are granted (such as derivative works or other editions). For any other uses, please submit a new request.

\section{BACK}

\section{CLOSE WINDOW}

Copyright (C) 2017 Copyright Clearance Center, Inc. All Rights Reserved. Privacy statement. Terms and Conditions. Comments? We would like to hear from you. E-mail us at customercare@copyright.com

\subsubsection{Manuscript "Iminium Catalysis Inside a Self-Assembled Supramolecular Capsule:}

\section{Scope and Mechanistic Studies"}




\title{
$\mathbf{J}|\mathbf{A}| \mathbf{C} \mid \mathbf{S}$

\section{Iminium Catalysis inside a Self-Assembled Supramolecular Capsule: Scope and Mechanistic Studies}

\author{
Thomas M. Bräuer, ${ }^{\dagger}$ Qi Zhang, ${ }^{\dagger}$ and Konrad Tiefenbacher* ${ }^{\dagger}, \neq \odot$ \\ †Department of Chemistry, University of Basel, BPR 1096, Postfach 3350, Mattenstrasse 24a, CH-4002 Basel, Switzerland \\ ${ }^{\ddagger}$ Department of Biosystems Science and Engineering, ETH Zürich, Mattenstrasse 26, CH-4058 Basel, Switzerland
}

S Supporting Information

\begin{abstract}
Although iminium catalysis has become an important tool in organic chemistry, its combination with supramolecular host systems has remained largely unexplored. We report the detailed investigations into the first example of iminium catalysis inside a supramolecular host. In the case of 1,4-reductions of $\alpha, \beta$-unsaturated aldehydes, catalytic amounts of host are able to increase the enantiomeric excess of the products formed. Several control experiments were performed and provided strong evidence that the modulation of

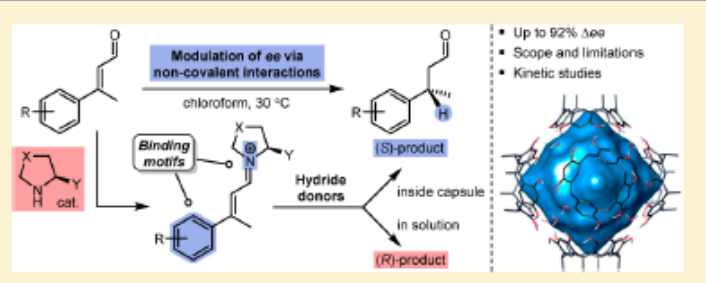
enantiomeric excess of the reaction product indeed stems from a reaction on the inside of the capsule. The origin of the increased enantioselectivity in the capsule was investigated. Furthermore, the substrate and nucleophile scope were studied. Kinetic investigations as well as the kinetic isotope effect measured confirmed that the hydride delivery to the substrate is the rate-determining step inside the capsule. The exploration of benzothiazolidines as alternative hydride sources revealed an unexpected substitution effect of the hydride source itself. The results presented confirm that the noncovalent combination of supramolecular hosts with iminium catalysis is opening up new exciting possibilities to increase enantioselectivity in challenging reactions.
\end{abstract}

\section{INTRODUCTION}

The field of intermolecular enantioselective enamine ${ }^{1}$ and iminium $^{1 \mathrm{~b}-\mathrm{d}, 2}$ organocatalysis has flourished since the seminal reports in the year 2000 by List $^{3}$ and MacMillan, ${ }^{4}$ respectively. Iminium catalysis is now regularly used for the construction of chiral building blocks via mainly 1,4-addition and cycloaddition, while enamine catalysis is a potent tool for the construction of $\alpha$-functionalized carbonyl compounds. Although these fields were heavily investigated and still receive tremendous attention, efforts to combine these activation modes with supramolecular assemblies have been very limited. The Rebek group investigated a Knoevenagel reaction accelerated by an amine catalyst bound to an open cavitand. ${ }^{5}$ A series of rotaxane-based switchable aminocatalysts were prepared by the Leigh group and used for iminium and enamine catalysis. ${ }^{6}$ Recently, an additional rotaxane-based organocatalyst was reported by the Leung group. In all of these cases, the supramolecular structure functioned as the amine catalyst itself or entrapped the catalyst in an open cavity. The reactions themselves were still taking place in solution. In other words, the supramolecular structure just modified the catalyst and did not allow entrapping the reactive intermediates. The groups of Raymond and Bergman did encapsulate an iminium species inside a supramolecular container but did not observe conversion. ${ }^{8}$ Recently, our group reported the first example of an iminium-catalyzed reaction taking place inside a supramolecular container.' Due to the binding of the reactive iminium species on the inside of the capsule, the enantiomeric excess of the product was increased as compared to the reaction in solution under otherwise identical conditions. We now report the full details concerning this reaction including substrate scope and mechanistic details and also expand the reaction to further nucleophiles.

Catalysis inside self-assembled supramolecular containers is gaining interest in the scientific community. ${ }^{10}$ It offers the potential to observe substrate and product selectivities not observed in regular solution experiments and, additionally, could facilitate multicatalyst tandem reactions. ${ }^{11}$ Recent examples included a Kemp elimination, ${ }^{12}$ reductive elimination, ${ }^{13}$ gold-catalyzed reactions, ${ }^{14}$ epoxidations, ${ }^{15}$ and an allylic oxidation/Diels-Alder cycloaddition sequence. ${ }^{16}$

Our group 9,17 and the groups of Scarso and Strukul ${ }^{18}$ have utilized the supramolecular capsule I, first reported by the Atwood group, ${ }^{19}$ successfully as catalyst. Container I selfassembles from six resorcinarene units $\mathbf{1}$ and eight water molecules in noncompetitive solvents such as chloroform. With an internal volume of approximately $1.4 \mathrm{~nm}^{3}$ it is one of the largest hydrogen-bond-based molecular capsules available. ${ }^{20}$ Guest exchange, which is believed to occur via a portal mechanism, is facile. ${ }^{21}$ Cationic molecules, for instance alkyl ammonium ions, bind strongly to the cavity of $\mathbf{I}$ due to cation $-\pi$ interactions. ${ }^{19 b, 22}$ We reported that capsule $\mathbf{I}$ acts as a reasonable strong Brønsted acid. ${ }^{17 a}$ This acidity, in combination with the capsule's ability to stabilize cationic intermediates/

Received: August 29, 2017

Published: November 1, 2017 


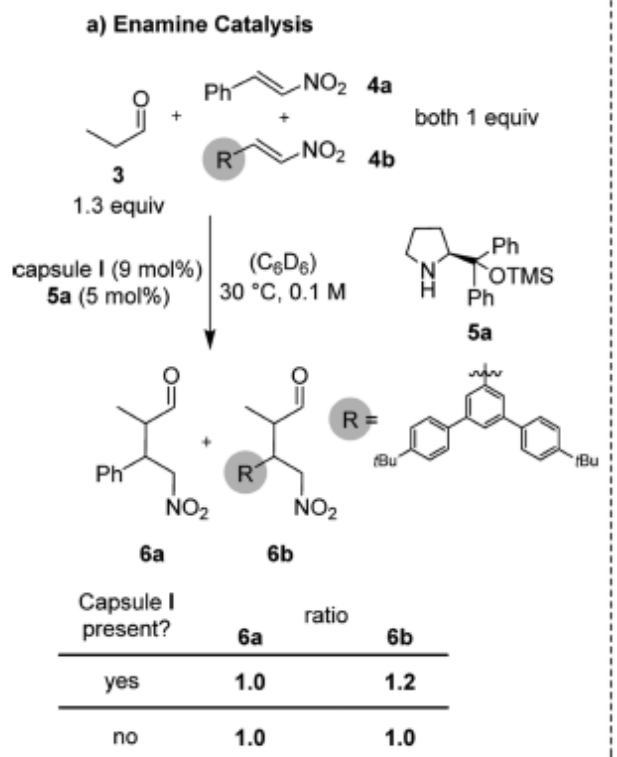

b) Iminium Ion Catalysis

$$
\mathrm{C}_{10} \mathrm{H}_{21}=0 \quad 7 \mathrm{a}
$$

capsule I (26 mol\%)

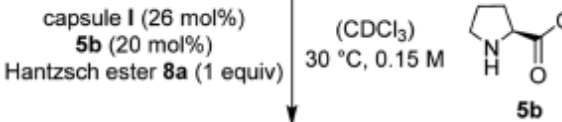

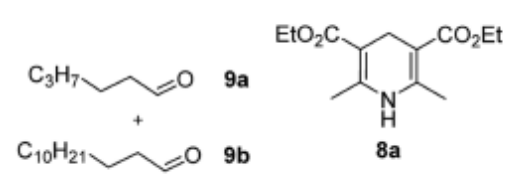

\begin{tabular}{ccc}
$\begin{array}{c}\text { Capsule I } \\
\text { present? }\end{array}$ & $9 \mathrm{a}$ & ratio \\
\hline yes & 10 & 1.0 \\
\hline no & 1.0 & 1.2
\end{tabular}

Figure 3. Size selectivity experiments for enamine and iminium ion catalysis in the presence and absence of capsule $\mathbf{I}$.

capsule (98\% ee). As an example for iminium catalysis, the 1,4 reduction of an $\alpha, \beta$-unsaturated aldehyde utilizing a Hantzsch ester as a hydride equivalent was utilized (Figure 3b). Again, two differently sized substrates (trans-2-hexenal $(7 \mathbf{a})$ and trans2-tridecenal (7b)) were utilized to detect a potential size selectivity imposed by capsule I. Indeed, a significant selectivity toward the smaller product 9a $(10: 1.0)$ was observed in the presence of catalytic amounts of I ( $26 \mathrm{~mol} \%)$. This is in stark contrast to the reaction without capsule under otherwise identical reaction conditions, where even a slight selectivity toward the larger product was detected (1.0:1.2). These initial results confirmed our assumption that indeed iminium catalysis is feasible in the inside of capsule I and that the transiently formed reactive iminium species are encapsulated fast enough to efficiently suppress the background reaction outside in solution. Intrigued by these results, we decided to explore enantioselective iminium catalysis inside the capsule. Since the enantiotopos-differentiating step, the attack of the nucleophile onto the encapsulated iminium ion, would be required to take place inside the densely packed environment of the host, we expected to observe an alteration in enantioselectivity as compared to the solution experiment. Preliminary results confirming this hypothesis were published last year by our group.

The known enantioselective 1,4-reduction of $\beta$-substituted $\alpha, \beta$-unsaturated aldehydes with Hantzsch ester 8a (1.5 equiv) as a reducing agent was utilized as a starting point in this investigation (Table 1). ${ }^{25}$ In the initial screening, ${ }^{9}$-proline (5b, $20 \mathrm{~mol} \%)$ was identified as the most promising organocatalyst for this study. Interestingly, in the presence of catalytic amounts of capsule I (26 mol \%), a much higher enantioselectivity $(74 \%$ ee $(S)$ vs $9 \%$ ee $(S)$; corresponding to a $\Delta$ ee of $65 \%$ ) was observed than in a regular solution experiment under otherwise identical conditions (Table 1, entries 1 and 2). The experiment using D-proline delivered, as expected, the opposite result of the experiment using L-proline (5b) as organocatalyst $(77 \%$ ee $(R))$. The closely related pyrogallolarene capsule II, on the other hand, did not display
Table 1. Comparison of the Resorcinarene $I$ and the Pyrogallolarene II Capsule in the 1,4-Reduction of (E)-3Phenyl-2-butenal (10a)

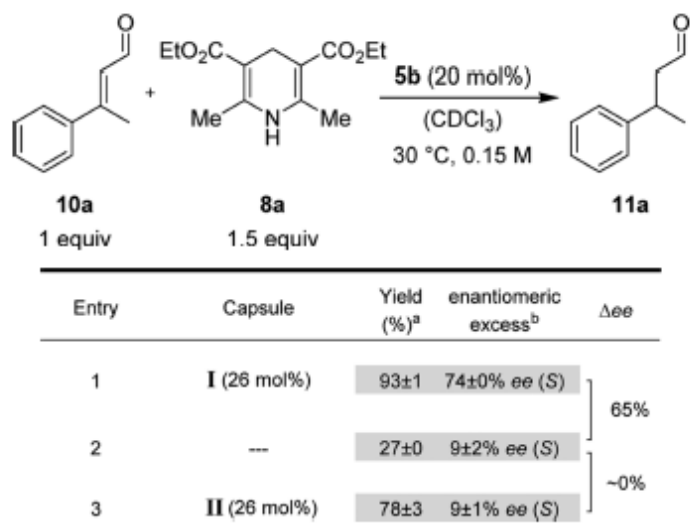

${ }^{a}$ Determined by GC analysis. ${ }^{b}$ Determined by chiral GC analysis.

this modulation effect on the enantioselectivity observed (no $\Delta$ ee was observed; Table 1 , entry 3 ).

Control Experiments. To learn more about these results, we first aimed at understanding where the reaction takes place. Several control experiments were performed to elucidate the role of capsule I. Separate reactions were run with either a large Hantzsch ester (Table 2, $\mathbf{8 b}$ ), a large organocatalyst (5c), or a large aldehyde (10b) instead of the respective standard reactants (Table 1). Molecular modeling ${ }^{26}$ indicated that reactions involving one of these enlarged reactants/reagents would not be possible inside the confined environment of $\mathbf{I}$. Therefore, such reactions would have to occur outside in the solution and/or on the outer surface of capsule I. In all these three cases, $\Delta$ ee values well below $\pm 10 \%$ were observed, much lower than the value of $65 \%$ observed under the regular conditions. In an ideal control experiment of this kind, no $\Delta$ ee would be expected. We attribute the small modulating effect 
Table 2. Performed Control Experiments Involving a Large Hantzsch Ester (8b), a Large Catalyst (5c), a Large Aldehyde (10b), and Hexamethonium Bromide (12)

\begin{tabular}{|c|c|c|c|c|c|}
\hline Entry & $\begin{array}{l}\text { Changed or } \\
\text { added reagent }\end{array}$ & $\begin{array}{l}\text { Capsule I } \\
\text { present? }\end{array}$ & $\begin{array}{l}\text { Yield } \\
(\%)^{a}\end{array}$ & $\begin{array}{l}\text { enantiomeric } \\
\text { excess }^{\mathrm{b}}\end{array}$ & $\Delta e e$ \\
\hline \multirow{2}{*}{1} & & yes & 20 & $14 \%$ ee (S) & \multirow{2}{*}{$-8 \%$} \\
\hline & & no & 71 & $22 \%$ ee (S) & \\
\hline
\end{tabular}

$\mathrm{Ph}$

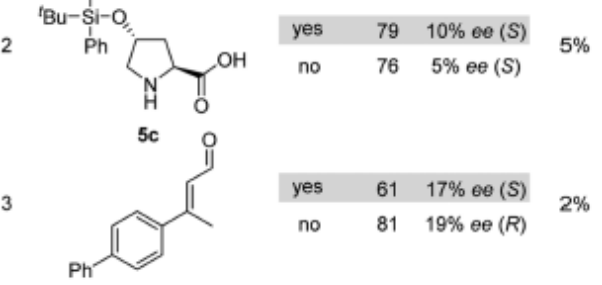

$10 \mathrm{~b}$

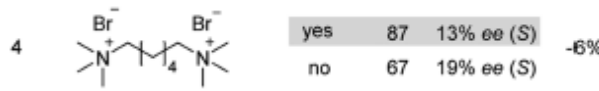

12

\begin{tabular}{ll|rrrr}
5 & DMSO & yes & 78 & $7 \%$ ee $(R)$ & $0 \%$
\end{tabular}

${ }^{a}$ Determined by GC analysis. ${ }^{b}$ Determined by chiral GC analysis.

observed in these control reactions to a (weak) interaction of the reactive iminium species to the outside of the capsule; this seems likely since it is known that tetraalkyl ammonium ions are able to bind weakly to the outside of capsule $\mathbf{I}^{27}$

Additionally, a control experiment was performed in which the cavity of I was blocked by hexamethonium bromide (12), a bis ammonium salt (Table 2, entry 4). In previous publications of our group, we successfully blocked capsule I with tetrabutyl ammonium bromide. In this project, however, the usage of singly charged ammonium salts would not suppress the uptake of the iminium species efficiently. Due to its higher charge, we expected 12 to outcompete the iminium species efficiently. Indeed, this control experiment also resulted in a greatly reduced $\Delta$ ee. In another control experiment, we added DMSO to the experiment with capsule. DMSO destroys the hexameric structure of capsule I by interrupting the hydrogen bond network. Also in this control experiment no modulation of enantiomeric excess is observed ( $\Delta$ ee of $0 \%$ ). These five control experiments provide convincing evidence that the strong modulation of enantiomeric excess indeed stems from an encapsulation effect inside host $\mathbf{I}$.

Source of ee Modulation. The modulation of enantioselectivity inside $\mathbf{I}$ is even more intriguing when taking into account that the building blocks of capsule I, resorcinarene 1 (Figure 1) and water, are achiral. This means that no additional chiral information is added to the experiment. The different enantioselectivity observed within I may stem from altered reactivities of the respective $E$ - and $Z$-alkene isomers of the iminium ion (Figure 4a). It was reported by MacMillan that both alkene isomers of aldehyde $10 \mathrm{a}$ are converted to the same product enantiomer. ${ }^{25 c}$ This stereoconvergence is attributed to a rapid iminium-catalyzed $Z \rightarrow E$ isomerization and a selective hydride delivery to the $E$-isomer. We, therefore, decided to
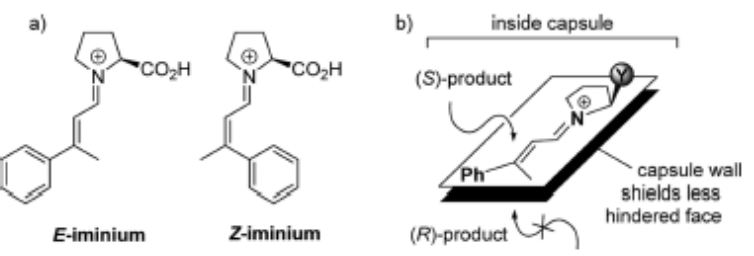

Figure 4. (a) E-iminium and Z-iminium ion of (E)-3-phenyl-2-butenal (10a). (b) Hypothesis for the increased enantioselectivity inside capsule I.

investigate the isomerization in the presence of the supramolecular system in detail. In solution, when starting from the $E$-isomer, the unreacted starting material 10a displayed an $E / Z$ ratio of 1.95 after $8 \mathrm{~h}$ under the standard reaction conditions (Table 3 , entry 1 without capsule). A similar ratio was reached after $8 \mathrm{~h}$ when starting from the $Z$-isomer (entry 2 without capsule). This indicates that an equilibrium distribution of approximately 1.8 between the $E$ - and $Z$-isomer is reached in the solution experiment (for details see the SI). Interestingly, the capsule experiments displayed contrasting results. In both cases, the purity of the alkene isomer added was retained rather efficiently. After $8 \mathrm{~h}$, the ratios were still 8.16 and 0.09 , respectively. Nevertheless, also in the capsule experiments a stereoconvergence of the final product was observed, indicating that an isomerization took place after iminium formation but before hydride addition in the case of the $\mathrm{Z}$-alkene isomer. This likely indicates that once a $Z$-iminium species is formed and encapsulated, it is isomerized to the E-iminium species and predominantly converted to the product without hydrolysis in between, thereby retaining the substrate isomer ratio in solution. In a regular solution experiment, however, the formed iminium is predominantly hydrolyzed again after isomerization, resulting in the fast equilibration of the added alkene isomers. This interpretation of the results is also in line with observations with a different supramolecular host that is able to protect iminium ions from hydrolysis. ${ }^{8}$ Therefore, altered reactivities of the respective $E$ - and $Z$-alkene isomers of the iminium ion inside the capsule cannot explain the modulation of ee observed.

An alternative explanation for the observed modulation of enantioselectivity inside I may involve the chirality of $\mathbf{I}$. Although, as stated before, the building blocks of I are achiral, the assembly of $\mathbf{I}$ itself is chiral due to the twisted arrangement of the subunits (Figure 1). ${ }^{19 a}$ Nevertheless, the capsule is present as a racemate. It was recently shown that encapsulated chiral tertiary amines (good guests due to protonation by the capsule $I)^{17 a}$ induce optical activity onto the capsule itself. ${ }^{28}$ It is likely that the chiral iminium ion formed during iminium catalysis would impose a similar induction onto I. However, the weak chiral field produced by the slight twists of the capsule components is not the most likely source of the effect observed. Also the pronounced differences in ee modulation for very similar substrates (vide infra, Table 4) is supporting another mechanism. It is more likely that the modulation stems from a binding effect.

Our hypothesis is that the iminium preferentially binds to the inner walls of capsule I from the less hindered side (anti to the carboxylic acid of proline, Figure 4b). This arrangement then facilitates the attack of the nucleophile from the top face (syn to the carboxylic acid), which preferentially produces the $S$ product in the case of L-proline. This mechanism is in 
Table 3. Study of the Influence of the Alkene Isomer 10a Utilized in the Reduction Experiments ${ }^{a}$

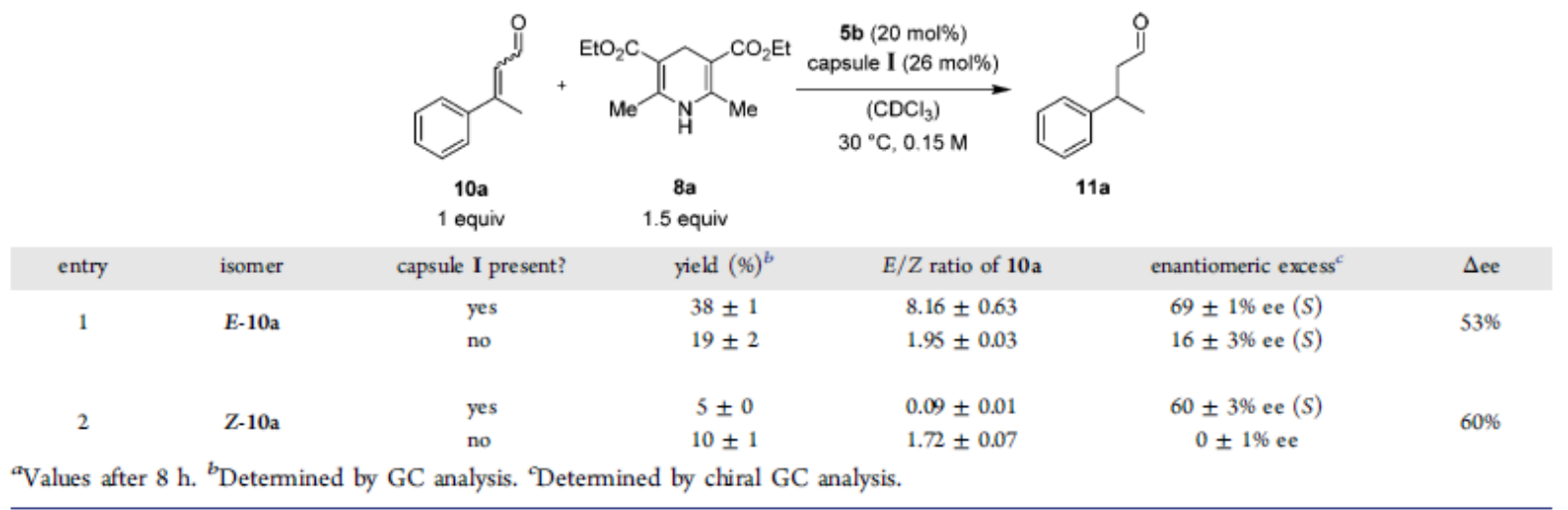

accordance with the selectivities observed and with our current understanding of the system.

In any case, why is the modulation effect not observed with capsule II? Recent findings from our group indicate that capsule II does not encapsulate ion pairs due to the absent stabilization of anions within its cavity. ${ }^{24}$ Since the iminium ion formed is present as an ion pair in an apolar solvent such as chloroform, it is likely that indeed failure of uptake into its cavity is the reason for the lack of modulation with II.

Aldehyde Substrate Scope. Next, the aldehyde substrate scope was investigated in detail. The cyclohexyl derivative 10c showed a reduced $\Delta$ ee of only $26 \%$, which might indicate that the aromatic moiety of the aldehyde plays an important role in binding of the iminium species inside I via $\pi-\pi$ interactions. Subsequently, three methyl derivatives of $(E)$-3-phenyl-2butenal (10a) were investigated. Interestingly, the results differed dramatically: The para-derivative (10d, $\Delta$ ee $=9 \%)$ and meta-derivative $(10 \mathrm{e}, \Delta \mathrm{ee}=41 \%)$ produced only low to modest selectivity differences inside the capsule. However, the ortho-derivative (10f) displayed a very high $\Delta$ ee of $92 \%$. These dramatic differences for the methyl derivatives $10 \mathrm{~d}-\mathbf{f}$ support our hypothesis that the binding of the iminium species to the capsule walls is responsible for the selectivity increase. In the case of 10 , however, a yield of only $12 \%$ was obtained. To examine if the ortho-position generally delivers poor yields, we tested the ortho-methoxy derivative $10 \mathrm{~g}$. To our delight a high yield of $96 \%$ and a noteworthy $\Delta$ ee of $69 \%$ were obtained. Further ortho-substituted derivatives were investigated: All halogenated substrates $10 \mathbf{h}-\mathbf{j}$ displayed high $\Delta$ ee values, indicating that indeed the ortho-substituted derivatives in general display better selectivities inside the capsule. The decrease in yield and conversion in the series $10 \mathrm{~h}$ to $10 \mathrm{j}$ indicates that a large ortho-substituent is slowing down the reaction considerably. The smaller fluoro-substituted aldehyde $10 \mathrm{~h}$ produced a good yield of $76 \%$, whereas the much larger bromo-substituted aldehyde $10 \mathrm{j}$ formed the respective product $11 \mathrm{j}$ in only $14 \%$ yield. The even larger nitro-compound $10 \mathrm{k}$ also followed the observed trend.

Mechanistic Studies. To gain a better insight into the 1,4 reduction inside capsule $\mathbf{I}$ at hand, mechanistic studies were performed by using the initial rate method. Under the standard reaction conditions, pseudo-first-order consumption of the $\alpha, \beta$ unsaturated aldehyde was observed (Figure 4a). Additionally, the activation parameters were measured by performing the reaction at different temperatures (Figure $4 \mathrm{~b}$ ).
The obtained parameters for the capsule-mediated 1,4 reduction reaction are $\Delta H^{\ddagger}=21.10 \pm 0.16 \mathrm{kcal} / \mathrm{mol}, \Delta S^{\ddagger}=$ $-9.57 \pm 0.49 \mathrm{~J} / \mathrm{mol}$, and $\Delta G^{\ddagger}=24.00 \pm 0.02 \mathrm{kcal} / \mathrm{mol}$. The negative entropy of activation observed may indicate that the bimolecular hydride transfer is the rate-determining step of the reaction inside capsule $\mathbf{I}$. Additional evidence was sought by investigating the kinetic isotope effect for the hydride transfer. The known $d_{2}$-Hantzsch ester $8 \mathrm{c}^{29}$ (Figure 6) was synthesized from $d_{2}$-paraformaldehyde utilizing the classical Hantzsch ester synthesis. The experiments utilizing the regular and deuterated Hantzsch ester $\mathbf{8 a}$ and $\mathbf{8 c}$, respectively, were run in triplicate. A primary kinetic isotope effect of $k_{\mathrm{H}} / k_{\mathrm{D}}=1.90 \pm 0.05$ was observed, providing strong evidence that indeed the hydride transfer is the rate-determining step.

Alternative Hydride Sources. Since transfer of the hydride is the rate-determining step, changing the hydride source potentially has a strong impact on the selectivities observed. Therefore, we investigated alternative hydride sources. Our interest turned to benzothiazolidines, which were shown to reduce imines in a phosphoric acid-catalyzed transfer hydrogenation. ${ }^{30}$

The phenyl (13a), methyl (13b), and naphthyl (13c) derivatives of this class of reducing agents were investigated (Table 5). As with Hantzsch ester $\mathbf{8 a}$ as hydride donor, Lproline (5b) displayed good enantioselectivity in the presence of capsule $(78 \% R)$ with benzothiazolidine 13a. However, the other enantiomer is formed! To rule out mistakes, the absolute configuration of L-proline ( $\mathbf{5 b}$ ) was checked by measuring the optical rotation. Additionally, the experiments were repeated in triplicate, confirming this surprising result (entry 1, Table 5). Unfortunately, and although starting material was converted, no $\Delta$ ee value could be determined since the corresponding solution experiment did not yield the desired product 11a at all. In general, the yields using benzothiazolidines as reducing agents were only low to modest, although the conversion of the starting material was good. Investigations revealed that the starting material (the $\alpha, \beta$-unsaturated aldehyde) as well as the product aldehyde underwent trans- $\mathrm{N}, \mathrm{S}$-acetalization with the benzothiazolidine (see SI Figures S14-S16). Although these side reactions unfortunately reduced the yield, the results obtained are, in our opinion, nevertheless of high conceptual interest. When utilizing proline derivative $\mathbf{5 d}$, a $\Delta$ ee value near $0 \%$ was observed with benzothiazolidine 13a. Like in the case of L-proline (5b), a preference toward the R-enantiomer was also observed with proline amide $5 \mathrm{e}(\Delta \mathrm{ee}$ of $-18 \%)$ and Lthioproline ( $\mathbf{5 f}, \Delta \mathrm{ee}$ of $-\mathbf{7 3 \%})$ as organocatalysts. This is the 
Table 4. Results of the Iminium-Catalyzed 1,4-Reduction of Different Aldehydes 10 Utilizing Proline (5b) as Catalyst

Capsule I
present? $\begin{gathered}\begin{array}{c}\text { Yield } \\ (\%)^{\mathrm{a}}\end{array} \\ \begin{array}{c}\text { enantiomeric } \\ \text { excess }\end{array}\end{gathered}$

${ }^{a}$ Determined by GC analysis. ${ }^{b}$ Determined by chiral GC analysis.

first time we observed selectivity toward the $R$-enantiomer inside the capsule when utilizing the $S$-configured secondary amines utilized for this study. What causes this tendency toward the $R$-enantiomer? There might be additional $\pi-\pi$ interactions of the aromatic benzothiazolidine 13a with the capsule walls or, alternatively, cation $-\pi$ interactions between the iminium ion and the hydride source. Such interactions could override the proposed binding of the iminium species (Figure $4 \mathrm{~b}$ ) and, therefore, lead to opposite enantioselectivites. With proline tetrazole $5 \mathrm{~g}$, which features an electron-poor aromatic surface, this effect is not detected ( $\Delta$ ee of $47 \%$ ). To learn more about these surprising observations, catalysts $5 \mathrm{f}$ and $\mathbf{5 g}$ were further

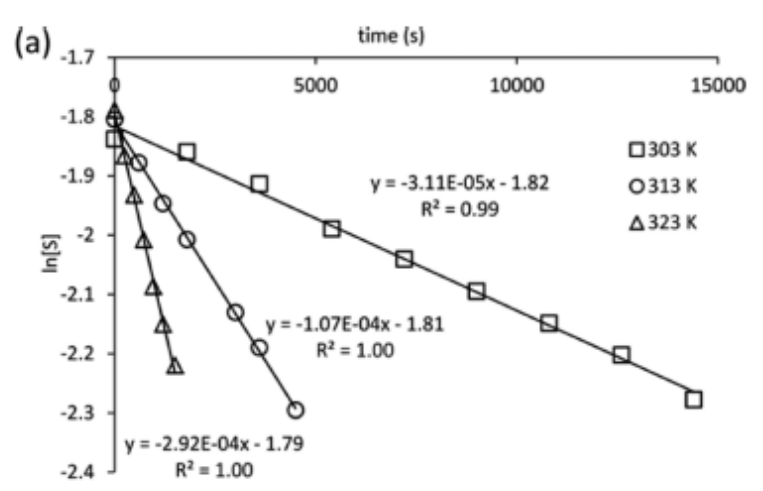

(b)

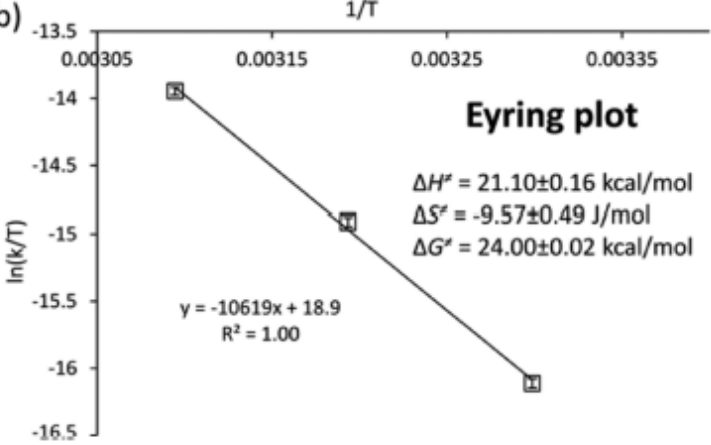

Figure 5. (a) Initial rates at 303,313 , and $323 \mathrm{~K}$. (b) Eyring plot.

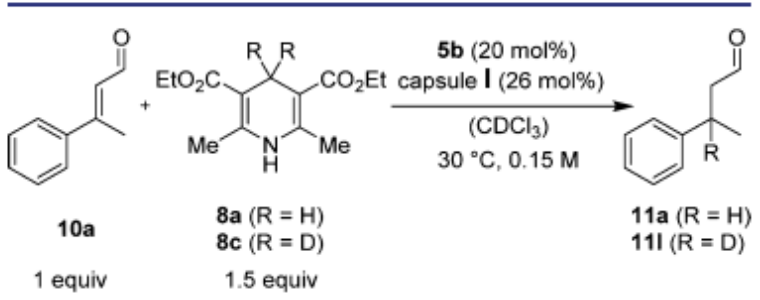

Figure 6. Kinetic isotope effect of the examined 1,4-reduction.

investigated using other benzothiazolidines. First benzothiazolidine $\mathbf{1 3 b}$, which carries a methyl group instead of a phenyl substituent, was tested. With L-thioproline (5f) as catalyst and $13 \mathrm{~b}$ as hydride donor, a high $\Delta \mathrm{ee}$ of $67 \%$ is observed, whereas $18 \%$ is obtained with $5 \mathrm{~g}$. In both cases the expected $S$-product is formed preferentially inside $I$ again. This supports the notion that indeed the additional phenyl ring in reducing agent 13a caused the observed preference for the $R$-configured product inside the capsule, since the methyl derivative $13 \mathbf{b}$ did not display this effect. When using the larger naphthyl-benzothiazolidine $13 c$, the size limit of capsule $I$ is reached and only very low yields of product are observed in these cases. The investigations into the benzothiazolidine revealed how subtle noncovalent interactions between the reactants and the capsule can lead to complete changes in the optical activity of the reduction product. Although these modulation effects are not predictable at this stage, we believe that further investigations with additional supramolecular structures are justified. The increased enantiomeric excess observed within capsule I will be especially helpful in examples of iminium catalysis where no satisfactory enantiocontrol can be achieved with regular solution chemistry so far. ${ }^{31}$ 
Table 5. Results of the Iminium-Catalyzed 1,4-Reduction Utilizing Different Benzothiazolidines 13

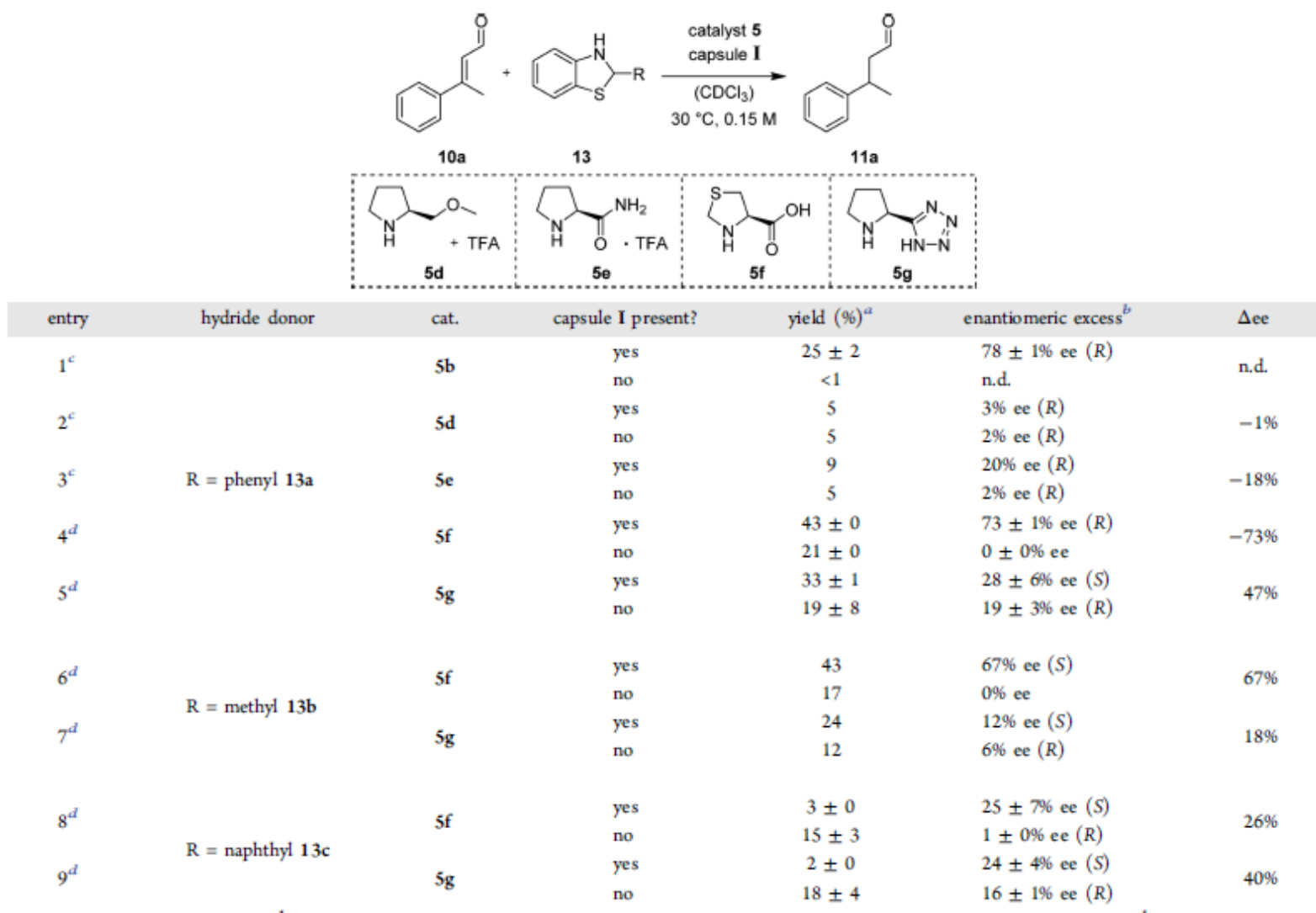

${ }^{a}$ Determined by GC analysis. ${ }^{b}$ Determined by chiral GC analysis. ${ }^{c} 1.5$ equiv of reducing agent and concentration of $0.15 \mathrm{M} .{ }^{d} 1$ equiv of reducing agent and concentration of $0.075 \mathrm{M}$.

\section{CONCLUSION}

In summary, detailed investigations into the first example of iminium catalysis inside a supramolecular host are described. The differences in influencing enamine- and iminium-catalyzed reactions inside capsule I were explored. Several control experiments were performed and provided strong evidence that the modulation of enantiomeric excess of the reaction product indeed stems from a reaction on the inside of capsule $\mathbf{I}$. The origin of the increased enantioselectivity in the capsule was explored. Failure of the related capsule II to provide a similar effect likely stems from its inability to encapsulate ion pairs. Furthermore, the substrate scope of the reduction with Hantzsch ester was explored. The best enantioselectivities were observed with ortho-substituted derivatives. Kinetic investigations as well as the kinetic isotope effect measured confirmed that the hydride delivery to the substrate is the ratedetermining step inside the capsule. Investigations into benzothiazolidines as alternative hydride sources revealed an unexpected substitution effect of the hydride source itself. The research presented confirms that the noncovalent combination of supramolecular hosts with iminium catalysis is opening up new exciting possibilities to increase enantioselectivity in challenging reactions.

\section{ASSOCIATED CONTENT}

(S Supporting Information

The Supporting Information is available free of charge on the ACS Publications website at DOI: 10.1021/jacs.7b08976.

Additional information (PDF)

(PDF)

\section{AUTHOR INFORMATION}

\section{Corresponding Author}

*konrad.tiefenbacher@unibas.ch/tkonrad@ethz.ch

ORCID $\odot$

Konrad Tiefenbacher: 0000-0002-3351-6121

Notes

The authors declare no competing financial interest.

\section{ACKNOWLEDGMENTS}

This work was supported by funding from the Swiss National Science Foundation as part of the NCCR Molecular Systems Engineering and the Bayerische Akademie der Wissenschaften (Junges Kolleg). T.M.B. thanks the National Research Fund, Luxembourg, for an AFR fellowship. We thank Dr. Johannes Richers for graphical design.

\section{REFERENCES}

(1) (a) Mukherjee, S.; Yang, J. W.; Hoffmann, S.; List, B. Chem. Rev. 2007, 107, 5471-5569. (b) Melchiorre, P.; Marigo, M.; Carlone, A; 
Bartoli, G. Angew. Chem, Int. Ed. 2008, 47, 6138-6171. (c) Bertelsen, S.; Jørgensen, K. A. Chem. Soc. Rev. 2009, 38, 2178-2189. (d) Matos Paz, B; Jiang, H.; Jørgensen, K. A. Chem. - Eur. J. 2015, 21, 18461853.

(2) (a) Erkkila, A.; Majander, I.; Pihko, P. M. Chem. Rev. 2007, 107, 5416-5470. (b) Mahlau, M.; List, B. Angew. Chem, Int Ed. 2013, 52, $518-533$.

(3) List, B.; Lemer, R. A; Barbas, C. F. J. Am. Chem. Soc. 2000, 122, 2395-2396.

(4) Ahrendt, K. A.; Borths, C. J.; MacMillan, D. W. C. J. Am. Chem. Soc. 2000, 122, 4243-4244.

(5) Berryman, O. B; Sather, A. C.; Lledó, A.; Rebek, J. Angew. Chem., Int. Ed. 2011, 50, 9400-9403.

(6) (a) Blanco, V.; Carlone, A.; Hănni, K. D.; Leigh, D. A.; Lewandowski, B. Angew. Chem., Int. Ed. 2012, 51, 5166-5169. (b) Blanco, V.; Leigh, D. A.; Lewandowska, U; Lewandowski, B.; Marcos, V. J. Am. Chem. Soc. 2014, 136, 15775-15780. (c) Blanco, V.; Leigh, D. A; Marcos, V.; Morales-Sema, J. A; Nussbaumer, A. L. J. Am. Chem. Soc 2014, 136, 4905-4908. (d) Beswick, J.; Blanco, V.; De Bo, G.; Leigh, D. A.; Lewandowska, U.; Lewandowski, B.; Mishiro, K. Chem. Sci. 2015, 6, 140-143. (e) Cakmak, Y.; Erbas-Cakmak, S.; Leigh, D. A. J. Am. Chem. Soc. 2016, 138, 1749-1751. (f) Eichstaedt, K.; Jaramillo-Garcia, J.; Leigh, D. A.; Marcos, V.; Pisano, S.; Singleton, T. A. J. Am. Chem. Soc. 2017, 139, 9376-9381.

(7) Kwan, C.-S.; Chan, A. S. C.; Leung, K. C.-F. Org. Lett. 2016, 18, 976-979.

(8) Dong, V. M.; Fiedler, D.; Carl, B.; Bergman, R. G.; Raymond, K. N. J. Am. Chem. Soc 2006, 128, 14464-14465.

(9) Bräuer, T. M.; Zhang, Q.; Tiefenbacher, K. Angew. Chem, Int. Ed. 2016, 55, 7698-7701.

(10) (a) Vriezema, D. M.; Comellas Aragonès, M.; Elemans, J. A. A. W.; Cornelissen, J. J. L. M.; Rowan, A. E.; Nolte, R. J. M. Chem. Rev. 2005, 105, 1445-1490. (b) Koblenz, T. S.; Wassenaar, J.; Reek, J. N. H. Chem. Soc Rev. 2008, 37, 247-262. (c) Yoshizawa, M; Klosterman, J. K.; Fujita, M. Angew. Chem., Int. Ed. 2009, 48, 3418-3438. (d) Meeuwissen, J.; Reek, J. N. H. Nat. Chem. 2010, 2, 615-621. (e) Marchetti, L; Levine, M. ACS Catal. 2011, 1, 1090-1118. (f) Wiester, M. J.; Ulmann, P. A; Mirkin, C. A. Angew. Chem., Int Ed. 2011, 50, 114-137. (g) Raynal, M.; Ballester, P.; Vidal-Ferran, A.; van Leeuwen, P. W. N. M. Chem. Soc Rev. 2014, 43, 1734-1787. (h) Brown, C. J.; Toste, F. D.; Bergman, R. G.; Raymond, K. N. Chem. Rev. 2015, 115, 3012-3035. (i) Leenders, S. H. A. M.; Gramage-Doria, R.; de Bruin, B.; Reek, J. N. H. Chem. Soc. Rev. 2015, 44, 433-448. (j) Zarra, S.; Wood, D. M.; Roberts, D. A; Nitschke, J. R Chem. Soc. Rev. 2015, 44, 419-432. (k) Catti, L.; Zhang, Q.; Tiefenbacher, K. Synthesis 2016, 48, 313-328. (1) Otte, M. ACS Catal. 2016, 6, 64916510.

(11) Catti, L; Zhang, Q.; Tiefenbacher, K. Chem. - Eur. J. 2016, 22, 9060-9066.

(12) Cullen, W.; Misuraca, M. C.; Hunter, C. A; Williams, N. H.; Ward, M. D. Nat Chem. 2016, 8, 231-236.

(13) Levin, M. D.; Kaphan, D. M.; Hong, C. M.; Bergman, R G.; Raymond, K. N.; Toste, F. D. J. Am. Chem. Soc. 2016, 138, 96829693.

(14) (a) Jans, A. C. H.; Gómez-Suárez, A.; Nolan, S. P.; Reek, J. N. H. Chem - Eur. J. 2016, 22, 14836-14839. (b) Wang, Q.Q.; Gonell, S.; Leenders, S. H. A. M.; Dür, M.; Ivanovié-Burmazović, I; Reek, J. N. H. Nat Chem. 2016, 8, 225-230.

(15) Kuijpers, P. F.; Otte, M.; Dürr, M.; Ivanović-Burmazović, L; Reek, J. N. H.; de Bruin, B. ACS Catal. 2016, 6, 3106-3112.

(16) Ueda, Y.; Ito, H.; Fujita, D.; Fujita, M. J. Am. Chem. Soc. 2017, $139,6090-6093$.

(17) (a) Zhang, Q.; Tiefenbacher, K. J. Am. Chem. Soc. 2013, 135, 16213-16219. (b) Catti, L; Tiefenbacher, K. Chem. Commun. 2015, 51, 892-894. (c) Zhang, Q; Tiefenbacher, K. Nat. Chem. 2015, 7, 197-202. (d) Catti, L.; Pöthig, A; Tiefenbacher, K. Adv. Synth Catal. 2017, 359, 1331-1338. (e) Zhang, Q.; Catti, L.; Pleiss, J; Tiefenbacher, K. J. Am. Chem. Soc. 2017, 139, 11482-11492.
(18) (a) Bianchini, G.; La Sorella, G.; Canever, N.; Scarso, A; Strukul, G. Chem. Commun. 2013, 49, 5322-5324. (b) Giust, S.; La Sorella, G.; Spemi, L.; Fabris, F.; Strukul, G.; Scarso, A. Asian J. Org Chem. 2015, 4, 217-220. (c) La Sorella, G.; Spemi, L; Strukul, G.; Scarso, A. ChemCatChem 2015, 7, 291-296. (d) La Sorella, G.; Spemi, L.; Ballester, P.; Strukul, G.; Scarso, A. Catal. Sa. Technol. 2016, 6 6031-6036. (e) La Sorella, G.; Sperni, L.; Strukul, G.; Scarso, A. Adv. Synth. Catal. 2016, 358, 3443-3449. (f) Caneva, T.; Spemi, L.; Strukul, G.; Scarso, A. RSC Adv. 2016, 6, 83505-83509.

(19) (a) MacGillivray, L. R; Atwood, J. L. Nature 1997, 389, 469472. (b) Avram, L; Cohen, Y. J. Am. Chem. Soc. 2002, 124, 1514815149. (c) Avram, L.; Cohen, Y.; Rebek, J. Chem. Commun. 2011, 47, $5368-5375$.

(20) Beaudoin, D.; Rominger, F,; Mastalerz, M. Angew. Chem, Int. Ed. 2016, 55, 15599-15603.

(21) Yamanaka, M.; Shivanyuk, A.; Rebek, J. J. Am. Chem. Soc. 2004, $126,2939-2943$

(22) Shivanyuk, A.; Rebek, J. Proc. Natl. Acad. Sci. U. S. A. 2001, 98 $7662-7665$.

(23) For pioneering work see: (a) Gerkensmeier, T,; Iwanek, W.; Agena, C.; Frohlich, R; Kotila, S.; Nather, C.; Mattay, J. Eur. J. Org. Chem. 1999, 1999, 2257-2262. (b) Atwood, J. L.; Barbour, L. J.; Jerga, A. Chem. Commun. 2001, 0, 2376-2377. (c) Shivanyuk, A.; Rebek, J. Chem. Commun. 2001, 2374-2375. (d) Atwood, J. L.; Barbour, L. J.; Jerga, A. Proc Natl. Acad. Sci. U. S. A. 2002, 99, 4837-4841. (e) Avram, L.; Cohen, Y. Org. Lett. 2003, 5, 3329-3332. (f) Avram, L.; Cohen, Y. J. Am. Chem. Soc. 2003, 125, 16180-16181. (g) Shivanyuk, A.; Friese, J. C.; Döring, S.; Rebek, J. J. Org. Chem. 2003, 68, 64896496. (h) Avram, L; Cohen, Y. J. Am. Chem. Soc. 2004, 126, $11556-$ 11563. For recent studies see: (i) Guralnik, V.; Avram, L.; Cohen, Y. Org. Lett. 2014, 16, 5592-5595. (j) Avram, L.; Goldbourt, A.; Cohen, Y. Angew. Chem, Int. Ed. 2016, 55, 904-907. (k) Yariv-Shoushan, S.; Cohen, Y. Org. Lett. 2016, 18, 936-939.

(24) Zhang, Q.; Catti, L.; Kaila, V. R. I.; Tiefenbacher, K. Chem. Sci. 2017, 8, 1653-1657.

(25) (a) Yang, J. W.; Hechavarria Fonseca, M. T.; List, B. Angew. Chem, Int. Ed. 2004, 43, 6660-6662. (b) Yang, J. W.; Hechavarria Fonseca, M. T.; Vignola, N.; List, B. Angew. Chem., Int. Ed. 2005, 44, 108-110. (c) Ouellet, S. G.; Tuttle, J. B.; MacMillan, D. W. C. J. Am. Chem. Soc. 2005, 127, 32-33.

(26) Modeling was perfomed with Spartan'14; Wavefunction Inc. Irvine, CA, USA.

(27) Slovak, S.; Cohen, Y. Supramol. Chem. 2010, 22, 803-807.

(28) Pollok, C. H.; Zhang, Q.; Tiefenbacher, K.; Merten, C. ChemPhysChem 2017, 18, 1987-1991.

(29) (a) Norcross, B. E.; Klinedinst, P. E.; Westheimer, F. H. J. Am. Chem. Soc. 1962, 84, 797-802. (b) Stockinger, S.; Troendlin, J.; Rominger, F.; Trapp, O. Adv. Synth. Catal. 2015, 357, 3513-3520.

(30) (a) Zhu, C.; Akiyama, T. Org. Lett. 2009, 11, 4180-4183. (b) Zhu, C.; Akiyama, T. Adv. Synth. Catal. 2010, 352, 1846-1850 (c) Henseler, A; Kato, M.; Mori, K.; Akiyama, T. Angew. Chem., Int. Ed. 2011, 50, 8180-8183.

(31) For a recent example see: Kaldre, D.; Gleason, J. L. Angew. Chem, Int. Ed. 2016, 55, 11557-11561. 